\title{
Counting for EU enlargement?
}

Citation for published version (APA):

Hoh, A-L. K. I. (2018). Counting for EU enlargement? Census-taking in Croatia, Bosnia and Macedonia. [Doctoral Thesis, Maastricht University]. Datawyse / Universitaire Pers Maastricht. https://doi.org/10.26481/dis.20180926ah

Document status and date:

Published: 01/01/2018

DOI:

10.26481/dis.20180926ah

Document Version:

Publisher's PDF, also known as Version of record

\section{Please check the document version of this publication:}

- A submitted manuscript is the version of the article upon submission and before peer-review. There can be important differences between the submitted version and the official published version of record.

People interested in the research are advised to contact the author for the final version of the publication, or visit the DOI to the publisher's website.

- The final author version and the galley proof are versions of the publication after peer review.

- The final published version features the final layout of the paper including the volume, issue and page numbers.

Link to publication

\footnotetext{
General rights rights.

- You may freely distribute the URL identifying the publication in the public portal. please follow below link for the End User Agreement:

www.umlib.nl/taverne-license

Take down policy

If you believe that this document breaches copyright please contact us at:

repository@maastrichtuniversity.nl

providing details and we will investigate your claim.
}

Copyright and moral rights for the publications made accessible in the public portal are retained by the authors and/or other copyright owners and it is a condition of accessing publications that users recognise and abide by the legal requirements associated with these

- Users may download and print one copy of any publication from the public portal for the purpose of private study or research.

- You may not further distribute the material or use it for any profit-making activity or commercial gain

If the publication is distributed under the terms of Article $25 \mathrm{fa}$ of the Dutch Copyright Act, indicated by the "Taverne" license above, 


\section{Counting}

for EU enlargement?

Census-taking in Croatia, Bosnia and Macedonia 
(c) copyright Anna-Lena Hoh, Maastricht 2018

ISBN: 978-94-93019-73-7

Cover: Johannes Wockenfuß (johannes-wockenfuss@gmx.de) Printing: Datawyse Universitaire Pers Maastricht 


\title{
Counting for EU enlargement?
}

\section{Census-taking in Croatia, Bosnia and Macedonia}

\author{
DISSERTATION \\ to obtain the degree of Doctor at Maastricht University, \\ on the authority of the Rector Magnificus, \\ Prof. dr. Rianne M. Letschert \\ in accordance with the decision of the Board of Deans, \\ to be defended in public \\ on Wednesday, 26 September 2018 at 16.00 hours
}

by

Anna-Lena Katharina Inge Hoh 


\section{Supervisor:}

Prof. Dr. Hans Schmeets

\section{Co-supervisors:}

Dr. Gergana Noutcheva

Dr. Petar Petrov

\section{Assessment Committee:}

Prof. Dr. Tannelie Blom (chair)

Dr. Pieter Everaers, Eurostat, Luxembourg

Prof. Dr. Evelyn Ruppert, Goldsmiths University of London, United Kingdom Dr. Aneta Spendzharova

Prof. Dr. Esther Versluis 


\section{Table of Contents}

Tables and figures 8

Acknowledgements 9

Chapter 1 Introduction 13

1.1 Census-taking and EU enlargement in the Western Balkans 15

$\begin{array}{ll}1.2 \text { Research question(s) } & 18\end{array}$

$\begin{array}{ll}1.3 \text { Europeanisation } & 20\end{array}$

$\begin{array}{ll}1.4 \text { Methodology } & 21\end{array}$

1.5 The paradox of collecting ethno-cultural data in censuses 23

1.6 Europeanisation of census-taking in the Western Balkans 25

1.7 State capacity, domestic and external actors 26

1.8 Contributions \& relevance $\quad 27$

1.9 Outline of the thesis 29

Chapter 2 Counting for enlargement? The theory behind the Europeanisation of census-taking 31

Abstract 32

2.1 Introduction 33

2.2 Europeanisation $\quad 35$

2.3 Europeanisation in enlargement countries 39

2.4 Compliance with the EU census regulations 42

2.4. 1 The census requirements 43

2.4.2 Measuring compliance with the EU census regulations 47

2.5 Embedding Europeanisation in the chapters 50

2.5. 1 Europeanisation of census-taking and the paradox of collecting ethno-cultural data 51

2.5.2 Conditionality and legitimacy of the Europeanisation of censustaking 52

2.5.3 State capacity, domestic and external actors 52

2.6 Conclusion $\quad 53$

Chapter 3 Using a mixed methods research design while studying census-taking in the Western Balkans $\quad 55$

Abstract 56

3.1 Introduction 57

3.2 Mixed methods: potential designs and selected model 58

3.3 Illustrative study 59

3.4 Research design 61

3.5 Qualitative data collection: In-depth interviews 64 
3.6 Quantitative data collection: Expert survey

3.7 Discussion and conclusion

Chapter 4 Counting for what purpose? The paradox of including ethnic and cultural questions in the censuses of Croatia, Bosnia and Macedonia

Abstract

4.1 Introduction

4.2 The sensitivities of census-taking $\quad 72$

4.3 Europeanisation and census-taking $\quad 74$

4.4 Expert perspectives on counting ethnic and cultural characteristics $\quad 77$

4.5 Ethnic and cultural categories in Croatia, Bosnia and Macedonia $\quad 80$

$\begin{array}{ll}\text { 4.5.1 Croatia } & 80\end{array}$

4.5.2 Bosnia and Herzegovina 82

4.5.3 Macedonia $\quad 85$

$\begin{array}{ll}4.6 \text { Comparison } & 87\end{array}$

4.7 Conclusion 88

Chapter 5 'When counting counts': Europeanisation of census-taking in Croatia, Bosnia and Macedonia 91

Abstract $\quad 92$

5.1 Introduction 93

5.2 Census-taking within Europeanisation 94

5.3 Europeanisation of census-taking: Conceptual framework 96

5.3.1 Conditionality 96

$\begin{array}{ll}\text { 5.3.2 Legitimacy } & 97\end{array}$

5.4 Method, case selection and data 98

5.5 When counting counts: Case analysis 99

5.5.1 Bosnia and Herzegovina 99

5.5.2 The Former Yugoslav Republic of Macedonia 101

$\begin{array}{ll}\text { 5.5.3 Croatia } & 104\end{array}$

5.6 Conclusion 105

Chapter 6 Census-taking in the Western Balkans: A matter of state capacity or the influence of domestic and external actors? 107 Abstract 108

$\begin{array}{ll}6.1 \text { Introduction } & 109\end{array}$

6.2 Census-taking in the Western Balkans $\quad 110$

$\begin{array}{ll}6.3 \text { State capacity and census-taking } & 111\end{array}$

6.4 Domestic and external actors $\quad 115$

6.5 Case analyses 116

$\begin{array}{ll}\text { 6.5.1 Croatia } & 116\end{array}$

6.5.2 Bosnia and Herzegovina 118 
6.6 Comparison 121

$\begin{array}{ll}6.7 \text { Conclusion } & 122\end{array}$

$\begin{array}{ll}\text { Chapter } 7 \text { Conclusion } & 125\end{array}$

$\begin{array}{ll}7.1 \text { Introduction } & 126\end{array}$

$\begin{array}{ll}7.2 \text { Main findings } & 127\end{array}$

7.3 Contribution to the literature 131

$\begin{array}{ll}\text { 7.4 Generalisability of the findings } & 133\end{array}$

$\begin{array}{ll}7.5 \text { Limitations and suggestions for further research } & 134\end{array}$

$\begin{array}{ll}7.6 \text { Policy recommendations } & 135\end{array}$

$\begin{array}{ll}\text { References } & 137\end{array}$

Appendices 151

Appendix 1: Regulation (EC) No 763/2008 of the European Parliament

and the Council of 9 July 2008 on Population and Housing Censuses 152

Appendix 2: List of interviews 156

Appendix 3: Topic guide for the interviews 156

Appendix 4: Questionnaire first survey round 157

Appendix 5: Questionnaire second survey round 173

Appendix 6: Indicators and average score for State Capacity

(Government Effectiveness, Regulatory Quality, Political Stability,

and Control of Corruption) for 2004-2015 184

$\begin{array}{ll}\text { Valorisation addendum } & 185\end{array}$

Summary/Samenvatting 193

English summary 194

$\begin{array}{ll}\text { Nederlandse samenvatting } & 199\end{array}$

$\begin{array}{ll}\text { About the author } & 205\end{array}$ 


\section{Tables and figures}

Table 1: Overview of research question and sub-questions 20

Table 2: Assessing compliance with census-taking 49

Table 3: Embedding Europeanisation in the chapters 51

Table 4: Methods and data applied in the separate parts and the overall design of this research $\quad 64$

Table 5: Sensitivity per aspect 78

Table 6: Agreement/Disagreement with ethnic and cultural characteristics as part of census questionnaire: UNECE/CES recommendations 78 Table 7: Agreement/Disagreement with ethnic and cultural characteristics as part of census questionnaire: EU census regulations

Table 8: Should ethnicity, language and religion be excluded, as they might threaten the data collection?

Table 9: Comparison of ethnic and cultural questions in the census questionnaires of Croatia, Bosnia and Herzegovina and Macedonia

Table 10: Comparison of state capacity, domestic actors and external actors, by country

Table 11: Relevant factors for census-taking in Croatia, Bosnia and Macedonia

Table 12: World Bank Governance Indicator scores for Croatia, Bosnia,

and Macedonia

Figure 1: Overview of the status of EU enlargement and the census

outcomes

Figure 2: Articles of the Regulation (EC) No 763/2008 of the European

Parliament and the Council of 9 July 2008 on Population and Housing

Censuses

Figure 3: Visual research design

Figure 4: Qualitative and quantitative approach of the research design

Figure 5: Average sum of Indicators for State Capacity (Government

Effectiveness, Regulatory Quality, Political Stability, and Control of

Corruption) for 2004-2015 


\section{Acknowledgements}

There are a couple of things that have a high risk of increasing the amount of grey hair on your head, including having a child and finishing your PhD. Over the last 12 months, I have managed both, and I am very lucky that there were people along my way who were there for me and slowed down the pace of me becoming grey. A PhD usually takes more than 12 months, mine did at least, and I will try to do justice to all the people who supported me and deserve my thanks.

First of all, I am tremendously thankful to Hans as my supervisor, who is very supportive and remains friendly under all circumstances. Without him the journey of this PhD would not have been the same. I am also thankful to my other supervisors, Gergana and Petar. Gergana, thank you for your valuable feedback and your guidance. I learned a lot from you, not only about the Balkans and Europeanisation, but also the more practical aspects of doing research. Petar, thanks for pushing my writing beyond of what I could do by myself.

I am very grateful to the external advisory board of this project, especially Pieter Everaers and Eric Schulte Nordholt, who not only were highly valuable for the data collection of the expert survey, but also helped a lot by introducing me to the census community. Without their support many of the interviews would not have taken place. I am also grateful to Annemieke Luiten from Statistics Netherlands, who helped with the formulation of the survey questionnaire. And I need to thank the respondents of my survey and my interviewees. Without them this research would not have been possible.

Coming from a different disciplinary background to work on a project in Political Sciences had its challenges, but I learned a lot during the trainings of the Netherlands Institute of Government (NIG), and I thank Markus Haverland and Dvora Yanow for their feedback on my drafts during the tutorials. I am also thankful to Evelyn Ruppert for the short research stay at the ARITHMUS project in November 2016.

Many thanks to the Graduate School and my colleagues at FASOS, who helped me survive the FASOS jungle of teaching and research. I am especially thankful to John Harbord who gave me feedback on my writing. 
Bandito deserves my thanks for their supply of caffeine. The approximately 500 flat whites over the last five years definitely contributed to the process of this project.

Working on a PhD can be quite lonely, so I am thankful to all my colleagues who accompanied me on this journey; in particular my fellow PhD's who invited me to join for lunch and/or coffee. This list is quite long and I am afraid I forgot a name or two over the years, but it definitely includes Martina, Ewa, Jinhee, Marith, Karlijn and Hortense. There are others, such as Floris, who almost never made it for lunch, but often randomly bumped into my office and who gave me good advice on how to write these acknowledgements.

Working at FASOS in the 76 building has had its own charm. From very cold winters to overly hot in the summer, my office has nevertheless been a good place - not only because of the banana plants which were there before me, but mostly because of the colleagues in the building and especially my office mates. Without Marieke who was there when I started, I would only understand half of the things going on at FASOS and I don't think she knows it, but she gave me good insights into life as a PhD. After Marieke left, I tried to pass on some of this knowledge to the other people who shared the office with me. I am very glad that I could interrupt Marloes for frequent coffee breaks. I am also glad that Emma spent some time in our office and later Marie joined for my last months in 0.13 .

I am very grateful to my new colleagues at CICAM, especially Willemijn and Maarten, who got to know me in a very stressful period, but were very supportive.

And there are a couple of people who live further away, but are nonetheless close to my heart. Karina, thank you for being there for me, no matter how far. Elli, thank you for providing me with a potential place to hide from all the bad things in this world and a sufficient supply of sweets.

I am also thankful to Afke who is an inspiration when it comes to teaching, but also a very kind person and a very supportive paranimph. I will never forget our visit to Gödöllö. Next to her is my brother as second paranimph, who can drive me crazy at times, but is always there when I need him.

The latter is actually true for all members of my family, who, although they don't really understand what I am doing, nonetheless are always very supportive. My sister deserves my thanks, because due to her creative network the cover of this book looks the way it does. Thanks also to my Dutch family, in particular Marian and Foekje who helped me with the Dutch summary. I am tremendously thankful to my parents, who always supported me in whatever direction I am turning. Even though my mum never studied, the advice she gave me when I was little still is the most valuable: instead of freaking out over something in the evening, it is better to sleep on it. Her 
voice in my head provided me with the much needed strength to complete this project.

Finally, I need to thank Jorim for his endless support and for being the constant in my life and thanks to Ronja, who gives my life everlasting sunshine. 

Chapter 1

Introduction 



\subsection{Census-taking and EU enlargement in the Western Balkans}

The prospect of enlargement provides the European Union (EU) with a powerful tool to promote peace and stability beyond the territory of its member states. The possibility of joining the EU enables the Union to transform these countries into functioning member states by imposing preconditions. This was rather successful in Central and Eastern Europe (Vachudova, 2005), leading ultimately to the 2004 enlargement round when ten countries joined the EU, followed by Romania and Bulgaria in 2007; Croatia joined in 2013 as the first of the Western Balkan countries. The EU extended its membership perspective to all seven countries of the Western Balkan region' in 2000, but they have been more reluctant to accept the conditions set by the EU and are moving at different speeds towards accession. While Croatia is already a member state, Kosovo and Bosnia are still considered as potential candidates. Montenegro and Serbia have started membership negotiations, while Albania and Macedonia remain candidate countries that have not yet started negotiations.

Within the context of EU enlargement, the academic debate has focused on the transformative power of the EU in Central and Eastern Europe (Grabbe, 2006) and has established models for the effective transfer of EU rules in enlargement countries (Schimmelfennig \& Sedelmeier, 2004). These models, however, do not fully explain the enlargement processes in the Western Balkans and scholars have turned to the normative and strategic dimensions of EU external power (Noutcheva, 2009, 2012) as well as to the EU's approach of building functional states in the course of integrating them (Bieber, 2011; Denti, 2014; Keil, 2013a). Recently also the domestic circumstances that affect the influence of the EU in the enlargement process have gained attention, for example the concept of limited statehood which is the lack of structures to constrain human action and execute EU rules (Elbasani, 2013a, p. 6).

Even though the EU has a strong influence on its enlargement countries and have the same conditions to comply with, the Western Balkan countries show considerable differences in compliance. This is especially the case when looking at the population and housing censuses in the 2010 census round. ${ }^{2}$ Whereas in Croatia, Serbia and Montenegro the census processes were not very problematic and have been described as only marginally contested, ${ }^{3}$ the Albanian census is partially contested by the ethnic minori-

\footnotetext{
1 The Western Balkan region includes Albania, Croatia, Bosnia and Herzegovina, the former Yugoslav Republic of Macedonia, Montenegro, Serbia and Kosovo.

2 The 2010 census round includes all censuses collected between 2005 and 2014 (United Nations Statistics Division, 2013). Within the EU, the reference year for the census was 2011 (European Parliament \& Council of the European Union, 2008).

3 In Montenegro the census was marginally contested by the ethnic communities over lines of ethnic, religious and linguistic differences (Visoka \& Gjevori, 2013, p. 13). In Serbia the complex
} 
ties present in the country (Visoka \& Gjevori, 2013); in Kosovo the census was boycotted in some municipalities (Visoka \& Gjevori, 2013); and in Bosnia and Herzegovina (hereafter Bosnia) it was postponed twice before being conducted in October 2013, and the results were not published until June 2016. Finally, the census in the former Yugoslav Republic of Macedonia (hereafter Macedonia) was aborted after a couple of days of enumeration (Daskalovski, 2013). These differences in census outcomes have led also to a variation in compliance with the EU census regulations, which are part of the $18^{\text {th }}$ chapter of the acquis communautaire, the full body of EU rules and norms which consists of 35 chapters in total (European Commission, 2014b).

The aspect of compliance with EU conditions has been the focus of Europeanisation researchers (Noutcheva, 2009; Schimmelfennig, 2005; Steunenberg \& Dimitrova, 2007). While some authors have analysed the compliance behaviour of future member states in more general terms, others have looked at the compliance behaviour of accession countries by analysing specific criteria of EU enlargement (Glüpker, 2013; Mendelski, 2013; Strelkov, 2016). However, such studies relate more to the Copenhagen Criteria, the political criteria of the EU, rather than the chapters of the acquis communautaire, which tend to be regarded as more technical (Anastasakis, 2008). To address this gap in the literature this thesis analyses the compliance of three of the Western Balkans countries (Croatia, Bosnia and Macedonia) with one particular aspect of the more 'technical' acquis, the population and housing census (hereafter census).

This thesis will analyse the 2010 census processes as part of EU enlargement in Croatia, Bosnia and Macedonia. These countries have a relatively similar history as they were all part of former Yugoslavia, which conducted its last complete census shortly before dissolution in 1991. Besides this, all of these countries are enlargement countries, albeit at different stages, and they present very different cases of census-taking. In addition, these cases show that although the EU promotes enlargement as a tool for stability and spreading peace, the accession condition of census-taking can also increase domestic tensions. In general, the collection of population data is a tremendously complicated undertaking.

Although sometimes seen as an outdated concept, a population census is crucial in modern society. Census data forms the backbone for vital national statistics such as GDP per capita, and provides the state with information on its population and living standards. On average population censuses are collected every ten years, and involve a census law and the preparation of the census, as well as the collection, processing, publication and

relationship between the Serb majority and the Albanian and Bosniak minority led to minor contestations (Visoka \& Gjevori, 2013, p. 16). In Croatia the census data has been accepted overall, but because of the wording of the questionnaires the results are marginally contested by the Serb minority (Pavelic, 2012). 
dissemination of the population data. The collection of population data is very expensive and labour intensive (Schulte Nordholt, 2014, p. 9), but this data is needed to distribute subsidies and to make policy decisions. Censuses can be problematic even in established democracies. For example in Germany the 2011 census showed that the total population was 1.5 million less than expected, which in the end led to a decrease in subsidies for municipalities and cities where the number of inhabitants was lower than anticipated (Bundeszentrale für politische Bildung, 2013). ${ }^{4}$ Thus it can be expected that in the post-war societies of the Western Balkans censuses will be an even more delicate matter.

Within the framework of Europeanisation there is scant research on census-taking (Keil, 2015; Keil \& Perry, 2015). Recently more attention has been paid to the censuses in the Western Balkan region, but this research focuses foremost on the construction of national identity through the census categories (Bieber, 2015) or on the aspect of ethnicity (Daskalovski, 2013; Visoka \& Gjevori, 2013). The politics of numbers behind the population count have also been described as an important aspect (Daskalovski, 2013; Keil \& Perry, 2015), and even though censuses form part of the 'technical' acquis, scholars agree that they are not technical, but in fact highly political (Keil, 2015; Nobles, 2000; Perry, 2013; Vrgova, 2015).

Politicisation is inherent to census-taking, as population data is linked to important decisions over the distribution of public funds and can be used for the allocation of institutional quotas for various societal (ethnic/linguistic) groups (Everaers, 2015). Especially in multi-ethnic and multi-lingual societies census-taking is often highly politicised (Kertzer \& Arel, 2002b; Leibler \& Breslau, 2005; Urla, 1993). This is also the case in the Western Balkans (Bieber, 2015), where the strong focus on identity-related census questions, such as ethnicity, language and religion, can hinder the collection of reliable population data, as was for example the case with the aborted census in Macedonia (Daskalovski, 2013; Vrgova, 2015).

The quality of the data collection process has a direct impact on the reliability of the census and hence the decision-making connected to it. In order to harmonise census data within the Union, the EU has official rules on how censuses should be collected (European Parliament \& Council of the European Union, 2008). Even though (potential) EU candidate countries do not yet have a legal obligation to follow EU rules, they are strongly advised to do so, because it shows their level of preparedness for accession.

\footnotetext{
4 Due to protests based on the fear of invasion of personal privacy, Germany stopped collecting census data after 1987 (in West Germany population numbers have been based on municipality registers, and in the former East Germany the last population data is from 1990). Population data was thus based on estimates until in 2011 census data was again collected (Bundeszentrale für politische Bildung, 2013).
} 
The main puzzle of this research is the variation in compliance with the EU census regulations. Even though these countries have the same conditions to comply with they show a variation when it comes to the censuses.

\subsection{Research question(s)}

The main research question of this thesis is: What accounts for the variation in compliance with the EU census regulations in Croatia, Bosnia and Macedonia?

The second and third chapter of this thesis will outline the theory behind Europeanisation and the methodology used in this thesis. These are followed by three empirical chapters. Chapter 2 will outline the theoretical background of Europeanisation, as well as the operationalisation of compliance with the EU census regulations. Chapter 3 outlines the overall methodology of this thesis. The empirical chapters include sub-questions to answer the overall question and engage with the theoretical concept of Europeanisation. Broadly defined this concept looks at '[p]rocesses of a) construction, b) diffusion, and c) institutionalisation of formal and informal rules, procedures, policy paradigms, styles and "ways of doing things"' (Radaelli, 2006, p. 59). Since this concept is so broad, this thesis will research three angles of Europeanisation (see chapter 2 for a more elaborate explanation). The first angle, examined in Chapter 4, will set the stage for compliance with the EU census regulations and makes use of the concept of Europeanisation by assessing the explicit and implicit adherence to the EU census regulations by analysing census laws and methodologies of the case countries. This will provide an overview of whether and to what extent the EU conditions are adopted by the case countries. The other empirical chapters (Chapters 5 and 6) will assess Europeanisation as the direct influence of the EU on the census processes in order to show the effect of the EU on its accession countries. Chapter 5 engages with the second angle of Europeanisation by identifying two of its mechanisms-conditionality (based on the logic of rational choice) and legitimacy (based on the logic of appropriateness) - to analyse the strategies the EU employs to influence developments in the enlargement countries. Chapter 6 also analyses the influence of the $\mathrm{EU}$ on the domestic process, however by focusing on its power as external actor, the third angle of Europeanisation. These angles are important, because they provide an overall picture of the Europeanisation processes in the case countries.

Chapter 4 analyses the first sub-question of the thesis by asking whether we can speak of Europeanisation of census-taking, in the absence of concrete rules on collecting ethno-cultural data. Although the Western Balkans have a post-war history and the aspect of collecting data on ethno-cultural data is regarded as sensitive, all Western Balkans countries collect data on 
ethnicity, language and religion. In all case countries the census outcomes are connected to minority and/or language rights, and therefore the census has to collect data on ethno-cultural characteristics, which has led to different levels of contestation. Since the collection of data on ethno-cultural characteristics is not part of the EU requirements, this chapter analyses data from a survey conducted among census experts, in order to assess the general practice and implicit compliance of collecting ethno-cultural data.

The fifth chapter goes deeper into the analysis of the Europeanisation of census-taking by looking at two Europeanisation mechanisms: conditionality, which is based on the rational-choice calculation of the EU (dis)incentives, and legitimacy, which analyses whether the EU regulations are accepted or contested based on the perception of appropriateness. As part of the enlargement process the EU supports its future member states financially, but also with technical knowledge. With regard to the censuses, for example, the Statistical Office of the EU, Eurostat, has set up Technical Cooperation Meetings and in some countries the census processes are observed by International Monitoring Observation (IMO) missions. The EU has high stakes in the Western Balkan region and is therefore eager to develop a reliable statistical system in its potential future member states (Bieber, 2015, p. 11). The second sub-question is thus: Which of the Europeanisation mechanisms (conditionality or legitimacy) is more likely to explain compliance with the EU census regulations in the case countries?

Besides the influence of the EU, domestic aspects are also important when looking at census-taking processes. Based on the empirical evidence collected in the in-depth interviews it will be shown that the behaviour of local politicians and the National Statistical Institutes is crucial in census processes. As well as structural limitations, such as limited state capacity-which has been identified as one of the main obstacles for EU accession (Elbasani, 2013a)-Chapter 6 will also analyse the agency of domestic and external actors. The third sub-question is thus: How important are state capacity and domestic and external actors for compliance with the EU census regulations in Croatia, Bosnia and Macedonia?

Table 1 presents an overview of the overall research question, as well as the sub-questions addressed in the respective chapters. 
Table 1: Overview of research question and sub-questions

\begin{tabular}{|c|c|}
\hline & Research question and sub-questions \\
\hline Overall research design & $\begin{array}{l}\text { What accounts for the variation in compliance with the EU } \\
\text { census regulations in Croatia, Bosnia and Herzegovina and } \\
\text { the former Yugoslav Republic of Macedonia? }\end{array}$ \\
\hline $\begin{array}{l}\text { Chapter 4: Counting for what } \\
\text { purpose? The paradox of including } \\
\text { ethnic and cultural questions in the } \\
\text { censuses of Croatia, Bosnia, and } \\
\text { Macedonia }\end{array}$ & $\begin{array}{l}\text { Sub-question 1: Can we speak of Europeanisation of } \\
\text { census-taking, in the absence of concrete rules on } \\
\text { collecting ethno-cultural data? }\end{array}$ \\
\hline $\begin{array}{l}\text { Chapter 5: 'When counting counts': } \\
\text { Europeanisation of census-taking in } \\
\text { Croatia, Bosnia and Macedonia }\end{array}$ & $\begin{array}{l}\text { Sub-question 2: Which of the Europeanisation mechanisms } \\
\text { (conditionality or legitimacy) is more likely to explain } \\
\text { compliance with the EU census regulations in Croatia, } \\
\text { Bosnia and Macedonia? }\end{array}$ \\
\hline $\begin{array}{l}\text { Chapter 6: Census-taking in the } \\
\text { Western Balkans: A matter of state } \\
\text { capacity or the influence of } \\
\text { domestic and external actors? }\end{array}$ & $\begin{array}{l}\text { Sub-question 3: How important are state capacity and } \\
\text { domestic and external actors for compliance with the EU } \\
\text { census regulations in Croatia, Bosnia and Macedonia? }\end{array}$ \\
\hline
\end{tabular}

The main argument of this thesis unfolds in three steps. First, censuses are always political processes. With regard to the collection of ethno-cultural data there is no coherent EU approach as they are no binding regulations. Therefore it is basically not possible to speak of compliance with the EU census regulations when it comes to the collection of ethno-cultural data. However, if rights and representation are linked to the census outcomes, the domestic context needs to be taken into account as this can politicise and seriously hinder census processes. Second, the analysis shows that with regard to the domestic influence of the EU on census processes, both Europeanisation mechanisms matter, but as the effectiveness of conditionality and legitimacy differs by case country, it is not possible to explain their effectiveness in a one-size-fits-all Europeanisation model for the Western Balkans. And third, the structural aspect of state capacity cannot fully explain the variance in compliance with the EU census regulations, but domestic actors have an important role in compliance processes with the EU regulations, as depending on the census outcomes they can potentially gain or lose power and/or rights and therefore respectively hinder or facilitate the census processes. Depending on the resources available, EU pressure and rewards can overcome domestic disputes surrounding the census. Overall, this thesis will show that domestic influences should not be underestimated in Europeanisation research. The next sections present the content of the thesis and its methodology in more detail.

\subsection{Europeanisation}

The second chapter outlines the concept of Europeanisation and its background. Europeanisation originates from neo-functionalism and liberal- 
intergovernmentalism. The political integration of Europe is a result of economic spillovers, according to neo-functionalism (Haas, 1958). Liberalintergovernmentalism challenged this perception and regards states and elites as the drivers of integration (Moravcsik, 2005). Europeanisation has managed to go beyond the debate between neo-functionalism and liberalintergovernmentalism by widening the research spectrum and including the impact of the EU on institutions and policies in domestic systems (Graziano \& Vink, 2013, p. 36).

In this thesis, Europeanisation is used for analysing EU enlargement and census-taking in the Western Balkans. In order to do so, this chapter makes a distinction between internal and external Europeanisation, which respective$\mathrm{ly}$ is the influence of the EU on its members and non-members. Based on the definitions from Radaelli (2006) and Elbasani (2013), this thesis defines Europeanisation as the influence of the EU on its enlargement countries.

This thesis contributes to analysing the effect of Europeanisation on compliance with the acquis communautaire. In particular one aspect of the $18^{\text {th }}$ chapter on statistics: the population census. Chapter two outlines the specific aspects countries need to comply with when it comes to census-taking: the EU census regulations. In addition, this chapter explains the three phases of compliance with the EU census regulations: non-compliance, partial compliance and full compliance. This chapter also displays in more detail how the different angles of Europeanisation-the explicit and implicit compliance with the EU census regulations, the direct influence of the EU and the influence of the domestic aspects-are used in this thesis to analyse census processes in the three case countries (Croatia, Bosnia and Macedonia).

\subsection{Methodology}

The third chapter of this thesis will outline the overall research design of the project. The main research strategy is based on comparative case study research (George \& Bennett, 2005), and in order to analyse the cases qualitative as well as quantitative data has been collected. The case countries were chosen based on the method of 'crucial cases' (Blatter \& Haverland, 2012, pp. 176-177; George \& Bennett, 2005). The selection of 'crucial cases' is based on the likelihood that a case will confirm a certain theory, also called most-likely cases and least-likely cases (Blatter \& Haverland, 2012, p. 176). The case selection is thus based on expected variance in compliance with the EU census regulations. Figure 1 shows an overview of the status of EU enlargement and the census outcomes of all the Western Balkan countries. Except for Albania all of these countries were part of the former Yugoslavia, which collected its last population census shortly before its dissolution in 1991. 
After the Yugoslav wars (1991-2001), which resulted in the violent dissolution of Yugoslavia, issues of ethnicity and geographic belonging developed into tools for ethnic bargaining over borders, rights and political representation (Visoka \& Gjevori, 2013, p. 6). Population data was seen as a means to increase or decrease power and rights of certain population groups and as a result census-taking is highly political. For these reasons, the censuses in Macedonia have been highly politicised (Friedman, 2002) and Bosnia did not have a census until 2013 (Perry, 2013).

When this project started in June 2013, it was expected that based on the track record of the countries compliance with EU requirements that Croatia would be fully compliant. Considering the approach towards the EU, Macedonia was considered as partially compliant and Bosnia as non-compliant. At the start of this research project, the outcome of all the census processes was not yet clear, as Bosnia's census took place only in October 2013 and publication of the census outcomes came only after a long delay in June 2016. This however made for a very interesting and least-likely case. Macedonia was chosen because it was the only census that was aborted and therefore also presented a least-likely case. Taking into account that Macedonia was well on its way with implementing EU policies and nonetheless failed to collect population data makes for another interesting case. Croatia, by contrast, received its EU membership the same year this project started and completed its 2011 census, and thus was chosen as most-likely case for this study. In addition, these countries also represent the different stages of EU enlargement.

These cases are analysed using a mixed methods research design. The use of mixed methods designs is increasingly popular. For this research the additional coverage mixed methods model (Morgan, 2014) was chosen as it contributes to a more coherent understanding of the same phenomena by using qualitative as well as quantitative methods. In order to understand the census-taking processes in the case countries, in-depth interviews were conducted with representatives of the National Statistical Institutes (NSIs) of the case countries, as well as the European Commission (for example at DG Estat (Eurostat) and DG NEAR) and International Census Consultants. In addition, official documents from the EU and (for example) the NSIs, as well as newspaper articles have been used for contextualisation. Finally, 75 census experts were asked to fill in a survey, based on the Delphi method with survey data being collected in two rounds (with a response rate of $69 \%$ [ $n=52$ ] in the first round and $50 \%$ [ $n=38$ ] in the second round). Collecting the data in more than one round allowed for more interaction with and response from the census experts. The survey data provides important insights into the census-taking processes in the EU and Europe. 


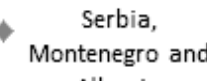

Albania

BiH, Kosovo

Figure 1: Overview of the status of EU enlargement and the census outcomes

The data collection and analysis method for this project is based on one coherent research design, as this makes it possible to analyse the phenomenon of census-taking both from the broader perspective, using the exploratory survey data, and according to the particularities of the case countries, using the explanatory in-depth interviews. In order to provide an overview of the different angles of Europeanisation, each of the separate chapters employs the most relevant methodological approach(es). The fourth chapter analyses the inclusion of ethno-cultural data by using the overall research approach as it combines the results of the survey with an analysis of the census practices of collecting ethno-cultural data by comparing the census methodologies and questionnaires of the case countries. The fifth and sixth chapters of this thesis use primarily qualitative data. The fifth chapter is based on the in-depth interviews, but also uses official documents and newspaper articles for contextualisation. The research design of this chapter is congruence analysis, which allows the researcher to compare and contrast different theories (Blatter \& Haverland, 2012). The sixth chapter uses interview data, and official documents and newspaper articles for contextualisation, but also makes use of the World Bank Governance Indicators for its comparison of state capacity. The conclusion brings all these separate findings together.

\subsection{The paradox of collecting ethno-cultural data in censuses}

The fourth chapter of this thesis will deal with the paradox of including ethnocultural questions in the census within the case countries, but also the Euro- 
pean perspective on this matter. The paradox of counting ethnic and cultural data reveals itself especially when population numbers are linked to numerical thresholds and minority rights. When you are not counted you officially do not exist; however if you are counted this ultimately can lead to either positive or negative discrimination (Nobles, 2000). Whereas within the census regulations of the European Union (European Parliament \& Council of the European Union, 2008) there are no concrete rules on how to collect sensitive data on ethno-cultural characteristics (Simon, 2011), in the census round of 2010 all Western Balkan countries asked for this data (Eurostat, 2014). This chapter will answer the first sub-question, which asks whether, in the absence of concrete rules on how to collect ethno-cultural data, it is possible to speak of Europeanisation of census-taking.

In the Western Balkans, censuses were already being conducted under Ottoman and Habsburg rule (Shaw, 1978) and they became relatively regular in socialist Yugoslavia. The last census of Yugoslavia was conducted in 1991, but in the same year the country also dissolved and violent conflicts broke out. After these conflicts, issues of ethnicity and geographic belonging developed into tools for ethnic bargaining over borders, rights and political representation (Visoka \& Gjevori, 2013, p. 6). The population census is an essential tool for ethnic groups to (re)assure legitimacy and supremacy (Visoka \& Gjevori, 2013). So when the census questionnaire includes questions on ethnic and cultural belonging, such as ethnicity, language and religion, it not only provides an overview of the demographic, social and economic characteristics of a country's population (Valente, 2010), it also creates an opportunity for individuals to identify as being part of this population (Ruppert, 2007). When categories are created for ethnicity, language and religion, people start identifying with these categories and therewith also legitimise them. In the end, they are forced to recognise themselves in these census categories (Ruppert, 2007), as being part of a societal group, and eventually as being part of the state. This can also lead to conflicts (Urla, 1993) and debates about the categories (Yanow, 2003). Since the relationship between the census and identities is connected to claims over territory and the power over people with other identities or ethnic and cultural characteristics, census-taking is highly political (Kertzer \& Arel, 2002a, p. 36).

Until the dissolution of the country in 1991, identity questions in Yugoslavian censuses were common and were based on self-identification; they included open answer questions for national identity, language and religion (Bieber, 2015, p. 10). In the Western Balkans, collecting ethnic and cultural data is therefore seen as normal, but this is not required by the EU and within the $\mathrm{EU}$ there are no concrete regulations or coherent practices on how to collect this data. As there are no rules, it is not possible to speak of explicit compliance with the EU census regulations. By analysing survey data collected among census experts, this chapter also assesses implicit compliance, 
but also here census practices and expert opinions diverge. Where rights are linked to census outcomes, this can make the census processes highly political. For example, in Croatia minority rights are linked to the census results (Petričušić, 2002). In Bosnia the population data of 1991 is linked to the Dayton Peace Agreement, which divides the political system among the three constituent ethnic groups (Bosniak, Croat and Serb) (Armakolas \& Maksimovic, 2014; Bieber, 2004). In Macedonia, the census is linked to the Ohrid Framework Agreement which stopped the armed conflict between ethnic Albanians and Macedonians in 2001, and according to which minorities making up more than $20 \%$ of the population receive language rights and proportional representation in the police and bureaucracy (Brunnbauer, 2002; Vasilev, 2013). Consequently, some groups in the population stand to benefit from the census, whereas other groups tend to lose. This chapter argues that censuses are always political processes, and this is especially crucial if the domestic circumstances are as complex as in the Western Balkans.

The paradox of collecting ethno-cultural data and the linkage of rights and numerical thresholds to the census outcomes leads to domestic disputes and contestations, which are also visible in the analysis provided in Chapters 5 and 6 , as well as in the following sections (1.6 and 1.7).

\subsection{Europeanisation of census-taking in the Western Balkans}

The fifth chapter addresses the effect of the Europeanisation mechanisms of conditionality and legitimacy on the census-taking processes in Croatia, Bosnia and Macedonia (sub-question 2). The term 'Europeanisation' is used to describe the domestic influence of the EU in the Western Balkans (Elbasani, 2013a, p. 5). Earlier research on the aspect of Europeanisation has looked into the normative and strategic dimensions of EU external power (Noutcheva, 2009, 2012) and 'EU member state building', a concept used for the EU's approach of building functional states while integrating them (Bieber, 2011; Denti, 2014; Keil, 2013a). Recently more attention has been paid to domestic factors that affect Europeanisation in the region, such as limited statehood (Börzel, 2013; Elbasani, 2013a). Domestic factors will be addressed in the next section (1.7) and covered in more detail in Chapter 6.

Within the framework of Europeanisation, census-taking is underresearched. The EU has high stakes in the stability of the Western Balkan region and wants to develop reliable statistics in its potential member states (Bieber, 2015, p. 11). Even though candidate countries are not legally obliged to follow the EU census regulations, it is strongly recommended that they do so. They are expected to have the same statistical standards as the current EU members (Everaers, 2015, p. 185). All the Western Balkan countries 
were in the 2010 census round either financially and/or technically supported by the European Commission, through for example Eurostat, the statistical office of the EU. 5

In order to fully understand the influence of the EU on the census processes in the Western Balkans, two mechanisms will be used to assess the Europeanisation of census-taking in the Western Balkans. These are conditionality, which looks at the (dis)incentives the EU offers in light of a cost/benefit calculation, and legitimacy, which will be analysed by looking at the implementation of the EU census rules in addition to the nature of the debates and contestations surrounding the censuses. Conditionality can be best understood as a rational choice concept and is based on the logic of consequences. In this thesis it will be used to assess whether EU rewards/pressure can outweigh the domestic adoption costs. Legitimacy derives from social constructivism and is based on the logic of appropriateness. Here, it is used to look into whether domestic actors are more likely to comply with the EU census regulations if they accept these as the most (appropriate) legitimate course of action. In Central and Eastern Europe, it has been shown that conditionality can explain the transfer of EU rules in candidate countries (Schimmelfennig \& Sedelmeier, 2004). In the Western Balkans, however, Noutcheva (2009) has found that the lack of perceived legitimacy of the EU rules leads to a difference in compliance with the EU conditions.

Chapter 5 of this thesis concludes that in Croatia legitimacy was more effective whereas in Bosnia the EU rewards and pressure were able to tip the balance in favour of compliance. In Macedonia noncompliance can be explained either by conditionality-since there were no concrete EU rewards, the cost/benefit calculation could not outweigh the domestic adoption costs-or by legitimacy, since there was a strong contestation against the EU census regulations. Both mechanisms have been effective in the three case countries and thus this chapter contributes to the Europeanisation literature (Noutcheva, 2009) by stating that conditionality and legitimacy do matter. Nonetheless the domestic adoption costs and the contestations also show that the domestic aspects should not be underestimated, and this will be addressed in more detail in the next section and in Chapter 6.

\subsection{State capacity, domestic and external actors}

State capacity is closely connected to census-taking since statistics have always been seen as a description of the state, 'by and for itself' (Desrosières, 1998, p. 147). Within the EU 'good quality statistics are a part of the basic infrastructure' (Everaers, 2015, p. 188) and therefore countries aim-

\footnotetext{
5 The official name is Directorate General European Statistics (DG ESTAT) of the European Commission.
} 
ing to join the EU need to show that they can collect reliable population data. Census-taking is closely connected to state institutions and is 'an assertion of sovereign authority over people and social relations' (Curtis, 2001, p. 36). Research (Börzel, 2013; Elbasani, 2013a, p. 6) suggests that limited statehood-the lack of structures to constrain human action and execute EU rules-is one of the main obstacles for the Western Balkans' compliance with EU regulations. In addition to the structural aspect of state capacity, which can potentially inhibit the compliance behaviour of accession countries, the agency of domestic and external actors will also be assessed. The evidence will show that as well as the influence of the EU as external actor, the behaviour of domestic actors, for example of local politicians and the National Statistical Institutes, can be crucial when analysing census processes. Chapter 6 therefore analyses the importance of state capacity, but also of domestic and external actors, in terms of compliance with the EU census regulations in Croatia, Bosnia and Macedonia (sub-question 3).

While comparing state capacity using the data from the World Bank Governance Indicators, this chapter finds that state capacity is not able to fully explain the variance of the case countries' compliance with the EU census regulations. As in countries with contested statehood, external actors can take over authority and fill the gaps left by the local government (Krasner \& Risse, 2014), this chapter also assesses the agency of actors and their influence on the census processes. In addition to the EU as an external actor the responses of political and other domestic actors, as mentioned in section 1.6, will also be taken into account.

The analysis in this chapter shows that when there are domestic disputes, as in the case of Bosnia, the influence of the EU as an external actor is important. However, if the EU has little leverage and there are domestic disputes, census processes can also be hindered to the extent that they have to be aborted, as in Macedonia. The case of Croatia shows that if there are almost no domestic disputes, the influence of external actors is not needed in order to be compliant with the EU census regulations. This also confirms the finding in Chapter 5, where for Croatia the Europeanisation mechanism of legitimacy was most important and for Bosnia conditionality was able to tip the balance in favour of compliance, but in the case of Macedonia the EU could not overcome the domestic contestations. These cases show that domestic agency should not be underestimated in census processes.

\subsection{Contributions \& relevance}

The contributions of this thesis are twofold. First, this project builds on a mixed methods approach, which combines in-depth interview data with an expert survey collected in two rounds. This strategy of data collection is innovative 
and provides us with the domestic perspective as well as the broader European perspective on census-taking.

Second, by analysing census-taking in Croatia, Bosnia and Macedonia in the context of EU enlargement, this project will make some important empirical contributions. First, by unpacking the census processes and differences in the Western Balkans and the EU it will be shown that a seemingly technical aspect of the acquis communautaire is in fact highly political. Second, as there is no research yet on the influence of the EU on compliance with the specific requirements of the acquis communautaire of enlargement countries, this research widens the horizon for new pathways in Europeanisation research. Third, this research will confirm that the outcomes of categorisation practices and the collection of ethno-cultural data in the census questionnaire can have important political consequences, but also seriously hinder the collection of population data. Fourth, the analysis of the Europeanisation mechanisms will show that conditionality and legitimacy are important when looking at the compliance behaviour of enlargement countries. Fifth, the analysis in Chapter 6 will show that weak state capacity cannot fully explain the variation of the case countries regarding their compliance with the EU census regulations, which challenges the claim made by Börzel (2013) and Elbasani (2013a) that limited statehood is an obstacle towards EU enlargement. It will however also highlight that the domestic circumstances and actors should not be underestimated when studying censuses and compliance with the EU regulations in the Western Balkans.

The topic of this thesis is relevant, because census data is crucial for good policy and decision-making. Reliable data is of key importance when it comes to the appropriate allocation of resources on the municipal, regional, national and even the European level. Within the European Union, the use of statistical data for policy-making has been described as the 'cornerstone of European society' (Everaers, 2015, p. 185) and 'good quality statistics' as part of the basic infrastructure (p. 188). However, the collection of population data is costly and although there are alternatives to the traditional penand-paper census used in the Western Balkans, such as the register-based census in the Netherlands, in countries without that kind of infrastructure a traditional census remains the most viable option.

Besides these more practical aspects, the political state of the Balkan countries needs to be taken into account. The processes of state-building and democratisation are still ongoing in these countries. Some countries are even described as being captured by elites organised along ethnicnationalistic lines (Kraske, 2017). Even though some former Yugoslav countries are more successful in state-building and are now members of the EU, issues of minority rights also remain a matter of concern in Croatia and Slovenia (Keil, 2015). The strong focus on identity-related questions in the censuses in the Western Balkans (Keil, 2015), and the connection of the census 
results to numerical thresholds and minority and language rights, adds an extra layer of complexity to the census and Europeanisation processes.

\subsection{Outline of the thesis}

The chapters of this thesis are based on academic articles. For this reason there may be some repetition, as each article is able to stand on its own without further explanation. In order to fit the overall style of the thesis, the articles have been slightly adjusted, for example with regard to the reference style, and an overall reference list can be found at the end of the text. Some of the chapters ( 4 and 5 ) have already been published as articles (Hoh, 2017a, 2017b). The fifth chapter is currently under review by an academic journal and it is planned that the third chapter will be submitted to a journal in a slightly revised form. 



\section{Chapter 2 \\ Counting for enlargement? \\ The theory behind the Europeanisation of census-taking}




\title{
Chapter 2
}

\begin{abstract}
This chapter outlines the concept of Europeanisation and how it is used for analysing EU enlargement and census-taking in the Western Balkans. Since the census is part of the $18^{\text {th }}$ chapter of the acquis communautaire, which outlines the rules and regulations countries need to implement in order to become an EU member, this is one of the conditions enlargement countries need to comply with. This chapter outlines how compliance with the EU census regulations is operationalised in this thesis. Next to this, the chapter displays the different angles on Europeanisation employed in this thesis, which address the explicit and implicit compliance with the EU census regulations, the direct influence of the EU on the census processes in the case countries and the domestic aspects that can affect the influence of the EU. By addressing these angles, this thesis contributes to a better overall understanding of the Europeanisation of acquis compliance, and in particular of the Europeanisation of census-taking in the Western Balkans.
\end{abstract}




\subsection{Introduction}

The concept of Europeanisation was originally developed to describe the influence of EU integration on its member states (Graziano \& Vink, 2013), but it has also been used to study EU influence in accession countries (Elbasani, 2013a). Unlike EU member states, enlargement countries are in an asymmetrical relationship with the EU, as they do not have a say with regard to the requirements they need to implement in order to become an EU member (Grabbe, 2003). Nevertheless, they need to comply with the same requirements as EU members. Therefore the concept of Europeanisation is also appropriate to study the impact of the EU in enlargement countries.

Europeanisation derives from the strands of neo-functionalism, liberalintergovernmentalism, and new institutionalism. According to neofunctionalism the political integration of Europe is a result of economic spillovers (Haas, 1958). Liberal-intergovernmentalism challenged this perception as it regards states and elites as the drivers of integration (Moravcsik, 2005). Europeanisation has managed to end this debate by widening the research spectrum and including the impact of the EU on institutions and policies in domestic systems (Graziano \& Vink, 2013, p. 36). Vital for understanding the background of Europeanisation is new institutionalism, which highlights the autonomy of institutions (Bulmer, 2007, p. 51). As will be explained in section 2.2, new institutionalism analyses Europeanisation from a rational-choice, constructivist and historical perspective. These theoretical strands are mostly used to explain the effects of the European integration process on its member states.

With regard to EU enlargement, the concept of Europeanisation emerged rather late in the process, and started with research on the integration of the Central and Eastern European countries as member states (Grabbe, 2006; Schimmelfennig \& Sedelmeier, 2005a; Vachudova, 2005). When looking at the enlargement process of the Western Balkan countries, academic literature has dealt with the general compliance of accession countries with EU demands as well as the influence that such demands have had (Noutcheva, 2009, 2012; Trauner, 2009). Apart from research focussing on the democratic criteria (Elbasani, 2013b; Glüpker, 2013), there is little research which analyses the influence of the EU on countries' compliance with particular requirements of enlargement, such as rule of law (Strelkov, 2016). To date, no research has explored the influence of the EU on compliance with the specific requirements of the acquis communautaire.

To differentiate from the influence of the EU on its member states, this thesis will use the term external Europeanisation to describe the influence of the $\mathrm{EU}$ on its non-members, in this case enlargement countries. External Europeanisation will be used to analyse the influence of the EU on one specific aspect of compliance with the EU acquis, the population and housing census. 
The acquis includes the whole body of EU law and practices that need to be implemented by enlargement countries (Grabbe, 2003, p. 304). The population and housing census is part of the $18^{\text {th }}$ chapter on the statistical requirements for EU membership. The census is important as it provides an overview of a country's population and living standards and is seen as the backbone of national statistics. As evidence-based decision making is important not only for states, but also for the EU (Everaers, 2015), the population census is an important aspect of the EU requirements. In order to be able to compare population data among member and enlargement countries, the data has to be harmonised. Therefore the statistical compendium (European Commission, 2014c) outlines the requirements of the statistics chapter. For the census several EU regulations (Commission of the European Communities, 2009; European Commission, 2010a, 2010b; European Parliament \& Council of the European Union, 2008) stipulate what kind of data has to be collected and transferred.

The census is an aspect of the acquis that is also indirectly connected with the Copenhagen Criteria, the democratic requirements for joining the European Union. This is especially relevant with regard to the Western Balkans, as in this region census outcomes are often connected to the proportional representation of population groups with regard to language and minority rights, which are essential aspects of the democratic requirements. This connection is especially visible in Macedonia, where the Ohrid Agreement clearly outlines that language rights are granted if minorities make up more than $20 \%$ of the population (Brunnbaver, 2002). Minority rights are thus dependent on the outcomes of the census. Compliance with particular aspects of the acquis, such as the census, can affect compliance with the democratic requirements. By analysing the Europeanisation of census-taking, this thesis contributes to the general literature of Europeanisation, and sets the stage for a more concrete analysis of the impact of the EU on acquis compliance.

In this thesis external Europeanisation, the influence of the EU on its enlargement countries, will be used to analyse the variation in census outcomes in Croatia, Bosnia and Macedonia. This will be done by analysing explicit compliance, whether or not the census laws and methodologies of these countries are in line with the EU census regulations-but also the implicit compliance when it comes to census practices that are not part of the regulations, such as the collection of ethno-cultural data. Although the collection of ethno-cultural data is not part of the official requirements, the collection of this data is needed in the Western Balkans to for example ensure minority rights. Next to the overall assessment of compliance, this thesis will analyse the direct influence of the EU in its enlargement countries from the European perspective. This will be done by comparing the effectiveness of two Europeanisation mechanisms-conditionality and legitimacy-to see 
whether the influence of the EU on compliance depends on rational cost/benefit incentives and/or countries' perception of these rules as appropriate and legitimate. In addition, it has been shown by Elbasani (2013a) that the domestic perspective is often neglected in Europeanisation research. Therefore this thesis also assesses whether domestic aspects affect the compliance behaviour of the case countries by comparing their state capacity and the influence of domestic actors with the external influence of the EU.

This chapter will outline the theoretical aspects of Europeanisation and the framework of Europeanisation within EU enlargement. In order to do so, first the general background of Europeanisation will be described and then the developments of this concept within the study of EU enlargement and in particular the Western Balkan enlargement. Thereafter the requirements of census regulations and the operationalisation of compliance will be specified. Finally, this chapter will embed the three angles of Europeanisationimplicit and explicit compliance, the direct influence of the EU and the impact of domestic aspects - in the empirical chapters of this thesis.

\subsection{Europeanisation}

Europeanisation is a concept that predates the European Union, having been used to describe earlier integration processes in Europe (Radaelli \& Pasqiver, 2007, p. 36). It is nevertheless mostly used to describe the process and the impact of the EU on its member states (Börzel, Hofmann, Panke, \& Sprungk, 2010; Caporaso, 2007), but more recently also on (potential) enlargement countries (Grabbe, 2003 and section 2.3) and even EU neighbourhood countries (Börzel \& Lebanidze, 2017; Gawrich, Melnykovska, \& Schweickert, 2010). Research on the Europeanisation of the EU neighbourhood is slowly finding its way into Europeanisation research, and research on external Europeanisation, the effect of the EU and its policies on non-EU members, is increasing (see for example: Anastasakis, 2008; Grabbe, 2006; Keil, 2013a; Noutcheva, 2012; Noutcheva \& Aydin-Düzgit, 2012; Schimmelfennig \& Sedelmeier, 2005a). Before elaborating on external Europeanisation, this chapter will first outline the theoretical background of Europeanisation and survey its many definitions.

Initially, the term Europeanisation was invented to answer the question of how European integration affects the policy making of states (Caporaso, 2007, p. 27). Deriving from Comparative Politics and theoretical Policy Analysis (Radaelli, 2006, p. 61), Europeanisation is based on the theoretical strands of neo-functionalism, (liberal) intergovernmentalism and new institutionalism. Mainly used in the 1950s and 60s, the theory of neo-functionalism predicted that through functional spillovers from the economic sector, driven by social actors' self-interest and promotion through supranational elites, (European) 
political integration would follow (Bourne \& Cini, 2006; Graziano \& Vink, 2013, p. 32). Neo-functionalism builds on the work of Haas (1958), who analysed the European political integration using the example of the European Coal and Steel Community. The ideas of the neo-functionalists were contested by liberal-intergovernmentalists, such as Moravcsik (1993), who argue that while there might be spillover in low political areas, there is no spillover when it comes to the core of national sovereignty (Bourne \& Cini, 2006). According to liberal-intergovernmentalists, European integration tends to strengthen the state and national governments (Bulmer, 2007, p. 49). This thesis will not reproduce the debate between neo-functionalism and liberalintergovernmentalism, as this has already been done elsewhere (Bourne \& Cini, 2006; Featherstone \& Radaelli, 2003; Graziano \& Vink, 2007; Moravcsik, 2005). The commonalities of these strands, however, are that they focus on the states and their influence on Europe, and look at European integration and governance from a 'bottom-up perspective' (Börzel \& Risse, 2000).

More recently researchers, such as Börzel and Risse $(2000,2003)$, have challenged this 'bottom-up perspective' and become interested in the 'topdown perspective', which assesses the process and impact of European integration on its member states and enlargement countries. This top-down perspective of Europeanisation is mainly influenced by new institutionalism, which emphasises the autonomy of political institutions and the importance of symbolic action (March \& Olsen, 1983).

Deriving from institutionalism, the process of standardised interaction to create social order (Jepperson, 1991, p. 145), new institutionalism has three main variants: rational-choice, historical and sociological institutionalism (Bulmer, 2007, pp. 49-50). Rational-choice institutionalists see institutions and Europeanisation as political opportunity structures, and explore the preferences of actors with regard to the institutional settings or rules. With regard to Europeanisation, this mostly refers to the mechanism of EU conditionality, whether or not EU conditions are implemented based on whether the EU rewards outweigh the domestic adoption costs. Historical institutionalists are concerned with the element of time, in terms of timing and tempo of the (European) integration process. By highlighting the interdependence of multiple causal variables (Steinmo, 2008, p. 166), historical institutionalism sees the evolution of institutions as a driving factor of change in governance and policy making (Georgescu, 2014). Sociological institutionalists are concerned with norms, ideas, discourse and organisational structure of politics, and focus, among other things, on the behaviour of domestic actors. This is related to the mechanism of legitimacy and whether or not EU rules are implemented because this is regarded as the appropriate thing to do.

New institutionalism is indispensable for understanding the context of Europeanisation (Bulmer, 2007, p. 51). The different variants of new institutionalism have been used to analyse Europeanisation (see for example: Börzel \& 
Risse, 2003). Inspired by rational-choice and sociological institutionalism, chapter 5 of this thesis assesses to what extent and how the EU influences the census processes in the case countries. Whereas earlier research on Central and Eastern Europe showed that EU conditionality, a rational-choice model, can explain patterns of EU rule transfer to candidate countries (Schimmelfennig \& Sedelmeier, 2004), this was less the case in the Western Balkans. In these countries the lack of perceived legitimacy-a model based on sociological institutionalism-of the EU rules led to different outcomes in compliance with EU conditions (Noutcheva, 2009). Thus in order to understand the influence of the EU on the census processes in the case countries, this chapter will compare the effectiveness of the Europeanisation mechanisms of conditionality, based on rational choice, and legitimacy, based on socialisation.

The existence of different variants of institutionalism might seem to suggest that they are competing. These variants are, however, not mutually exclusive and can occur simultaneously and/or in different phases of the integration process (Börzel \& Risse, 2000). Non-compliance based on rational cost-benefit calculations (rational-choice institutionalism) can later on still lead to compliance based on the implementation and adaptation of norms and ideas (sociological institutionalism) (Lightfoot \& Szent-Iványi, 2014, p. 1261). Before going deeper into the operationalisation of compliance (which will be outlined in section 2.4), the various definitions of Europeanisation will be outlined.

Over the last decades, Europeanisation has developed into an established academic concept (some examples are: Atanasova \& Bache, 2010; Börzel, 2013; Börzel \& Risse, 2011 a; Denti, 2014; Eigmüller, 2013; Elbasani, 2013a; Noutcheva \& Aydin-Düzgit, 2012; Schimmelfennig \& Sedelmeier, 2005a; Sedelmeier, 2011; Versluis, 2004). It is, however, used in various contexts and with diverging definitions (for an overview of the use of Europeanisation, see for example Featherstone, 2003). The debate on the boundaries of the concept of Europeanisation was started by Radaelli in 2000 and is still ongoing (Graziano \& Vink, 2013, p. 37). Radaelli uses a rather broad definition of Europeanisation:

$[P]$ rocesses of a) construction, b) diffusion, and c) institutionalisation of formal and informal rules, procedures, policy paradigms, styles and 'ways of doing things'. It also consists of shared beliefs and norms that are first defined and consolidated in the EU policy process and then incorporated in the logic of domestic (national and subnational) discourse. (Radaelli, 2006, p. 59)

Thus, according to Radaelli (2006, p. 59), Europeanisation is about the complexity of domestic change, how it is processed, constructed, institutionalised, adapted and implemented-thus, it is seen as more than a 
simple reaction to 'Brussels'. Vink and Graziano (2007, p. 7) describe Europeanisation in a similar manner, as a process of domestic adaptation to European regional integration, which refers to adaptive processes between the domestic and the EU with regard to policies and institutions. This is also in line with the definition given by Börzel (2002), who additionally highlights the context of uploading of domestic societal preferences to the EU level and the downloading of EU policies on the national level of EU member states. How Europeanisation is defined in this thesis will be described in the next section (2.3), but first the conceptual limitations of Europeanisation will be outlined.

Bulmer (2007, p. 47) identified that Europeanisation research revolves around topics regarding changes of external boundaries, the development of European institutions, the penetration of national governance systems, the export of political organisations and the EU as a political unification project. Within the field of research on Europeanisation, three important elements are addressed (Radaelli, 2006, p. 67). First, Europeanisation refers to how the logic of domestic political actors changes when Europe 'becomes the "grammar" of domestic political action' (Radaelli, 2006, p. 67). EU policy making thus becomes a frame of reference for domestic political actors. Second, Europeanisation means change as a response to the EU, for example when the EU uses political pressure. Third, the process of Europeanisation includes complex sequences and timing. Radaelli (2002) also describes that harmonisation, political integration and convergence are not part of Europeanisation. According to Radaelli, harmonisation is seen as an important goal of Europeanisation; however empirical research has shown that the impact of European requirements is rather differential (Graziano \& Vink, 2013, p. 38). With regard to political integration, a difference must be made between the political pooling and delegation of country's sovereignties and the dynamics and consequences this integration brings about (Graziano \& Vink, 2013, p. 38). Convergence is a consequence of Europeanisation and as such cannot be used synonymously with Europeanisation, as Europeanisation deals with the process of EU integration and not its outcome. Nevertheless, even Radaelli (2000) acknowledges the interrelatedness of these concepts with Europeanisation, and the distinction has not stopped researchers (some examples are: Börzel \& Risse, 2000; Delcour, 2013; Vos, 2006) from employing these elements as part of Europeanisation. Also in this thesis these aspects are crucial to understand the influence of the EU. For example when it comes to census-taking and national statistics, harmonisation is a crucial aspect. Without harmonisation of data it would not be possible to compare statistics in Europe and internationally. It is exactly this divergence that creates an interesting puzzle worth researching. Looking at the definition Radaelli gives for political integration, there is an essential difference with regard to Europeanisation of member states and non-members. As will be explained in the next section (2.3), enlargement countries do not have a say 
with regard to the requirements they need to implement in order to become an EU member. There is thus only limited political pooling and it is therefore possible to study the consequences of political integration.

Most of the work by early Europeanisation researchers, such as Börzel and Risse (2000) and Kohler-Koch (1996), focused on EU integration and the relation with its member states. What needs to be taken into account is the distinction between the process of policy formation within the EU and the consequences of that policy in (enlargement) countries (Grabbe, 2006, p. 47). When it comes to external Europeanisation, concerning the EU's enlargement countries, the influence of the EU is different than on its member states, as will be explained in the next section.

\subsection{Europeanisation in enlargement countries}

When it comes to the relationship of the European Union with its applicants, the political relationship is different from that of the EU with its member states, and this has implications for the occurrence of Europeanisation (Grabbe, 2003). First this section will outline enlargement and its differences with internal Europeanisation (the influence of the EU on its member states), then it will explain the particularities of external Europeanisation (the EU's influence on its non-members). Finally the section will explain the use of Europeanisation in the context of this thesis.

Even though enlargement is the EU's most powerful tool of foreign policy (Vachudova, 2005, p. 223), there has been rather limited research on the first enlargement rounds of the EU6 and in the 1990s this topic was still rather neglected in Europeanisation research (Schimmelfennig \& Sedelmeier, 2005b). After the end of the Cold War, enlargement became a permanent item on the agenda of the EU (Schimmelfennig \& Sedelmeier, 2006, p. 96). In 1995, Austria, Sweden and Finland and in 2004 eight countries (Czech Republic, Estonia, Hungary, Poland, Latvia, Lithuania, Slovenia and Slovakia) from Central and Eastern Europe joined. Bulgaria and Romania became EU members in 2007 and Croatia is the most recent member state, since 2013. With the 2004 enlargement of Central and Eastern Europe, research on enlargement and external Europeanisation increased (Grabbe, 2006; Schimmelfennig \& Sedelmeier, 2004, 2005a; Vachudova, 2005). The enlargement of Romania and Bulgaria was still on research agendas even after accession (Noutcheva \& Bechev, 2008; Spendzharova \& Vachudova, 2012) and of course the accession processes of the Western Balkan countries (Albania, Croatia, Bosnia and Herzegovina, Macedonia, Montenegro, Serbia and Kosovo) are being

\footnotetext{
6 The first enlargement round was in 1973 when Denmark, Ireland and the UK joined the EU. This was followed by the accession of Greece in 1981 and Spain and Portugal in 1986 (European Commission, 2016a).
} 
investigated (Bieber, 2011; Elbasani, 2013b; Keil, 2013b; Noutcheva, 2012; Papadimitriou \& Petrov, 2012).

Accession countries do not have a say in the requirements for enlargement, they must fulfil them in order to become a member of the EU. Uploading of domestic preferences on the EU level, as explained above and used in the research by Börzel and Risse (2000), is thus not possible for accession countries. This leads to an asymmetrical relationship, which arguably provides the EU with more influence in the domestic policy making process in accession countries than in its own member states. Additionally, the stakes for accession countries are higher than for member states, because EU membership is the main incentive to comply with the EU requirements (Grabbe, 2003, p. 303). As enlargement countries are already subject to the pressure and implementation procedures of EU policies, Europeanisation can also be applied to them (Grabbe, 2003, p. 304). However, as there are differences inherent in the Europeanisation of non-members, this will be denoted as external Europeanisation.

In order to join the EU, accession countries need to comply with the EU conditions for membership. In particular, they have to adopt the acquis communautaire, the whole body of EU law and practice, ideally before joining or in a transitional period afterwards (Grabbe, 2003, p. 304). The acquis consists of 35 chapters and about 80,000 pages (Vachudova, 2005, p. 123). Even though for enlargement countries there is no legal obligation to follow the EU rules, they are strongly advised to comply with the regulations as it shows their level of preparedness for EU membership. The content of the acquis is not negotiable and the EU Commission assesses whether and to what extent the EU norms and standards have already been implemented by the accession countries (Vachudova, 2005, p. 124). Next to the acquis, countries also need to meet the Copenhagen Criteria, which include: 'stable institutions guaranteeing democracy, the rule of law, human rights and respect for and protection of minorities; a functioning market economy [...]; [and] the ability to take on and implement effectively the obligations of membership [...]' (European Commission, 2014b).

Although compliance with these requirements has been rather straightforward in Central and Eastern Europe, in the Western Balkan countries this is more complicated. After the violent dissolution of Yugoslavia-which comprised all Western Balkan countries except Albania-the countries are dealing with a post-conflict environment. Since the Western Balkans are dealing with new state configurations and state building, the influence of the EU in the Balkans has also been described as EU member state building (Keil, $2013 a)$.

Within the research on EU enlargement, Schimmelfennig and Sedelmeier (2005b, p. 6) found four main research fields: '(1) applicants' enlargement politics, (2) member state enlargement politics, [...] (3) EU enlargement poli- 
tics' and (4) the 'impact of enlargement'. This thesis will analyse Europeanisation in terms of the impact of the EU on the enlargement processes. Compared with conceptual distinctions of Europeanisation made by Radaelli (2006) above, with regard to EU enlargement there are three additional important distinctions (Grabbe, 2003, pp. 310-312; 2006, pp. 47-49). First, Europeanisation is not about the reasons why enlargement is taking place, but is post-ontological, addressing the effects of the enlargement process. Second, within the processes of enlargement there are different kinds of influence and degrees of influence on the enlargement countries. With regard to kinds of influence a distinction must be made between effects from Europeanisation and from, for example, globalisation (Grabbe, 2003, p. 311). The same holds for the degrees of influence: since there is a general interest (by for example EU officials) to claim that change occurs because of the influence of the EU, there is the danger of overemphasising this influence. Third, one needs to distinguish between the intended and unintended effects of Europeanisation. The influence of the EU can be diffused as the EU operates through many different actors, such as the Commission and the Delegations in the countries, with often unclear goals. One of the unintended consequences of asking for population data in the Western Balkan countries was the high politicisation of these processes, because in these countries minority rights (for example) are connected to the census outcomes. This is also an illustration of how the domestic perspective has been underestimated when it comes to the influence of the EU.

Within Europeanisation research there has been a lack of focus on the domestic side of the equation (Elbasani, 2013a, p. 5; Mastenbroek, 2005). When it comes to the Western Balkans, the success story of previous EU enlargements that transformed countries into functioning market economies and contributed to peace and stability came to a halt (Elbasani, 2013a, p. 4). In this region, compliance with the EU requirements cannot sufficiently be explained by the model of EU conditionality. The focus of Europeanisation research nonetheless remained on expectations rather than the domestic factors that challenge the implementation of the requirements (Elbasani, 2013a, p. 5). Börzel (2013) argues that limited statehood can explain the variation in compliance with the EU conditions, and according to Elbasani (2013a, p. 9) the strength of the domestic elite, and whether or not they are potential EU allies, historical legacies such as post-communist transition, and weak stateness, such as the contestation of state sovereignty and territorial boundaries, are factors that affect the enlargement process.

In this thesis Europeanisation will be used to analyse the variation in compliance with the EU census regulations of Croatia, Bosnia and Macedonia. This will be done by looking at external Europeanisation. With regard to Europeanisation of enlargement countries, Elbasani (2013a, p. 5) describes Europeanisation as shorthand for the domestic influence of the EU. 
A similar definition will be used in this thesis: external Europeanisation will be defined as the influence of the EU on its enlargement countries. The overall compliance will be assessed through the explicit and implicit compliance with the EU census regulations, the direct influence of the $\mathrm{EU}$, as well as the domestic aspects that can affect Europeanisation.

Explicit and implicit compliance are both related to the harmonisation of population data. Explicit compliance measures whether or not the EU census regulations are applied in the case countries. Implicit compliance ${ }^{7}$ assesses whether there are practices that are not officially part of the regulations but still applied when it comes to census-taking, for example with regard to the collection of ethno-cultural data. Analysing explicit and implicit compliance will establish a framework to further investigate the reasons behind the variation of compliance with the EU census regulations.

The direct influence of the EU will be assessed by the effectiveness of two mechanisms of Europeanisation-conditionality (based on the logic of consequences) and legitimacy (based on the logic of appropriateness)-in order to analyse the strategies the EU employs to influence developments in the enlargement countries. The analysis of these Europeanisation mechanisms will measure the effectiveness of Europeanisation.

Additionally, there has been a lack of focus on the domestic aspects that can influence Europeanisation. Therefore this thesis will also analyse whether and to what extent domestic aspects, such as state capacity and domestic actors, play a role when assessing external Europeanisation. This will be done by comparing the influence of the EU as an external actor with the domestic aspects of state capacity and the influence of domestic actors.

These angles have been chosen as they present an overall picture of the Europeanisation of census-taking in the case countries in order to answer the overall research question of this thesis: What accounts for the variation in compliance with the EU census regulations in Croatia, Bosnia and Macedonia? However, before describing how these angles will be used to answer the research question in the empirical chapters, first the operationalisation of compliance with the EU census regulations will be outlined.

\subsection{Compliance with the EU census regulations}

Europeanisation research on enlargement in the Western Balkans has so far looked into the general compliance with the requirements for EU enlargement (Noutcheva, 2009, 2012; Trauner, 2009), but except for some authors

\footnotetext{
7 Implicit compliance is related to socialisation, the internalisation of norms and ideas, and for example the social learning model by Schimmelfennig and Sedelmeier (2004). The idea is that implicit compliance occurs through the exchange of census methods and practices by census experts.
} 
(Elbasani, 2013b; Glüpker, 2013; Strelkov, 2016) compliance with particular requirements of enlargement has been neglected. Research on compliance of accession countries with the criteria of the acquis has so far not been done in detail.

The research puzzle of this thesis is the variation in compliance with EU regulations with regard to census-taking in Croatia, Bosnia and Macedonia. These countries have been selected as they had the same EU conditions to comply with, but it was expected that they would show a strong variation with regard to census outcomes. This actually happened to be the case. The 2011 census in Croatia was conducted without any major irregularities and the results are published in the EU census hub. The census processes of Bosnia and Macedonia were much more complicated. The 2013 census of Bosnia had to deal with a lot of delays and the population data was only published in 2016. In Macedonia, the last census enumeration in 2011 was stopped after a couple of days because of methodological differences. Thus, although having the same requirements, the countries' outcomes differ significantly.

To understand the variation in compliance with the EU census regulations, the definition of compliance must be clear. According to Oran Young, '[c]ompliance can be said to occur when the actual behaviour of a given subject conforms to prescribed behaviour, and noncompliance or violation occurs when actual behaviour departs significantly from prescribed behaviour' (Oran Young, 1979, in: Simmons, 1998, p. 77). Compliance is thus the potential outcome of the implementation process in which all stages are fulfilled in a dutiful manner. Before describing in detail how compliance with the EU census regulations is assessed, the requirements for a population and housing census will be clarified.

\subsubsection{The census requirements}

The requirements of the population and housing census are part of the $18^{\text {th }}$ acquis chapter on statistics (European Commission, 2013a). The statistical requirements compendium (European Commission, 2014c) serves as a reference document for the statistics chapter of the acquis and as such as the framework to assess compliance. With regard to the census, the compendium (European Commission, 2014c, p. 97) includes the Commission regulations on the population and housing census (Commission of the European Communities, 2009; European Commission, 2010a, 2010b; European Parliament \& Council of the European Union, 2008). 
Articles of the Regulation (EC) No 763/2008 of the European Parliament and the Council of 9 July 2008 on Population and Housing Censuses

Article 1: Subject matter:

Outlines the common rules for the decennial population and housing census.

Article 2: Definitions:

Outlines the use of the definitions for categories such as: Population, housing, buildings, usual residence and the reference date.

Article 3: Data submission:

Outlines the submission of the data to the Commission (Eurostat).

Article 4: Data sources:

Outlines the possibilities for data collection, such as register-based and conventional censuses.

Article 5: Data transmission:

Outlines the reference date of the census and the dates, forms and metadata for the transmission of the population data to the Commission.

Article 6: Quality assessement:

Outlines the quality assessment dimensions: relevance, accuracy, timeliness/punctuality, accessibility/clarity, comparability and coherence, as well as how to report on these.

Article 7: Implementing measures:

Outlines the technical specifications and the technical format, as well as the modalities and structures of the quality reports.

Article 8: Committee procedure:

Outlines that the Commission will be assisted by the Statistical Programme Committee and refers to other relevant regulations, such as Decision 1999/468/EC which outlines the implementing powers of the Commission.

Article 9: Entry into force

Outlines that this regulation enters into force 20 days after its official publication.

Figure 2: Articles of the Regulation (EC) No 763/2008 of the European Parliament and the Council of 9 July 2008 on Population and Housing Censuses

Regulation (EC) No 763/2008 of the European Parliament and the Council of 9 July 2008 on Population and Housing Censuses (European Parliament \& Council of the European Union, 2008) is the main frame of reference for all censuses in the EU, but also in its enlargement countries. The regulation wants to achieve data harmonisation for the population data by outlining the 'methodology, definitions and the programme of the statistical data and the metadata', and it stresses the need for 'reliable, detailed and comparable data on the population and housing' (European Parliament \& Council of the 
European Union, 2008). The regulation includes nine articles (see figure 2 for an overview of the articles and appendix 1 for a copy of the regulation). Among others these articles define the subject matter (article 1), which refers to the 'common rules for the decennial provision of comprehensive data on population and housing' and the definitions used for census categories (article 2), as well as the data transmission (article 5) and submission to Eurostat (article 3). The data sources (article 4) to retrieve population data are also specified, for example the conventional pen and paper census, which is still in use in the case countries, but also register-based censuses, which are for example common in the Netherlands. Other aspects of the regulation are quality assessment (article 6), for example based on quality criteria such as relevance, timeliness, accuracy, accessibility, comparability and coherence of the data, and the implementing measures (article 7), such as technical specifications (see figure 2 and appendix 1, as well as European Parliament and Council of the European Union, 2008).

The subsequent regulations (Commission of the European Communities, 2009; European Commission, 2010a, 2010b) all refer to Regulation 763/2008. They address the technical specifications of the topics and of their breakdowns (Commission of the European Communities, 2009), the metadata and the specification of the so-called hypercubes, the cross-tabulations used in the census hub (European Commission, 2010a) and the procedures and structure of the quality reports and technical formats of the data transmission (European Commission, 2010b). As main frame of reference and with regard to the assessment of compliance, Regulation 763/2008 is the most important regulation.

When it comes to census-taking, not only the EU but also the United Nations Economic Commission for Europe (UNECE) is of importance. In order to improve the comparabity of population data on a regional level the UNECE organises regular meetings on census issues. Together with the statistical office of the European Communities (Eurostat), it publishes recommendations for each census round (these are also referred to as the Conference of European Statisticians [CES] recommendations). These include recommendations on census issues, such as 'users' needs, quality of the data, completeness of the count, data protection and security, comparability of the results between countries and over time, burden on the respondents, timeliness of the outputs, financial and political implications, and public understanding and acceptance' (United Nations Economic Commission for Europe, 2006, p. 13). Next to this, the UNECE is important as it facilitates guidance and assistance to the countries when preparing a census, and its meetings and publications are used to exchange good practices. Even though the CES recommendations are not official regulations, they are important as they not only address (potential) EU countries, but the whole 
UNECE region. ${ }^{8}$ In addition, they are more comprehensive than the EU regulations, which for example do not include rules on how ethnic data should be collected.

The collection of ethno-cultural data is an important aspect in the Western Balkans. Even though there is no agreement on how to collect such data in the EU (Simon, 2011), there is an increasing demand for data on background characteristics for example for migration statistics and to combat discrimination (Huddleston, Niessen, \& Tjaden, 2013; Kraler, Reichel, \& Entzinger, 2015; Official Journal of the European Communities, 2000; Salentin \& Schmeets, 2017). As data on ethno-cultural characteristics is not part of the requirements for a population census, one would expect that this is not important for compliance with the EU census regulations. However, all Western Balkan countries collect data on ethnicity, language and religion (Eurostat, 2014). This data is needed as it is used to ensure minority rights, in for example Croatia and Macedonia, and in Bosnia the political system is based on the outcomes of the 1991 census and the three constituent ethnic groups (Serbs, Croats and Bosniaks). In Bosnia, the last census before the war (1992-1995) was used to settle the Dayton Peace Agreement. It was expected that if the census outcome were to significantly diverge from the 1991 numbers, new negotiations about the distribution of political power would be necessary. In Macedonia the $20 \%$ threshold for, among others, additional language rights for minority groups, led to a high politicisation of the census process. Ethnic Albanians, the biggest minority group in Macedonia, wanted to increase their numbers, whereas the ethnic Macedonians wanted to decrease the number of the ethnic Albanians. Even in Croatia, which by now is a member of the EU, the census results showed that the number of ethnic Serbs increased in some municipalities and would allow them more language rights, but this was not to the liking of nationalist groups who started to protest and even wanted a referendum to change the constitution. Therefore, this thesis looks at the CES recommendations as a general framework on how to collect data on ethno-cultural aspects. Chapter 4 deals with the compliance of the accession countries with the EU census regulation, but next to explicit compliance with the census laws and methodologies, it also assesses the implicit compliance of how census experts assess census practices, with a particular focus on the collection of ethno-cultural data. Even though the EU does not require the collection of ethno-cultural data, by asking enlargement countries to collect population data, there are unintended consequences which need to be taken into account as they can have significant impact on the census processes and therewith the compliance with the EU census regulations.

8 UNECE 'member States include the countries of Europe, but also countries in North America (Canada and United States), Central Asia (Kazakhstan, Kyrgyzstan, Tajikistan, Turkmenistan and Uzbekistan) and Western Asia (Israel)' (United Nations Economic Commission for Europe, n.d.). 


\subsubsection{Measuring compliance with the EU census regulations}

To analyse the influence of the EU on enlargement countries, several models have been developed (Elbasani, 2013a; Noutcheva, 2012; Schimmelfennig \& Sedelmeier, 2004). The external incentives model by Schimmelfennig and Sedelmeier (2004) is one example of Europeanisation research in enlargement countries. Based on reinforcement by reward, the model measures whether and how the determinacy of the EU conditions, the size and speed of the EU rewards, the credibility of conditionality as well as veto players and adoption costs influence compliance with the EU conditions (Schimmelfennig \& Sedelmeier, 2004; 2005a, p. 12). This model follows the logic of consequences according to which countries adopt EU rules if the benefits of the EU rewards outweigh the domestic adoption costs. Next to this model, Schimmelfennig and Sedelmeier (2004) also introduce two alternative models: the social learning model, which is based on the logic of appropriateness and assesses whether countries adopt the EU rules based on the perception of appropriateness; and the lesson-drawing model, whereby countries adopt the EU rules if these can help to solve domestic problems.

Whereas the models by Schimmelfennig and Sedelmeier (2004) were either based on rational or constructivist explanations, the model by Noutcheva (2012, p. 32) combines both explanations. This model describes four possible outcomes with regard to compliance: substantial, partial, imposed and faked/reversed compliance. Three factors explain the variation in compliance behaviour in the Balkans. First, if the legitimacy of EU demands is perceived as high, compliance is substantial. Second, where the legitimacy of EU demands is perceived to be low the domestic adoption cost becomes the decisive factor. If the benefits exceed the costs, this can lead to partial compliance. Third, if the legitimacy of the EU demands is perceived as too low and adoption costs are high, compliance depends on the coercive power of the EU. If the power of the EU is strong, this can lead to imposed compliance. If EU power is limited or weak, this can lead to fake compliance, and the policies that were adopted can potentially be reversed.

In this thesis compliance with the EU census regulations will be assessed by a model based on the three phases by Elbasani (2013a, p. 14): verbal adoption, legal adoption and substantive compliance with EU policies. This model is used to assess compliance with the EU rules on the census, because the structure of ruled adoption is very similar to the process of census-taking. Verbal adoption relates to the rhetorical endorsement of EU norms and regulations by domestic actors. The subsequent step is legal adoption, which includes the establishment of formal institutions and legal adoption of EU rules. Substantive compliance addresses the implementation of the EU rules and is the final step in this model. Before describing how compliance with 
the EU census regulations is measured, the process and difficulties of censustaking will be outlined.

The process of census-taking includes the preparation of a census law and its methodology, as well as the collection of the data, the enumeration process, and finally the processing, publication and dissemination of the data. A population and housing census is the backbone of national statistics and on average population data is collected every ten years. The data is used for example to calculate GDP per capita, but also for the distribution of subsidies. The latter is a reason why the census can be highly political. For example minority groups have stakes in increasing their numbers when their rights are connected to proportional representation. In the case countries, the census data is collected via the traditional pen and paper method, meaning that during a period of about two to four weeks enumerators visit each house in the country to collect data on the inhabitants. After the enumeration, the data has to be ordered and processed in order to be published. Altogether, collecting census data is an enormous undertaking.

The assessment of compliance with the EU census regulations helps to clarify the Europeanisation of census-taking. In order to ensure compliance with the EU census regulations, the EU supports its enlargement countries financially and/or technically. For the decennial census, the EU Commission through DG Estat (Eurostat) has set up Technical Cooperation Meetings and in some countries the census processes are observed by International Monitoring Observation (IMO) missions. Since census data is crucial for national statistics, the EU is eager to develop a reliable statistical system in its potential future member states (Bieber, 2015, p. 11).

As described above (section 2.4), compliance is the potential outcome of the implementation process in which all stages are fulfilled in a dutiful manner. Compliance is related to the implementation of rules (Versluis, 2007, p. 52), which in this thesis will be assessed not only by the different phases of compliance, but also by looking at timeliness and correctness of the census process. These are two aspects which are especially important when it comes to the implementation of EU policies (Hartlapp \& Falkner, 2009, p. 283). Compliance with the EU census regulations is measured by a model based on the three phases of Elbasani, as well as timeliness and correctness of the rule adoption. This model has been adapted with regard to censustaking to identify non-compliance, partial compliance and full compliance with the EU census regulations (see table 2). The table also shows the data used to analyse compliance and the questions that are used to measure the different degrees of compliance. More information on the data collection and analysis methods used in this thesis can be found in chapter 3 . 
Table 2: Assessing compliance with census-taking

\begin{tabular}{|c|c|c|c|}
\hline $\begin{array}{l}\text { Degrees of } \\
\text { compliance }\end{array}$ & $\begin{array}{l}\text { Steps of assessing } \\
\text { compliance }\end{array}$ & Measurements & Data \\
\hline \multirow[t]{3}{*}{$\begin{array}{l}\text { Non- } \\
\text { compliance }\end{array}$} & No adoption & $\begin{array}{l}\text { Are there plans for a census? } \\
\text { No/Yes }\end{array}$ & $\begin{array}{l}\text { Official documents and } \\
\text { newspaper articles }\end{array}$ \\
\hline & Verbal adoption & Verbal agreement for the census & $\begin{array}{l}\text { Official documents and } \\
\text { newspaper articles }\end{array}$ \\
\hline & $\begin{array}{l}\text { Legal adoption and } \\
\text { methodological } \\
\text { preparation of the } \\
\text { census }\end{array}$ & $\begin{array}{l}\text { Legal agreement on the content } \\
\text { of questionnaire and data- } \\
\text { collection, in line with the EU } \\
\text { census regulations (in particular } \\
\text { articles 2, 4, } 7 \text { and 8) and the CES } \\
\text { recommendations }\end{array}$ & $\begin{array}{l}\text { National census law, } \\
\text { methodology of the } \\
\text { census \& expert survey }\end{array}$ \\
\hline $\begin{array}{l}\text { Partial } \\
\text { compliance }\end{array}$ & $\begin{array}{l}\text { Enumeration of the } \\
\text { population }\end{array}$ & $\begin{array}{l}\text { Census conducted in line with the } \\
\text { EU census regulations (in } \\
\text { particular article } 4 \text { and 6) and the } \\
\text { CES recommendations. } \\
\text { No severe difficulties/ } \\
\text { contestations during the } \\
\text { enumeration process. }\end{array}$ & $\begin{array}{l}\text { Official documents, in- } \\
\text { depth interviews and } \\
\text { newspaper articles }\end{array}$ \\
\hline \multirow[t]{2}{*}{$\begin{array}{l}\text { Full } \\
\text { compliance }\end{array}$} & $\begin{array}{l}\text { Publication of the } \\
\text { census data }\end{array}$ & $\begin{array}{l}\text { Publication of the census data in } \\
\text { line with the EU census regulations } \\
\text { (in particular articles } 3,5,6 \text { and } 7 \text { ) } \\
\text { and CES recommendations. } \\
\text { Acceptance of the census data } \\
\text { by the international community } \\
\text { and all domestic actors. }\end{array}$ & $\begin{array}{l}\text { Official documents, in- } \\
\text { depth interviews and } \\
\text { newspaper articles }\end{array}$ \\
\hline & $\begin{array}{l}\text { Part of the EU census } \\
\text { hub }\end{array}$ & $\begin{array}{l}\text { Census data part of the EU census } \\
\text { hub; see census hub (European } \\
\text { Statistical System, nd.) and } \\
\text { Commission Regulation (EU) No } \\
519 / 2010\end{array}$ & $\begin{array}{l}\text { Census hub and in-depth } \\
\text { interviews }\end{array}$ \\
\hline
\end{tabular}

Non-compliance includes the verbal and legal adoption of the census, as well as the methodological preparation. Although the preparation of the census law is already quite elaborate, these aspects are considered as noncompliant, as in this stage the case countries have only facilitated the census outset, but have not yet taken concrete measures to conduct the census. This, however, can already be highly sensitive, especially if the country is ethnically divided and the questionnaire includes questions on sensitive data (e.g., ethnicity, language, religion). Next to the verbal, legal and methodological compliance with regulations, the actual enumeration and the publication of the data are of high importance. Partial compliance in this model includes the actual collection of the census, the enumeration process. Even though the census law and the methodology already provide the framework for the census, the enumeration process is crucial as without it there is no data. In order to be fully compliant the case countries need to publish the census data and in the best case scenario, the population data should also be part of the European census hub. The census hub is a database of the European Statistical Service which disseminates the results of the 2010 census 
round of all EU members plus Switzerland, Iceland, Norway and Liechtenstein (European Statistical System, nd.). It was expected that enlargement countries also take part in this project, however only Croatia managed to publish its data in the census hub.

In addition to the three steps of compliance, the aspects of timeliness and correctness from Hartlapp and Falkner (2009) will be taken into account. These are very similar to the aspects of quality assessment mentioned in Regulation 763/2008 on the population and housing census. Timeliness is rather straightforward to assess, as it 'means to meet the transposition deadline of a directive' (Hartlapp \& Falkner, 2009, p. 283). However, the other aspects of quality assessment (relevance, accuracy, accessibility, comparability and coherence of the data) are more difficult to assess, since the quality reports are not always accessible. Furthermore, the focus of this research is on the political implications of the census and EU enlargement and less on the technical and methodological issues of census-taking. Therefore the remaining aspects of the quality assessment are measured via the aspect of correctness. According to Hartlapp and Falkner (2009, p. 284) correctness is achieved if all aspects are implemented, but it can also be partial, if only some aspects are implemented. Therefore whether or not the census data is accepted by the international community will be taken as an indicator to assess correctness. If the international community accepts the census results, it is expected that the data are correct. In addition, whether or not a country is part of the census hub serves as a further indicator. It is expected that because the census hub requires additional check-ups, countries that are part of the census hub have correct census data.

The next section will describe how this thesis embeds the theoretical concept of Europeanisation in the empirical chapters.

\subsection{Embedding Europeanisation in the chapters}

As outlined in this chapter, Europeanisation is used to study the influence of the EU on its enlargement countries, in particular how the enlargement process affects the compliance with specific requirements of the acquis, the population and housing census. This thesis analyses the impact of enlargement on the processes of census-taking in the case countries by using different angles of Europeanisation: explicit and implicit compliance, the direct influence of the EU as well as domestic aspects that can affect Europeanisation.

Each of the three separate empirical chapters includes one of the Europeanisation angles. Chapter 4 assesses the Europeanisation of census-taking via explicit and implicit compliance (see table 3 for an overview of how Europeanisation is embedded in the chapters of this thesis). The analysis reveals 
not only explicit compliance with the EU census regulations, but also divergence when it comes to the collection of ethno-cultural data. Chapter 5 analyses the effectiveness of two Europeanisation mechanisms and therewith contributes to the actual effects of Europeanisation. By analysing the effectiveness of conditionality and legitimacy on the compliance with the EU census regulations, this chapter assesses the extent of the influence of Europeanisation mechanisms. Chapter 6 assesses whether and to what extent other factors and/or actors than the EU play a role with regard to compliance with the EU census regulations. This chapter not only compares two domestic explanations (state capacity and domestic actors), it also compares the influence of domestic actors with the influence of external actors.

Table 3: Embedding Europeanisation in the chapters

\begin{tabular}{|c|c|c|}
\hline & Research question/sub-question & Europeanisation angle \\
\hline $\begin{array}{l}\text { Chapter 4: Counting for what } \\
\text { purpose? The paradox of } \\
\text { including ethnic and cultural } \\
\text { questions in the censuses of } \\
\text { Croatia, Bosnia, and } \\
\text { Macedonia }\end{array}$ & $\begin{array}{l}\text { Can we speak of the } \\
\text { Europeanisation of census-taking, } \\
\text { in the absence of concrete rules } \\
\text { on collecting ethno-cultural } \\
\text { data? }\end{array}$ & Explicit and implicit compliance \\
\hline $\begin{array}{l}\text { Chapter 5: 'When counting } \\
\text { counts': Europeanisation of } \\
\text { census-taking in Croatia, } \\
\text { Bosnia and Macedonia }\end{array}$ & $\begin{array}{l}\text { Which of the Europeanisation } \\
\text { mechanisms (conditionality or } \\
\text { legitimacy) is more likely to } \\
\text { explain compliance with the EU } \\
\text { census regulations in the case } \\
\text { countries? }\end{array}$ & $\begin{array}{l}\text { Domestic influence of } \\
\text { Europeanisation through the } \\
\text { mechanisms of conditionality } \\
\text { and legitimacy }\end{array}$ \\
\hline $\begin{array}{l}\text { Chapter 6: Census-taking in } \\
\text { the Western Balkans: A matter } \\
\text { of state capacity or the } \\
\text { influence of domestic and } \\
\text { external actors? }\end{array}$ & $\begin{array}{l}\text { How important are state } \\
\text { capacity, domestic and external } \\
\text { actors for compliance with the } \\
\text { EU census regulations in Croatia, } \\
\text { Bosnia and Macedonia? }\end{array}$ & $\begin{array}{l}\text { Domestic effects (state capacity } \\
\text { I and domestic actors) on } \\
\text { Europeanisation compared with } \\
\text { the influence of the EU as } \\
\text { external actor }\end{array}$ \\
\hline
\end{tabular}

\subsubsection{Europeanisation of census-taking and the paradox of collecting ethno- cultural data}

In looking at the overall compliance with regard to the EU census regulations, chapter 4 not only considers the explicit compliance visible in the census laws and methodologies, but also implicit compliance revealed in practices of census-taking not covered by the EU census regulations. The census law and methodology of the case countries are analysed to show their compliance with the EU census regulations, and in addition an expert survey was conducted to assess the general practices and views on census-taking, which are related to the implicit compliance with the census regulations (more information on the data collection can be found in chapters 3 and 4). Next to explicit compliance with regard to census laws and methodologies, or the variations thereof, chapter 4 analyses whether there is a common European 'grammar' with regard to the practices of census-taking. The analyses are based on a survey in which data was collected among census 
experts in two rounds. The survey questionnaire included questions about practices with regard to census-taking in the EU, but also within the UNECE countries (except for the Russian speaking ones; see chapters 3 and 4 for more information and appendices 4 and 5 for the questionnaires). Different viewpoints were discovered on aspects which are important for censustaking, but not yet part of the EU census regulations. An example is the collection of ethno-cultural data. This data is for example needed for migration statistics and to assess minority groups (Kraler et al., 2015). Next to the analysis of compliance with regard to the EU census rules, this chapter outlines the paradox of collecting ethno-cultural data.

\subsubsection{Conditionality and legitimacy of the Europeanisation of census-taking}

Chapter 5 assesses whether the impact of the EU enlargement process can explain the variation in census-taking outcomes in Bosnia, Croatia and Macedonia. In this chapter two mechanisms of Europeanisation are compared: conditionality and legitimacy. Conditionality is based on the logic of consequences and assesses the rational cost/benefit incentives behind the differences of countries in EU accession. Conversely, legitimacy focuses on the acceptance and implementation of the EU census regulations, as well as the nature of debates and contestations surrounding the census processes. This chapter analyses whether countries comply with the EU rules because the EU conditions (EU rewards) outweigh the domestic adoption costs, or because these are seen as appropriate and legitimate. For this purpose, in-depth interview data has been collected and is contextualised with newspaper articles (more information on the methods can be found in chapters 3 and 5). This chapter concludes that the two mechanisms are complementary.

\subsubsection{State capacity, domestic and external actors}

Within Europeanisation research there has been a lack of interest in the domestic side of the equation (Elbasani, 2013a; Mastenbroek, 2005). In order to assess the influence of the domestic perspective on Europeanisation of census-taking, chapter 6 analyses the influence of two domestic aspects (state capacity and domestic actors) and compares these with the influence from external actors to explain the variation in compliance with regard to censustaking in the case countries. In the literature on state-building, institutional factors (such as state capacity but also the agency of actors, both domestic and external) are mentioned as potential capacity builders (Risse, 2011; Schneckener, 2011) and while much research has been done on the EU's enlargement strategy (Börzel \& Schimmelfennig, 2017; Keil, 2013b; Schimmelfennig \& Sedelmeier, 2005b), little research has been conducted to analyse the agency that influences EU integration and census-taking processes. Therefore this chapter first tests whether the domestic factor of limited 
statehood-the lack of structures to enable the execution of EU rules -is one of the main obstacles for the Western Balkans' compliance with EU regulations. Next to this the influence of domestic actors, as well as that of the EU, is tested. State capacity is assessed by a comparison of the World Bank Governance indicators, 9 and the influence of actors by the use of in-depth interview data and newspaper articles (here also, more information on the methodology can be found in chapters 3 and 6). The chapter argues that state capacity cannot fully explain the variation in census-taking outcomes. The analysis shows that the influence of external actors, in this case the EU, potentially can be very strong. However, more importantly, the analysis shows that the influence of domestic actors can be crucial, which is in general underestimated in Europeanisation research.

\subsection{Conclusion}

This chapter outlined the theoretical background of Europeanisation research. To account for the asymmetrical relationship the EU has with its enlargement countries, this thesis makes a distinction between Europeanisation in member states and external Europeanisation, which is the influence of the EU on its enlargement countries. Within research on external Europeanisation there has not been a strong focus with regard to compliance with particular aspects of the acquis communautaire. The population and housing census is part of the chapter on statistics of this acquis, and presents an interesting case for Europeanisation research. This is necessary as the EU strives for harmonisation with regard to statistical data, also in its enlargement countries. However, and this is the main puzzle of this research, although the case countries had the same EU conditions to comply with, they show variation when it comes to the census outcomes: ranging from fully compliant (Croatia), to partially compliant (Bosnia) and non-compliant (Macedonia).

In order to analyse the variation in compliance in census outcomes, this chapter outlined the operationalisation of compliance with the EU census regulations. This is measured by different degrees of compliance (noncompliance, partial compliance and full compliance) depending on how and to what extent the actual census process is in line with the EU regulations and the CES recommendations.

The final task of this chapter was to situate three angles of Europeanisation-denoted in this thesis as the influence of the EU on its enlargement countries-and to embed them in the empirical chapters of the thesis: explicit and implicit compliance, the direct influence of the EU and the domestic aspects that can affect Europeanisation.

\footnotetext{
9 Although there is a lot of critique on these indicators, they are still the most used in research. For more information see section 6.3 and Schmeets (forthcoming 2018).
} 
Overall compliance is analysed by looking at the explicit compliance of the census laws and methodologies, but also the implicit compliance of census practices, such as the collection of ethno-cultural data. Although not officially required by the EU, the collection of ethno-cultural data is an important part of the census in the Western Balkans, as for example minority and language rights are based on the census outcomes. By analysing explicit and implicit compliance chapter 4 provides a background for further research to analyse the main research puzzle of this thesis: the variation in compliance. To analyse this puzzle from the EU perspective, the direct influence of the EU is analysed by comparing two Europeanisation mechanisms, conditionality and legitimacy (chapter 5). Chapter 6 looks beyond the EU perspective and incudes domestic factors that can influence census-taking and compliance with the EU census regulations. Therefore, state capacity and the influence of domestic actors are analysed and compared with the influence of the EU as external actor (chapter 6). Taking into account these three angles of Europeanisation, this thesis provides a coherent overview of the Europeanisation of census-taking in Croatia, Bosnia and Macedonia. 
Chapter 3

Using a mixed methods research design while studying census-taking in the Western Balkans 


\title{
Chapter 3
}

\begin{abstract}
This chapter illustrates how the use of the additional coverage mixed methods model contributes to a more coherent understanding of the phenomenon of census-taking-here, census-taking in the Western Balkans as part of European Union (EU) enlargement. The additional coverage approach enabled analysing the phenomenon of census-taking from the broader perspective of 'Europeanisation' as well as from the local perspective of the case countries (Croatia, Bosnia and Herzegovina and Macedonia). This model was applied because it matches the strengths of the quantitative expert survey data collected using the Delphi approach and the qualitative indepth interviews, in order to analyse the differences in compliance with the EU census regulations in the case countries.
\end{abstract}




\subsection{Introduction}

Mixed methods research is increasingly popular, but it presents different challenges than classical research designs. It is defined as a procedure to combine and integrate methods for data collection and analysis at some stage of the research process (Ivankova, Creswell, \& Stick, 2006). To do this, researchers need to know how to apply all the methods they are using. There is a lot of literature on how to select the optimal research design (inter alia: Creswell \& Plano Clark, 2011; Morgan, 2014; Tashakkori \& Teddlie, 2003). However, the application of a research design differs for every research project. This chapter will illustrate how the use of the additional coverage mixed methods model described by Morgan (2014) contributes to a more coherent understanding of the same phenomena, in a research project looking at census-taking in the Western Balkans as part of European Union (EU) enlargement. This research combines in-depth interview data with an expert survey conducted in two rounds, focussing on why countries in the Western Balkans comply differently with the EU census regulations.

Until recently, there was only limited research on the population and housing census (hereafter, census). The Western Balkan countries are considered to be future EU member states and as such are strongly recommended to comply with the EU census regulations (European Parliament \& Council of the European Union, 2008). The illustrative study is unique in that, for the first time in research on census-taking, it bridges the gap between qualitative and quantitative data collection, thereby providing a more coherent picture of the phenomenon of census-taking.

The purpose of this chapter is to demonstrate that a mixed method design has many advantages over a single method when researching censustaking processes. Whereas the expert survey used to analyse the understanding of census practices in Europe is exploratory, the in-depth interviews are more focussed and explanatory as they are with people directly involved in the censuses in the case countries. The expert survey applied the Delphi method to collect data among a population of 75 census experts. Combining this data with 28 in-depth interviews resulted in an original data collection strategy for census research.

This chapter starts by analysing the reasons for choosing a mixed methods model, and the different kinds of mixed methods research design. Next, the research design is described and the conceptual choices as well as the separate methodological choices for the individual chapters of the thesis are highlighted. The qualitative and quantitative data collection and analysis are described in detail in two separate sections. These sections are followed by a short explanation of how the findings are integrated, as well as the challenges that have to be taken into account in such an approach. 
The chapter then concludes with an overview of the advantages and challenges of the additional coverage model.

\subsection{Mixed methods: potential designs and selected model}

Mixed methods research consists of the collection, analysis and integration of qualitative as well as quantitative data in several stages of the research process of one study, which can happen either concurrently or sequentially (Creswell, Plano Clark, Gutmann, \& Hanson, 2003, p. 212). Importantly, it also includes the integration of the paradigmatic and philosophical backgrounds of both approaches/paradigms. Whereas quantitative research usually derives from the assumptions of deductive research, qualitative research is generally more inductive. This distinction however has been criticised by pragmatists who believe that both logics can be combined (Onwuegbuzie \& Leech, 2005, p. 270). Mixed methods research departs from the idea that research objectives should steer the research design. Alongside qualitative and quantitative research, mixed methods research is regarded as a third research paradigm (Johnson, Onwuegbuzie, \& Turner, 2007). Creswell et al. (2003, p. 213) have argued that by engaging in mixed methods research, the researcher emphasises the separate parts of the research strategy and thereby increases the artificial boundaries between qualitative and quantitative research. To avoid overemphasising these boundaries is in fact one of the challenges of mixed methods research.

Various authors (Morgan, 2014; Plano Clark, Garrett, \& Leslie-Pelecky, 2010; Teddlie \& Tashakkori, 2003) have addressed the challenges of organising and implementing qualitative and quantitative methods in a single coherent research design. One of the main advantages of mixed methods research is the possibility to answer research questions that cannot be tackled by single method approaches. Next to this, it also provides the opportunity to present a greater diversity of viewpoints (Teddlie \& Tashakkori, 2003, p. 15). This latter reason is why this study on census-taking chose to apply a mixed methods research design. So far, research on censuses has been either quantitative, focussing on the census processes and, for example, how to increase the quality of the data (Schulte Nordholt, Ossen, \& Haas, 2013), or qualitative, looking for example at the construction of the census categories and questionnaires (Yanow, 2003). Applying a mixed approach makes it possible to present a broader perspective on census-taking processes.

There are various options for mixed methods research designs (Creswell \& Plano Clark, 2011; Creswell et al., 2003; Leech \& Onwuegbuzie, 2009; Morgan, 2014). This chapter focuses on the research designs described by Morgan (2014, p. 10): the convergent design, the sequential design and the additional coverage design. According to Morgan (2014, p. 52), the re- 
searcher's choice among these designs depends on the purpose and procedures of the research. The convergent model is used for cross-validation or triangulation of the results by different methods. The purpose of such research is to find convergent findings while addressing the same research question. In the sequential model the different methods build upon each other, which means that either the qualitative approach is used to enhance the quantitative approach or the other way around. In this approach the priority of one method over the other, as well as the time sequence, needs to be established (Morgan, 2014, pp. 11-14). In the additional coverage approach the goal of the research is to 'serve separate, but closely linked purposes so that the results of one can enhance the effectiveness of the other' (Morgan, 2014, p. 11). Designs similar to the additional coverage model that have been developed by other authors, and that would fit the purpose of complementarity in this research, include the partially mixed methods design (Leech \& Onwuegbuzie, 2009, p. 267) and the convergent parallel design (Creswell \& Plano Clark, 2011, p. 69).

The sequential model supposes that each method has its own separate purpose and that the results of each method are used to enhance the other (Morgan, 2014, p. 11), which is not the aim of the current study. The convergent model would not be a good fit either, as in order to be fully convergent, the different methods have to measure the exact same phenomenon. However in this research the quantitative and the qualitative methods measure different facets of the same phenomenon. For this study, the additional coverage model was most appropriate, because it allows studying the different facets of census-taking and therewith providing a more coherent answer to the overall research question, as will be described in the next section.

\subsection{Illustrative study}

The importance of studying different facets of the same phenomenon via different methods is especially salient in the research on census-taking in the Western Balkans as part of EU integration. This thesis analyses the effect of EU enlargement on census-taking in the Western Balkans, in particular in Croatia, Bosnia and Herzegovina (hereafter Bosnia) and the former Yugoslav Republic of Macedonia (hereafter Macedonia). All enlargement countries have the same conditions to fulfil in order to become EU members; however, they differ widely with regard to fulfilling them. The population and housing census (hereafter census) is one of these conditions for membership, as it is part of the $18^{\text {th }}$ chapter of the acquis communautaire on statistics. The puzzle of this research is the differences in compliance with EU standards with regard to census-taking in Croatia, Bosnia and Macedonia. The overarching 
research question of the project is: What accounts for the variation in compliance with the EU regulations with regard to census-taking in Croatia, Bosnia and Herzegovina and the former Yugoslav Republic of Macedonia?

The research strategy of this project is based on comparative case studies (George \& Bennett, 2005). The selection of the three case countries (Croatia, Bosnia and Macedonia) is based on the method of 'crucial cases' (Blatter \& Haverland, 2012, pp. 176-177; George \& Bennett, 2005). The case studies have a relatively similar history, as they were all part of the former Yugoslavia, and all of them are (or in the case of Croatia were) EU enlargement countries. They also present three different cases of census-taking. Croatia conducted its second complete census in 2011 . Bosnia conducted its first census since independence from the former Yugoslavia in October 2013 and published the results almost three years later, in June 2016. Macedonia aborted its third census during the enumeration phase in 2011 and there are currently no new plans for a population census.

This research is embedded in the theoretical framework of Europeanisation, which has many definitions-broader ones, looking at 'processes of a) construction, b) diffusion, and c) institutionalisation of formal and informal rules, procedures, policy paradigms, styles and "ways of doing things"' (Radaelli, 2006, p. 59), and more concrete ones, which see Europeanisation as shorthand definition for the domestic influence of the EU (Elbasani, 2013a, p. 5). Earlier research has studied the influence of the EU from a primarily qualitative perspective (Noutcheva, 2009; Schimmelfennig \& Sedelmeier, 2004). Some studies on Europeanisation apply a mixed methods approach (Noutcheva \& Aydin-Düzgit, 2012; Sedelmeier, 2011). Most of the Europeanisation research which focuses on the Western Balkan region is qualitative (Aybet \& Bieber, 2011; Elbasani, 2013b; Keil, 2013a; Noutcheva, 2009), but the topic can also be approached using quantitative measures (Böhmelt \& Freyburg, 2017).

As for censuses in the Western Balkans, there has been a recent increase in research projects (Bieber, 2015; Daskalovski, 2013; Keil \& Perry, 2015; Visoka \& Gjevori, 2013). All of these studies are qualitative, and are for example based on single cases (Daskalovski, 2013) or comparative case studies of the countries (Bieber, 2015; Visoka \& Gjevori, 2013).

According to Teddlie and Tashakkori (2003, p. 15), most quantitative research is steered towards confirmation and explanation, whereas qualitative research tends to be more exploratory in nature. This is however not the case in the current work; the qualitative part of this research has an explanatory character, whereas the quantitative survey addressing general aspects of census-taking is exploratory. In this research, both quantitative and qualitative data were collected in order to answer the overall research question. Since there was very little information available on census-taking in the European context and in order to fully understand the Europeanisation of census- 
taking, the quantitative expert survey was exploratory and designed to explain the broader perspective on census-taking in Europe. The qualitative indepth interviews provide explanatory data on the domestic aspects surrounding the census in the individual case countries. The thesis not only looks at the phenomenon of census-taking as it appears in the case countries, as made possible by the in-depth interview data, but also how this phenomenon is seen within the EU and by census experts related to the EU and the United Nations Economic Commission for Europe (UNECE).

In the next section the additional coverage research design chosen for this research will be elaborated in more detail.

\subsection{Research design}

In the additional coverage model, data collection and analysing methods run parallel to each other, thus each has its own analysis section in a research project. In order to provide a better overview of the mixed methods approach used here, a visual model is presented in the form of a pyramid (see Figure 3). Since the research question is the place of departure for the research design, it is placed in the middle. From the middle, there are connection points to the qualitative and the quantitative approaches, which are respectively left and right from the research question. The two approaches address different data collection and analysis processes: the qualitative part is based on the in-depth interviews, whereas the quantitative part looks at the data from the expert survey. Although the data is collected and analysed separately, in the end the results are integrated, which is shown at the top of the pyramid. Initially both approaches were given equal weight, but because in this research the qualitative part ultimately proved more valuable in its contribution, as it gave more insight into the cases, its triangle is represented as bigger than the quantitative side. In other designs that might use this pyramid shape to visually present their research, both parts could have equal size or the quantitative part could be dominant. The overall process could also be made iterative, especially when the results feed (new) research question(s). 


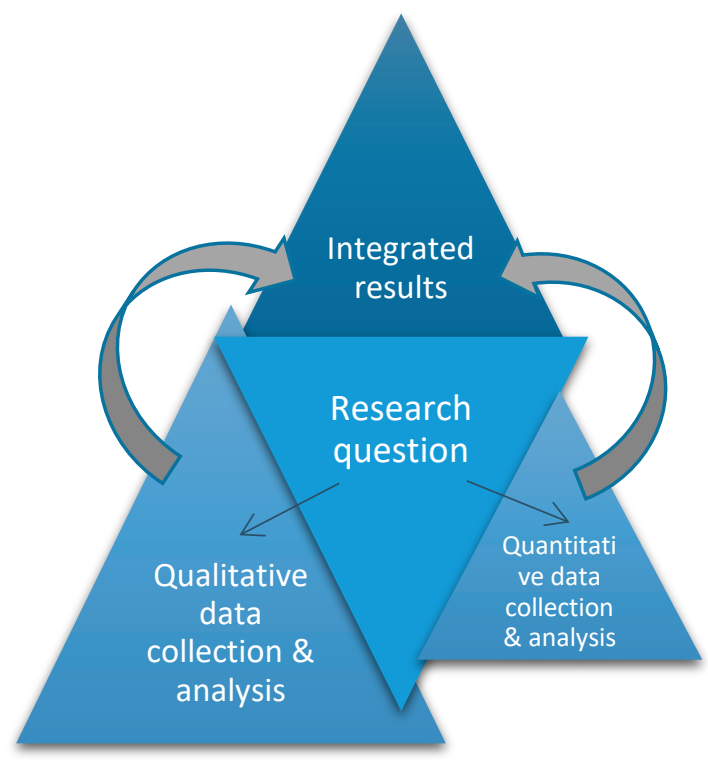

Figure 3: Visual research design

Unlike a sequential approach, the timing of the data collection was almost parallel. Apart from some explorative and follow-up interviews (in March 2014 and January 2016), most of the interviews were collected in September and October 2015, in between the two rounds of data collection of the survey, which was in June and November/December of 2015 (see Figure 4).
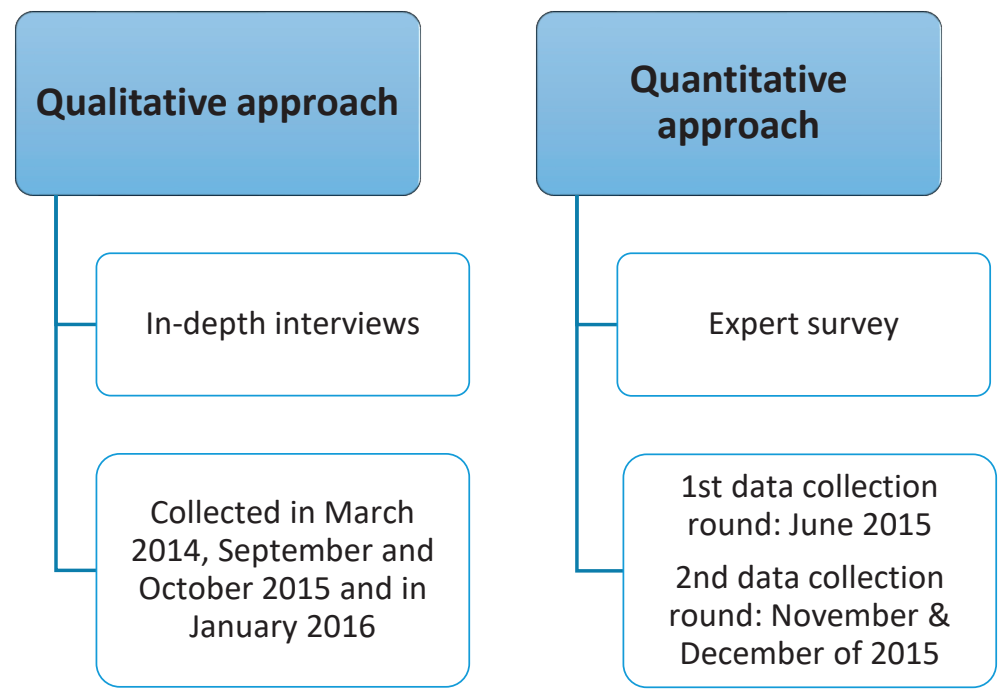

Figure 4: Qualitative and quantitative approach of the research design 
The overall research design of this project is based on the additional coverage mixed methods model, but because the separate chapters have different foci, some of them apply a different research design (see Table 4). In most cases both methods have been used to provide background knowledge for the chapters, however the interplay of the methods was not always suitable to answer the sub-questions posed in the chapters. Chapter 4 for example assesses the practices of collecting ethno-cultural data in the EU by using the exploratory expert survey and comparison of census methodologies and questionnaires, applying the additional coverage model as research design. Chapter 5 uses a form of case study research, congruence analysis (Blatter \& Haverland, 2012), based primarily on the explanatory indepth interview data, in order to assess the effectiveness of two Europeanisation mechanisms in relation to the censuses in the case countries. Chapter 6 is based on case study research and the in-depth interviews in order to analyse the influence of state capacity, domestic actors and external actors on the censuses in the case countries. The conclusion in Chapter 7 integrates the results and answers the overall research question of this thesis.

The following sections will describe in greater detail the separate data collection and analysis processes used for the qualitative and the quantitative data, in the overall research design. 
Table 4: Methods and data applied in the separate parts and the overall design of this research

\begin{tabular}{|c|c|c|c|}
\hline & $\begin{array}{l}\text { Research question/sub- } \\
\text { question }\end{array}$ & Methods & Data \\
\hline \multicolumn{2}{|c|}{$\begin{array}{l}\text { Overall research design What accounts for the } \\
\qquad \begin{array}{l}\text { variation in compliance with } \\
\text { the EU census regulations in } \\
\text { Croatia, Bosnia and } \\
\text { Herzegovina and the former } \\
\text { Yugoslav Republic of } \\
\text { Macedonia? }\end{array}\end{array}$} & $\begin{array}{l}\text { Additional } \\
\text { coverage model }\end{array}$ & $\begin{array}{l}\text { Exploratory expert } \\
\text { survey and } \\
\text { explanatory Interview } \\
\text { data }\end{array}$ \\
\hline \multicolumn{2}{|c|}{$\begin{array}{ll}\text { Chapter 4: Counting for Can we speak of the } \\
\text { what purpose? The } & \text { Europeanisation of census- } \\
\text { paradox of including } & \text { taking, in the absence of } \\
\text { ethnic and cultural } & \text { concrete rules on collecting } \\
\text { questions in the } & \text { ethno-cultural data? }\end{array}$} & $\begin{array}{l}\text { Additional } \\
\text { coverage model }\end{array}$ & $\begin{array}{l}\text { Exploratory expert } \\
\text { survey and } \\
\text { comparison of census } \\
\text { methodologies and } \\
\text { questionnaires }\end{array}$ \\
\hline $\begin{array}{l}\text { Chapter 5: 'When } \\
\text { counting counts': } \\
\text { Europeanisation of } \\
\text { census-taking in } \\
\text { Croatia, Bosnia and } \\
\text { Macedonia }\end{array}$ & $\begin{array}{l}\text { Which of the Europeanisation } \\
\text { mechanisms (conditionality or } \\
\text { legitimacy) is more likely to } \\
\text { explain compliance with the } \\
\text { EU census regulations in the } \\
\text { case countries? }\end{array}$ & $\begin{array}{l}\text { Congruence } \\
\text { r analysis }\end{array}$ & $\begin{array}{l}\text { Explanatory Interview } \\
\text { data (plus official } \\
\text { documents for } \\
\text { contextualisation) }\end{array}$ \\
\hline $\begin{array}{l}\text { Chapter 6: Census- } \\
\text { taking in the Western } \\
\text { Balkans: A matter of } \\
\text { state capacity or the } \\
\text { influence of domestic } \\
\text { and external actors? }\end{array}$ & $\begin{array}{l}\text { How important are state } \\
\text { capacity, domestic and } \\
\text { external actors for } \\
\text { compliance with the EU } \\
\text { census regulations in Croatia, } \\
\text { Bosnia and Macedonia? }\end{array}$ & $\begin{array}{l}\text { Comparative case } \\
\text { study }\end{array}$ & $\begin{array}{l}\text { Explanatory Interview } \\
\text { data \&World Bank } \\
\text { Governance } \\
\text { indicators }\end{array}$ \\
\hline
\end{tabular}

\subsection{Qualitative data collection: In-depth interviews}

For the qualitative part of this research, in-depth interviews were conducted with census experts and representatives from Eurostat, the DirectorateGeneral for Neighbourhood and Enlargement Negotiations (DG NEAR) and the National Statistical Institutes, as well as international census consultants who were part of the International Monitoring Operations in the Balkans. This happened in the period from June to October 2015; the interviews at Eurostat were conducted in March 2014 and in January 2016. For the interviews, the author travelled to the case countries, to speak to the National Statistical Institutes and other organisations, but also to Brussels and Luxembourg, for interviews at DG NEAR and Eurostat respectively. In total 28 interviews were conducted, some of them with several people at the same time, for example at the Croatian Statistical Office where two census methodologists were present. Some of the interviewees were interviewed more than once, most of them at Eurostat. Most interviews were conducted in person at the place of work or in a café close to the interviewee's preferred location, and two in- 
terviews were held over the phone for logistical reasons. A short general overview of the topics discussed during the interviews can be found in the appendices (see Appendix 3). The interview questions themselves were adapted according to the interviewee, depending on their position or role with regard to the census. For example, the questions posed to the International Census Consultants were phrased differently than those posed to the individuals working at the National Statistical Institutes. Since it was not permitted to tape record the interviews at the European Commission, and also to ensure that interviewees were able to speak freely and would not be inhibited by the tape recording device, it was decided to take notes only, for all the interviews. In order to increase the quality of these notes, after each interview valuable information was added where necessary. In the end, the interview data was also contextualised with official documents from the EU Commission, the National Statistical Offices and newspaper articles. For analysis of the interview notes, Qualitative Analysis Software Atlas.ti was used while applying the method of constant comparison (Boeije, 2005, pp. 75-78). This method relies on theoretical selection, for example in this case on Europeanisation. The main purpose of the method is to detect and describe variations in manifestations of certain phenomena, in this case census-taking (Boeije, 2005, p. 75).

When planning interviews, there are a couple of aspects to take into account. First are practical issues such as the geographical location of the interviews and the research budget (Rubin \& Rubin, 2011, pp. 53-54). Fortunately budget restraints were not an issue here. Access to interviewees, however, was problematic in some cases, but could be solved by including additional interviewees. 10 The main strength of the qualitative interviews is the very detailed in-depth knowledge and the local perspective on all of the case studies. The semi-open structure of the interviews provided the flexibility needed in order to fully understand the specific nature of each case. Asking people directly involved with the censuses, and in the case of Bosnia and Macedonia also people involved in the monitoring of the censuses, gave direct insights into their domestic census-taking processes. Without these detailed insights from the interviews (on, for example, the census enumeration phase and reactions of domestic actors, used in the analysis provided in Chapters 5 and 6), it would not have been possible to answer the main research question of the project. Nonetheless, in order to embed the cases in the broader framework of Europeanisation, additional data collection was necessary.

\footnotetext{
10 For example the State Statistical Office in Macedonia lacked staff to provide an intervieweeor used this as an excuse not to speak to the author. This was solved by contacting the former Director of this institution who was willing to be interviewed. So even though it was not possible to obtain direct contact with the National Statistical Office, the author was able to get in touch with other relevant interlocutors.
} 


\subsection{Quantitative data collection: Expert survey}

Compared to interviews, expert surveys are a more standardised tool of measurement. However, when using surveys as a method the researcher needs to be aware of the respective steps and the inherent challenges in the selected survey design: the defined population and sample design (e.g., sample method, selection of cases), data-collection mode (e.g., web, telephone and/or paper and pencil) and (re)approach strategy, the (non)response target and tailored questionnaire design (Dillman, Smyth, \& Christian, 2014). In this research the survey design is based on the Delphi method (Turoff, 2002; see also Hsu \& Sandford, 2007; Linstone \& Turoff, 2002), adjusted to only two data collection rounds. The Delphi method is in essence an expert survey which has several rounds of questionnaires. The first round is used to obtain general knowledge about a certain topic and the second to test and rank the importance of the knowledge; further rounds can be used to discuss the results (see also: Aichholzer, 2009; Hsu \& Sandford, 2007; Yousuf, 2007). It allows for interaction with the respondents, as it includes the possibility for reflection and elaboration in the second round. The first round of the survey was used to, for example, identify sensitive census questions and to see how census experts perceive the EU census regulations. In the second round the respondents were mainly asked to reflect on their answers from the previous round, but also to answer some more detailed follow-up questions such as specifying the kind of help the Western Balkans need. The questionnaires for both rounds can be found in appendices 4 and 5 .

The questionnaire used in this survey was developed with the help of the questionnaire laboratory from Statistics Netherlands and was tested extensively to assure that, for example, the order and grouping of the questions made sense (Dillman et al., 2014, pp. 230-231). In addition, the questionnaire was also checked by the external advisors of this project, in particular on aspects such as content, sensitivity of the questions and length. The survey was conducted through the online survey platform Qualtrics. It included questions on the background characteristics of the respondents; they were for example asked to indicate their knowledge of a particular topic (such as the EU census regulations or the Western Balkan region). Even though the survey is a fairly quantitative data collection method, by including open questions it also provided a certain amount of qualitative data. The use of more than one round of data collection gave the opportunity to ask more detailed follow-up questions and provided the respondents with an opportunity for interaction and clarification.

As mentioned above, the census expert survey was carried out in two rounds in June 2015 and November/December 2015. For this survey only census experts were contacted (for more background information on surveying experts see Bogner, Littig, \& Menz, 2009; Meuser \& Nagel, 2009). As a 
basis the list of census experts attending the United Nations Economic Commission for Europe (UNECE) census meetings in Geneva was consulted (with the exception of Russian-speaking ones), but this list was enhanced with census experts identified by Eurostat. The final list was checked by the external advisors of the project: Pieter Everaers, Director at Eurostat, and Eric Schulte Nordholt, Senior Researcher and project leader of the census at Statistics Netherlands. The list included all census experts from the National Statistical Institutes of the EU member states as well as experts from the Balkans, " Norway, Switzerland, Iceland, Canada, Turkey, the United States and Israel, as well as people working for Eurostat, the UNECE and International Census Consultants. There is a wide geographical scope, but as the census community is rather small, it can be assumed that these experts were familiar with the issues at stake. As the total number of experts was limited, instead of approaching only some of the census experts, all of them $(n=75)$ were invited to participate in the survey. The survey thus included the whole population of identified census experts. The response rate of the first round was $69 \%(n=52)$ and the second round had a $50 \%(n=38)$ response rate.

For the analysis of some questions, a deliberate division was made between experts who declared that they had knowledge about the Western Balkans and those who declared that they did not know much about the region. This was, for example, used in Chapter 4 , to test whether respondents familiar with the historical situation and ethnic cleavages in the Western Balkans would have a greater tendency to wish to exclude ethnic and cultural aspects from a census than those with less background awareness.

The quantitative part of this research has the main strength of giving a broader context of the European 12 census-taking practices. Without this knowledge it would have not been possible to give an overview of European census practices and opinions of how these should ideally be implemented by census experts, as will be described in Chapter 4. This part of the project provides additional background knowledge without which the project would not be able to explain the concept of 'Europeanisation' of censustaking. Nonetheless in order to analyse the individual case studies the indepth interviews were invaluable.

\footnotetext{
11 These include Bosnia and Herzegovina, Croatia, Albania, Serbia, Montenegro, Macedonia and Kosovo.

12 The author is aware that the term European is rather broad in this context. It is used to denote census practices on the European continent. The census community is through the UNECE however also interwoven also with non-European countries (such as for example Canada). In the analysis of the data a distinction is made between the EU census regulations and the CES recommendations (see chapter 4 for more information).
} 


\subsection{Discussion and conclusion}

The main advantage of this mixed methods research design is that by engaging in more than one means of data collection, it was possible to study the aspect of census-taking within the specific case contexts, while also providing more information on the broader issues surrounding census-taking in the European context. Both aspects are crucial in order to answer the overall research question: What accounts for the variation in compliance with the EU census regulations in Croatia, Bosnia and Herzegovina and the former Yugoslav Republic of Macedonia?

When doing mixed methods research, there are challenges to consider (Creswell et al., 2003; Morgan, 2014). Some of these relate to the practical implications of doing mixed methods research: for example if the research project is not being done by a team, the researcher has to be an expert in both data collection and analysis methods. It can also be a challenge not to overemphasise the boundaries between qualitative and quantitative approaches (Creswell et al., 2003, p. 213).

In the illustrative study, the choice for a mixed methods model was driven by the conceptual decision to collect data on census-taking from the European as well as the local perspective. Mixed methods research 'provides a better understanding of research than either approach itself' (Creswell \& Plano Clark, 2011, p. 8). The integration of the results from different data collection and analysis methods can also be challenging, but there are suggestions to remedy this (for example: Plano Clark et al., 2010). The additional coverage model allowed for separate data collection and analysis (as is also made visible in the separate chapters of this thesis), but to later integrate them in the overall conclusion of this thesis. Nonetheless, the combination of the different methods has revealed different facets of census-taking. Without the in-depth interviews the domestic aspects of the censuses in Bosnia, Croatia and Macedonia, such as the enumeration of the census and the domestic reactions, could not have been analysed. In addition, the expert survey delivered valuable insights on the European perspectives on census-taking, for example on the collection of ethno-cultural data. The separate data collection and analysis was necessary because the qualitative and quantitative parts measured different facets of the same phenomena, and it would not have been possible to provide a coherent picture of the censuses in the Western Balkans using only one approach. The following chapters present an exemplar on the interplay of the use of qualitative and quantitative data, while researching census-taking in the Western Balkans. 


\section{Chapter 4 \\ Counting for what purpose? \\ The paradox of including ethnic and cultural questions in the censuses of Croatia, Bosnia and Macedonia}

A slightly different version of this chapter has been published as Hoh, A.-L. (2017a). Counting for what purpose? The paradox of including ethnic and cultural questions in the censuses of Croatia, Bosnia and Macedonia. Südosteuropa, 65(1), 125-148. 


\title{
Chapter 4
}

\begin{abstract}
The Western Balkan countries are on the long road to EU membership. One aspect of the accession process is the requirement for a population census, which falls under the acquis communautaire chapter covering the statistics needed. In the Western Balkans, censuses have included questions on ethnicity, language and religion. The collection of data on ethnic and cultural characteristics raises an unresolved paradox: Such questions are highly sensitive, but, in order to be able to protect minorities through, for example, antidiscrimination laws, the authorities need to know that these minorities exist. This chapter uses the additional coverage model mixed methods approach to illustrate the effects of including ethnic and cultural characteristics in the census questionnaires in Croatia, Bosnia and Macedonia, where population numbers are used to determine group rights and/or proportional representation. The chapter argues that, although taking a census forms part of the requirements for EU membership, it is not possible to speak of Europeanisation in this area, since there is no coherent European approach on how to collect ethnic and cultural data. However, as what appears in the censuses is linked to rights, the census processes can be highly politicized, and this is being overlooked in the general process of Europeanisation.
\end{abstract}




\subsection{Introduction}

Collecting sensitive ethnic and cultural data, such as ethnicity, language and religion, raises an unresolved paradox. On the one hand, if population groups are not defined by category, they do not formally exist and are consequently not given their due rights. On the other hand, the definition of these groups and the linking of political benefits to population numbers may lead to negative discrimination or may even challenge concepts of national identity and state boundaries. Hence the inclusion of ethnic and cultural questions and categories in a population census is highly problematic (Bochsler \& Schläpfer, 2015; Cooley \& Mujanović, 2016). The difficulties that arise can influence the whole census operation and even lead to its failure. This chapter does not aim to provide answers on whether to record ethnic and cultural characteristics or how this should be done, but it points out the paradox involved and the consequences that follow.

Census data is used not only for national purposes such as taxation, but also as a requirement by the EU. The demand for reliable and comparative population data through census-taking falls under Chapter 18 of the acquis communautaire, which covers the necessary statistics and is outlined in the statistical compendium (European Commission, 2014c). Although censustaking would appear to be a rather small aspect of the process, given the size of the acquis, it is in fact an enormous undertaking.

On average, population censuses are taken every ten years. In the Western Balkans, this average has not been attained by all the post-Yugoslav countries, however. For example, due to the difficulties created by war after the dissolution of Yugoslavia (1992-1995), Bosnia and Herzegovina (hereafter Bosnia) did not conduct its first census till 2013. Other countries, such as Croatia, held censuses in 2001 and 2011, and the former Yugoslav Republic of Macedonia (hereafter Macedonia) conducted censuses in 1994 and 2002, but aborted one planned for 2011.

Although the EU does not require data on ethnic and cultural characteristics from its potential member states, all the Western Balkan countries have included questions about these aspects in their censuses, and this was also a practice in the former Yugoslavia. In the post-conflict environment in most of these countries, these questions are now connected with discrimination. Positive discrimination can ensure the granting of minority rights. ${ }^{13}$ However, the labelling of people which puts them into different categories can also lead to exclusion and negative discrimination. Especially when privileges and rights are specifically linked to numerical thresholds, census processes can become problematic. This has been shown in ethnically divided socie-

\footnotetext{
${ }^{13}$ This is, however, just one of the tools to ensure minority rights. The Organization for Security and Cooperation in Europe (OSCE), for example, affirms the principles of non-discrimination and equality (OSCE High Commissioner on National Minorities, 2012).
} 
ties, where the process of counting and categorising a population can lead to negative discrimination against minority groups (Leibler \& Breslau, 2005; Urla, 1993). As Croatia, Bosnia and Macedonia were enlargement countries at the time of their recent censuses, we would expect the censuses to have been carried out in the same way; however, the countries have shown considerable variation in their census-taking procedures. Croatia carried out a complete census in 2011 ; Bosnia collected census data in 2013 but only published the results, after serious delays, in June 2016; and Macedonia aborted its 2011 census altogether.

The argument of this chapter is that, although taking a census has been made part of the EU conditions for joining, it is not possible to speak of any 'Europeanisation' dictating the collection of ethnic and cultural data, since there is no coherent European approach on how to accomplish this. The effects of including questions to elicit ethnic and cultural data in the population census can all too easily politicise the census process, as will be shown in the examples of Croatia, Bosnia and Macedonia, where population numbers are linked to rights and/or proportional representation.

As there are no EU rules on collecting ethnic and cultural data, this chapter uses the additional coverage model mixed methods approach (Morgan, 2014). This combines survey data from census experts who provide an international perspective on census-taking with case analyses of the ethnic and cultural characteristics present in the census questionnaires for Croatia, Bosnia and Macedonia. By these means, the thesis demonstrates the paradox of collecting ethnic and cultural data. The approach is innovative, not only because it combines new methods and data, but because existing research has not yet looked at the censuses in the Western Balkans within the general framework of Europeanisation (Bieber, 2015; Visoka \& Gjevori, 2013).

\subsection{The sensitivities of census-taking}

In the Western Balkans, there has been a long tradition of census-taking. Censuses were already being conducted when these territories were under Ottoman and Habsburg rule (Shaw, 1978; van der Plank, 2012). After the First World War the Kingdom of Serbs, Croats and Slovenes held a census (in 1921), and in socialist Yugoslavia after the Second World War, population counts became relatively regular events. Their most important question, closely related to ethnic and cultural characteristics in socialist Yugoslavia, concerned 'nationality', though initially without a category for 'Yugoslav'. This was only added in the census of 1961 (Sekulic, Massey, \& Hodson, 1994); and it was only in 1971 that 'Muslim' was first allowed as a national category for Bosniaks (Bringa, 1993). This remained the practice until the last Yugoslav census, which took place in 1991, after which 'Bosniak' was adopted as an 
official category (Visoka \& Gjevori, 2013). Until the dissolution of the country in 1991, identity questions in Yugoslav censuses were based on selfidentification and included open-answer questions for national identity, language and religion (Bieber, 2015, p. 10).

When it includes ethnic and cultural questions, a census not only provides an overview of the demographic, social and economic characteristics of a country's population (Valente, 2010); it also creates the opportunity for individuals to identify themselves as being members of this population (Ruppert, 2007). With the creation of identity categories through questions on ethnicity, language and religion, individuals and peoples start identifying with specific groupings which thereby become legitimised. In the end, they are impelled to recognize themselves as representatives of these census categories-as members of societal groups, and eventually of the state (Ruppert, 2007). The relationship between a census and sense of identity is highly political as it connects with claims over territory and the assumption of power over people with other identities or ethnic and cultural characteristics (Kertzer \& Arel, 2002a, p. 36).

After the dissolution of Yugoslavia, issues of ethnicity and geographic belonging developed into tools for ethnic bargaining over borders, rights and political representation (Visoka \& Gjevori, 2013, p. 6). A population census is an essential lever by which ethnic groups can (re)affirm their legitimacy and supremacy (Visoka \& Gjevori, 2013). Although it was recognized that questions on ethnicity, language and religion were sensitive matters (Kertzer \& Arel, 2002a), in the census round of 2010 all the Western Balkan countries asked for this data (Eurostat, 2014). Mapping identity in the region seems still to be a major objective and the key reason for conducting censuses. Visoka and Gjevori (2013, p. 1) have shown how census processes in the Western Balkans have given ethnic groups the opportunity to fight identity battles so as to (re)claim political ownership. This is possible because rights are linked to numerical thresholds. For example, in Croatia minority rights are granted according to the census results (Petričušić, 2002). In Bosnia, they are linked to the Dayton Peace Agreement, which stopped the war of 1992-1995, and which divided the political system among the three constituent ethnic groups-Bosniak, Croat and Serb-as judged on the population distribution shown in the 1991 census (Bieber, 2004). In Macedonia, the census is linked to the Ohrid Framework Agreement, which stopped the armed conflict between ethnic Albanians and Macedonians in 2001. Under this agreement, minorities making up more than $20 \%$ of the population received language rights and proportional representation in the police and bureaucracy (Brunnbauer, 2002; Vasilev, 2013).

Although there is much discussion about these census questions and categories, there is no coherent agreement as to what exactly constitutes ethnicity (Simon, 2011 ). Nonetheless, ethnicity is regarded as being closely relat- 
ed to other cultural characteristics, such as language and religion (United Nations Economic Commission for Europe, 2006). In Central and Eastern Europe, religion and language are taken not only as markers of individual identity, but as indicators of national or ethnic identity: they are part of an 'ethnic package' (Bieber, 2015, p. 5). In the recommendations of the Conference of European Statisticians (CES) on the population and housing census formulated by the UNECE and Eurostat (United Nations Economic Commission for Europe, 2006), ${ }^{14}$ these aspects are taken into account under the heading of 'ethno-cultural characteristics' (United Nations Economic Commission for Europe, 2006, pp. 95-98). Language, in particular, is seen as an indicator of national identity, since it cannot be disconnected from the state (unlike religion, through secularisation) and tends to fluctuate since, in comparison with other identity markers like religion, linguistic assimilation can be achieved relatively easily (Arel, 2002). There has been much discussion on how to convert exploration of these categories into census questions, and the formulation of the census questions and categories shows the construction of ethnic discourses (Goldschneider, 2002; Kertzer \& Arel, 2002b; Ruppert, 2011; Urla, 1993; Yanow, 2003). These discourses follow (ethnic) group preferences, which are used to define public policy (Nobles, 2002). In the cases of Croatia, Bosnia and Macedonia, they are linked to rights and political representation through numerical thresholds. This linking of population numbers to rights and thresholds ultimately leads to discrimination: either positive (in the granting of minority rights) or negative (in enforcing segregation) (Nobles, 2002). This is what constitutes the paradox of collecting ethnic and cultural data. If population groups are not defined in terms of categories, they do not formally exist and consequently have no rights. However, if political benefits are linked to population numbers, this can lead to negative discrimination or even create a challenge to national identity and state boundaries. Since census processes give ethnic groups the opportunity to (re)claim political ownership, census-taking is necessarily political (Cooley \& Mujanović, 2016). Therefore it is important to look at the dynamics that exist between censuses and the ethnic and cultural categories they may impose. Since the census is also part of the EU acquis and the countries at the time of the last census were all enlargement countries, the next section will look at the potential influence of Europeanisation on census-taking.

\subsection{Europeanisation and census-taking}

Within the acquis communautaire, the requirement to conduct censustaking appears in the chapter on statistics, and is a condition countries need

\footnotetext{
14 The Ljubljana guidelines also provide some ideas on good practices for collecting statistical data in ethnically diverse societies (OSCE High Commissioner on National Minorities, 2012).
} 
to comply with before accession to the EU. Unlike the Copenhagen Criteria, which are regarded as being part of the political conditionality for EU accession (focusing on political transformation towards democratisation and EU member state building (Anastasakis, 2008; Keil, 2013b)) the acquis conditions are regarded as more technical (Anastasakis, 2008, p. 367). The census is part of the acquis for the EU: members and aspiring members have to be able to present 'sufficiently reliable, detailed and comparable data on the population and housing' every ten years (European Parliament \& Council of the European Union, 2008). The methodology, definitions and programme of the statistical data and metadata need to be aligned, both within the Union and in its enlargement countries. Officially the enlargement countries do not yet need to adhere to these regulations, but it is strongly recommended that they do so (Everaers, 2015). Such institutionalisation of EU rules, procedures and policy paradigms is denoted as Europeanisation (Radaelli, 2006, p. 59). This thesis defines Europeanisation as the influence of the EU on the censuses conducted in Croatia, Bosnia and Macedonia.

The EU conditions for census-taking include EU regulations on, for example, the technical specifications, definitions and data sources of censuses (Commission of the European Communities, 2009; European Commission, 2010a; European Parliament \& Council of the European Union, 2008). They also rely on CES recommendations (United Nations Economic Commission for Europe, 2006).15 The latter provide guidance and assistance to countries conducting a census, and also have the same purpose as the EU census regulations: to ensure the harmonisation of statistical data (United Nations Economic Commission for Europe, 2006, p. 1). Sensitive aspects around ethnic and cultural characteristics-ethnicity, language and religion-are not covered by the EU regulations. In the CES recommendations, they do indeed appear, but only as non-core topics. The collection of ethnic data is excluded from the population censuses in most West European countries, with the notable exceptions of Ireland and the United Kingdom (Simon, 2011). The reasons for not including such data in the western part of Europe are, firstly, adherence to data protection laws, and, secondly, because the categories are seen as imprecise and inaccurate, with the potential to challenge the self-perceptions of ethnically homogeneous societies (Simon, 2011, p. 1376). This last is the case in France (Simon, 2008). Most European countries, therefore, use 'country of birth' and 'citizenship' as proximate indicators of ethnicity (Simon, 2011).

In order to go deeper into the issue of collecting ethnic and cultural characteristics, this chapter uses an additional coverage model mixed method approach (Morgan, 2014), which enables integration of qualitative

\footnotetext{
15 For an overview of the content of the EU census regulations and the differences with the CES recommendations see chapter 2.4.1 and appendix 1.
} 
and quantitative data. The chapter combines discourse analysis and descriptive statistics. Since there is no coherent EU approach to collecting data on ethnicity, a survey has been conducted among census experts from all over Europe and beyond, to get a reference frame and to elicit expert opinions on current practices regarding this aspect. The experts came from the National Statistical Offices of the different countries and were present at the United Nations Economic Commission for Europe (UNECE) census meetings in Geneva. ${ }^{16}$ In addition, this research draws on contacts from Eurostat and further census experts whose names were provided by Eurostat-the list was checked by Pieter Everaers, Director at Eurostat, and Eric Schulte Nordholt, Senior Researcher and project leader of the census at Statistics Netherlands. Those consulted included census experts from all the EU member states as well as experts from the Balkans, Switzerland, Iceland, Canada, Turkey and Israel. Thus there is a wide geographical scope, but as the census community is rather small, it can be assumed that these experts were familiar with the issues at stake.

In total, 75 census experts were contacted. The response rate for the first round was $69 \%(n=52) .{ }^{17}$ The second round had a response rate of $50 \%$ $(n=38)$. The survey was conducted following the Delphi method (Hsu \& Sandford, 2007). It took place in two rounds in June, and then November/December 2015, as this allowed for interaction with the respondents and for reflection and elaboration on the answers the first round returned. In the first round, specific aspects were identified, such as what might be perceived as sensitive issues in a census. These aspects were then taken up in the second round and follow-up questions were asked about them. In addition, the survey included control questions to aid in filtering the data. For instance, the respondents were asked to indicate their knowledge of a particular topic (such as the EU census regulations or the Western Balkans). For the analysis of some questions, a deliberate division was made between experts who declared that they had knowledge about the Western Balkans and those who declared that they did not know much about the region. This was to test whether respondents familiar with the historical situation and ethnic cleavages in the Western Balkans would have a greater tendency to wish to exclude ethnic and cultural aspects from a census than those with less background awareness.

In order to analyse the practices of enquiring into ethnic and cultural categories, this chapter looks at census methodologies and questionnaires from Croatia, Bosnia and Macedonia. I have selected the censuses from the

\footnotetext{
16 With the exception of experts from Russian-speaking countries, such as Belarus, Georgia, Moldova and others.

17 The ' $n$ ' represents the total number of respondents.
} 
2010 census round so as to compare the three countries. ${ }^{18}$ (Bosnia had no census before 2013.) The analysis is based on documents in the English language. In some instances, interview data and newspaper articles have been used to contextualise the findings. The three West Balkan countries I follow were chosen because, at the time of the census, they were all (potential) candidates for EU enlargement, and because of the variations they showed with regard to census-taking. Croatia-today an EU member-had its census enumeration in 2011 and presented its results in November 2013.19 Macedonia aborted its census enumeration of 2011, a few days into the process. Bosnia completed its census enumeration in October 2013, but the census data was only published, after serious delay, in June 2016.

\subsection{Expert perspectives on counting ethnic and cultural characteristics}

As already stated, there are no clear EU conditions on collecting data on ethnic and cultural categories in the EU census regulations (Simon \& Piché, $2011)$. This section of the chapter therefore analyses the results of the census expert survey conducted, so as to provide a broad perspective.

In general, census experts are aware that there are census topics which can be very sensitive. When these experts were faced with the question whether sensitive questions should be part of a population and housing census questionnaire in general $(n=49)$, most of them $(49 \%)$ said they would include sensitive questions that could be answered on a voluntary basis: the questions would be included, but there would be no obligation to answer them. ${ }^{20}$ Some $14 \%$ would include sensitive aspects in a census, and $20 \%$ would exclude sensitive aspects altogether. Further, 12\% of the experts stated that the issue was not applicable, as in their countries the collection of census data was not made in the traditional way, but through registers or other sources. Also, 4\% would consider including sensitive questions if they were important for the distribution of subsidies. The question addressed to these respondents was formulated very broadly and it was left open to them to make their own choice of what was meant by 'sensitive'. However, when asked directly what kind of census topics they thought might cause difficulties, the vast majority of the experts indicated ethnicity (94\%) and religion $(94 \%)$ as sensitive or highly sensitive, while language (61\%), nationality $(61 \%)$, citizenship (30\%) and place of birth (20\%) were identified as sensitive or highly sensitive by a smaller proportion of the experts (Table 5). Even though na-

\footnotetext{
18 The 2010 census round comprised all the censuses conducted between 2005 and 2014 (United Nations Statistics Division, 2013).

19 Croatia's census data is also part of the European project called the 'Census Hub', which is a tool to compare the census data of all EFTA countries (European Statistical System, n.d.).

20 The percentages may not total 100, due to rounding. This is also the case for the tables below.
} 
tionality is high on the list, the focus of this chapter will remain on the aspects of ethnicity, religion and language, as these are identified as the key ethnic and cultural characteristics in the CES recommendations and are seen as identity markers for the 'ethnic package'.

Table 5: Sensitivity per aspect

\begin{tabular}{|c|c|c|c|c|c|}
\hline & Highly sensitive & Sensitive & Not sensitive & Not at all sensitive & $\mathrm{n}$ \\
\hline Income & $44 \%$ & $42 \%$ & $12 \%$ & $2 \%$ & 50 \\
\hline Place of Birth & $2 \%$ & $18 \%$ & $44 \%$ & $36 \%$ & 50 \\
\hline Citizenship & $2 \%$ & $28 \%$ & $44 \%$ & $26 \%$ & 50 \\
\hline Language & $12 \%$ & $49 \%$ & $31 \%$ & $8 \%$ & 49 \\
\hline Religion & $65 \%$ & $29 \%$ & $4 \%$ & $2 \%$ & 49 \\
\hline Ethnicity & $72 \%$ & $22 \%$ & $2 \%$ & $4 \%$ & 50 \\
\hline Nationality & $25 \%$ & $36 \%$ & $21 \%$ & $17 \%$ & 47 \\
\hline
\end{tabular}

The census experts were asked whether they agreed or disagreed with the inclusion of citizenship, ethnicity, language and religion in census questionnaires for all countries in the UNECE region. ${ }^{21}$ In their replies, there was a clear trend-most experts disagreed or strongly disagreed with including ethnicity $(57 \%)$ or religion $(61 \%)$ in the census questionnaire (table 6). However, with regard to language (32\%) and citizenship (10\%), a lower proportion were against the inclusion of questions. This result is not completely surprising, since citizenship is a required census topic under the EU census regulations and a core topic in the CES recommendations, and language is an indicator often used in policy-making (Simon, 2005, p. 22). As described above, ethnicity and religion are not mentioned in the EU regulations and are non-core in the CES recommendations. That most of the experts would not include these aspects probably explains why there are no coherent rules and why practices are so divergent. This theme will be developed at a later stage in this chapter.

Table 6: Agreement/Disagreement with ethnic and cultural characteristics as part of census questionnaire: UNECE/CES recommendations

\begin{tabular}{lllllll}
\hline & Strongly & Agree & Agree & Neither Agree or Disagree & Disagree & Strongly Disagree \\
\hline Citizenship & $33 \%$ & $45 \%$ & $12 \%$ & $8 \%$ & $2 \%$ & 49 \\
Ethnicity & $2 \%$ & $18 \%$ & $22 \%$ & $18 \%$ & $39 \%$ & 49 \\
Language & $12 \%$ & $35 \%$ & $20 \%$ & $16 \%$ & $16 \%$ & 49 \\
Religion & $4 \%$ & $10 \%$ & $24 \%$ & $24 \%$ & $37 \%$ & 49 \\
\hline
\end{tabular}

\footnotetext{
${ }^{21}$ The UNECE region encompasses 'the countries of Europe, but also countries in North America (Canada and United States), Central Asia (Kazakhstan, Kyrgyzstan, Tajikistan, Turkmenistan and Uzbekistan) and Western Asia (Israel)' (United Nations Economic Commission for Europe, n.d.). As described above, the countries in Central Asia, as well as Russia, Belarus, Moldova and Ukraine, were not included in the survey.
} 
The survey included another question that was very similar, but instead of asking about the UNECE region, this one focused on the EU census regulations: Did the census experts think the EU population and housing census regulations should contain more precise rules about census questions that enquire into citizenship, ethnicity, language and religion (table 7)? The results show answers for citizenship to be fairly spread out and indecisive. But for ethnicity, language and religion, the results were relatively similar: about two experts in every three disagreed or strongly disagreed with any need for more concrete EU rules. This may reflect the diverging practices in Europe on how to collect ethnic data; but also it may be seen as an indicator of the degree of sensitivity that surrounds these issues.

Table 7: Agreement/Disagreement with ethnic and cultural characteristics as part of census questionnaire: EU census regulations

\begin{tabular}{lllllll}
\hline & Strongly & Agree & Agree & Neither Agree nor Disagree Disagree & Strongly Disagree & $\mathrm{n}$ \\
\hline Citizenship & $11 \%$ & $9 \%$ & $45 \%$ & $29 \%$ & $6 \%$ & 35 \\
Ethnicity & $3 \%$ & $3 \%$ & $30 \%$ & $24 \%$ & $39 \%$ & 33 \\
Language & $6 \%$ & $9 \%$ & $30 \%$ & $24 \%$ & $30 \%$ & 33 \\
Religion & $3 \%$ & $6 \%$ & $27 \%$ & $24 \%$ & $39 \%$ & 33 \\
\hline
\end{tabular}

Table 8 shows that there was a divide in responses between those experts claiming they had good knowledge of the Western Balkan region and those stating that they did not. Although they came from a small sample of respondents, the results were significant (at the 0.05 level) for ethnicity and language. ${ }^{22}$ While experts who indicated that they were knowledgeable about the Western Balkan region preferred to exclude the aspect of ethnicity from censuses or would only include it as a voluntary category, the answers from experts who indicated that they did not know the region were more spread out. This shows that the sensitivity of the question is known to census experts especially if they know the Balkan region. Most Balkan experts would also only include enquiry into language as a voluntary category in the census, while the majority of non-Balkan experts would most definitely include this aspect in a census.

Table 8: Should ethnicity, language and religion be excluded, as they might threaten the data collection?

\begin{tabular}{lllll}
\hline Census category & \multicolumn{2}{l}{ Ethnicity $(n=33)$} & \multicolumn{2}{l}{ Language $(n=32)$} \\
\hline Balkan expert & No $(n=15)$ & Yes $(n=18)$ & No $(n=15)$ & $\begin{array}{l}\text { Yes } \\
(n=17)\end{array}$ \\
Excluded in any case & $40 \%$ & $44 \%$ & $27 \%$ & $6 \%$ \\
I would include them on a voluntary basis & $20 \%$ & $50 \%$ & $20 \%$ & $88 \%$ \\
They should definitely be included & $40 \%$ & $6 \%$ & $53 \%$ & $6 \%$ \\
\hline
\end{tabular}

22 The results for religion were not significant and are therefore not shown. 
In the main, census experts-and especially those with a good knowledge of the Western Balkans-do not agree with the inclusion of questions on ethnicity and religion in a census. Language and especially citizenship are characteristics often used for policy-making and mapping migration, and so questions on these can more often be justified. The survey reflects what was established earlier: that there are no EU conditions requiring the collection of data on ethnic and cultural categories. Even the census experts' opinions diverge on how to collect such details. It should be noted that although, in the main, the experts were against including ethnicity and religion in a census, the national censuses under investigation did include these questions.

\subsection{Ethnic and cultural categories in Croatia, Bosnia and Macedonia}

The Western Balkan countries are on their way to EU membership, and as such present an interesting case for the analysis of census-taking. On the one hand, the census is part of the EU acquis-though, as the survey results have shown, there are no coherent European guidelines on how to ask about ethnicity, language or religion, and the EU does not require countries to enquire into these aspects. On the other hand, since the dissolution of Yugoslavia, ethnicity has been institutionalised (Bieber, 2004). It is intricately intertwined with positive and negative discrimination. In part, this is a legacy from the old Yugoslav system, which had elaborate mechanisms for ethnic representation and minority protection; but after the wars following the dissolution of Yugoslavia, ethnic representation increased (Bieber, 2004, pp. 4-5). Particularly in ethnically heterogeneous societies like Bosnia and Macedonia, this can lead to difficulties in the census process, as will be outlined in the following sections.

\subsubsection{Croatia}

The latest census in Croatia was conducted, as planned, in April 2011 . Even though, due to difficulties in hiring staff, there was a delay in the publication of the census data, no major difficulties were experienced (Hoh, 2015). In the methodological guidelines for the Croatian census of 2011 , ethnicity is grouped with language and cultural identity, being seen as 'sense of belonging to a society (nation)' (Croatian Bureau of Statistics, n.d.). This includes awareness of integration into the community, and also 'special qualities in relation to other such communities' (Croatian Bureau of Statistics, n.d.). The description of 'sense of belonging' to the society or nation clearly links ethnicity to national identity, in this case the Croatian national identity. The latter part of the description also links it to a possible differentiation from other 'communities'. The methodological guidelines go on to provide details of 
how the data on ethnicity should be presented: first the data for Croats should be listed, and then the other 22 ethnic minorities in alphabetical order (Croatian Bureau of Statistics, n.d.). This shows Croats being differentiated from other ethnic groups, which are ranked separately in the official presentation. By listing only a set number of ethnicities, the presentation ensures that a selection entailing inclusion/exclusion must be made (Bieber, 2015, p. 4). In this case, one might be left wondering why the selection is presented alphabetically and not according to which group is most prevalent.

Thus, in the Croatian census questionnaire, citizenship is grouped with questions about ethnic and cultural identity (Republic of Croatia \& Croatian Bureau of Statistics, 2011). This is not in line with the CES recommendations, according to which the question on citizenship should be clearly distinguished from ethnic and cultural characteristics to avoid confusion or indirect links being made between them (United Nations Economic Commission for Europe, 2006, p. 96). In addition, there is no option to abstain from declaring citizenship, unless a person does not possess citizenship at all. In the methodology it is stipulated that if a person does not want to declare his/her citizenship, the results will present this person as having unknown citizenship (Croatian Bureau of Statistics, n.d.). By putting citizenship so close to the other ethnic and cultural categories, the census implies that there is a link between citizenship and the ethnic identity package.

With regard to the categories for the questions on ethnicity, language and religion, instead of offering open categories, as advised in the CES recommendations, the questionnaire first offers the option 'Croat' (or in the case of language, 'Croatian' and for religion 'Catholic' or 'Atheist') (Republic of Croatia \& Croatian Bureau of Statistics, 2011). Only afterwards is there an open field to declare anything else. In the methodology it is stated, with regard to the categories for ethnicity and religion, that 'persons [can] freely declare' their ethnic or religious affiliation (Croatian Bureau of Statistics, n.d.). This facility is not offered, however, with the question on language. Language in Croatia is taken to be a person's mother tongue (Croatian Bureau of Statistics, n.d.). Individuals speaking more than one language at home should declare the one they consider to be their mother tongue. This too is out of line with the CES recommendation, according to which the questionnaire should include at least two questions on language and give open-answer boxes (United Nations Economic Commission for Europe, 2006, p. 97). On the Croatian census it is not possible to declare more than one language. According to the enumerators' instructions, the answers for these categories should not be read out by the enumerators, so as not to influence outcomes (Interview 1: Croatian Bureau of Statistics official). Fines for possible malpractice by enumerators are described in the census law (Croatian Parliament, 2010). The questionnaire offers a box to tick 
for undeclared ethnicity and religion; but this option is unavailable when it comes to language.

Though enumerators should not influence responses, when we look at the census questionnaire it seems that 'Croat', 'Croatian' and 'Catholic' are the preferred categories for the questions on ethnicity, language and religion. The questionnaire shows that, among the sensitive aspects, language is treated differently from ethnicity and religion. Whereas ethnicity and religion have an option for non-declaration, this is not the case with language. However, when the categories are grouped, they can be seen as an 'ethnic package', with language being the most important indicator-and one that may be taken to show national identity (Arel, 2002). In addition, in the Croatian questionnaire, citizenship is linked with ethnic and cultural characteristics, which is something that should definitely be avoided according to the CES recommendations.

In Croatia, rights granted to minorities depend on a numerical threshold as outlined in the 2002 Constitutional Law on the Rights of National Minorities. If national minorities make up more than $1.5 \%$ of the total population, they receive at least one seat, or a maximum of three seats, for their representatives in the Croatian parliament (Petričušić, 2002, pp. 617-618). Representation in local government bodies depends on population numbers too: the threshold is $15 \%$ (Petričušić, 2002). If a certain minority makes up more than $30 \%$ in a local self-governed unit, this language can be used as the official minority language (Petričušić, 2002, p. 615). According to the law, Cyrillic script could be introduced as the official form of writing in about 30 municipalities where Serbs make up more than $30 \%$ of the population. This caused major protest in 2014, as well as a call for a referendum for changing the constitution (Milekic, 2014; Pavelic, 2014). The implementation of the law on minority languages was highly influenced by the EU accession process of Croatia (Petričušić, 2008; Tatalović, 2006). Although, with regard to ethnic and cultural questions, the census in Croatia was not in line with the CES recommendations, the collection of the census data was achieved without major difficulties. The census data is destined for use as a basis in policymaking and can have consequences for ethnic minority groups, as was shown by the protests in 2014. Since there are no EU conditions on how to deal with ethnic and cultural data and Croatia had closed the acquis chapter on statistics before the start of the census, it can be seen that the census did not play a big role in Croatian EU accession.

\subsubsection{Bosnia and Herzegovina}

In October 2013, Bosnia and Herzegovina held its first census. Although, according to the International Monitoring Operation led by Eurostat, "the census enumeration was carried out smoothly and in accordance with international standards, (Durr, Bianchini, Demirci, Kostadinova-Daslakovska, \& 
Pieraccini, 2013, p. 8), there were reports of minor irregularities (Jukic, 2013; Perry, 2013). The results were published after serious delays in June 2016 (Toe, $2016 b, 2016 c)$.

The Bosnian census law and methodology address the ethnic composition of the enumerators, which should follow the ethnic composition revealed by the census results of 1991, and mention fines for enumerators who try to influence a respondent's answer with regard to the sensitive questions on ethnicity, language and religion (Director of the Agency for Statistics of Bosnia and Herzegovina, n.d.). This already gives an indication of the sensitivity of these aspects in the region.

The census questionnaire issued by Bosnia and Herzegovina features questions on ethnic and cultural characteristics, which appear in a different order than in Croatia. Citizenship is not grouped in the same answer section as ethnic and cultural characteristics. However, the Bosnian questionnaire includes the category 'entity citizenship' (Agency for Statistics Bosnia and Herzegovina [Agencija za statistiku Bosne i Hercegovine], 2013). This has been much debated and it is believed that it might be used by ethnic Serbs to pave the way towards a referendum over independence for Republika Srpska, the entity which has a majority of ethnic Serbs (Armakolas \& Maksimovic, 2014; Perry, 2015; Popis, 2013).

If we look at the ethnic and cultural questions, the Bosnian census questionnaire asks first for ethnicity and religion, and only afterwards for language (Agency for Statistics Bosnia and Herzegovina [Agencija za statistiku Bosne i Hercegovine], 2013). For all these questions, the first answer category is an open-answer field in which to insert the reply the respondent gives. It is only below this open field that there are boxes giving preselected options. For ethnicity, these are 'Bosniak', 'Croat' and 'Serb'; for religion they are 'Islamic', 'Catholic', 'Orthodox', 'Agnostic' and 'Atheist'; for language they are 'Bosnian', 'Croatian' and 'Serbian'. While the preselected categories for ethnicity seem to be ordered alphabetically, the answer categories for religion appear connected with those for ethnicity in the question above. ${ }^{23}$ The same holds for the answer categories for language. It is made to look as if there is a clear connection between these categories, and that people should stick to the preselected ethnic, religious, and linguistic answers in an 'ethnic package' so as to increase the numbers shown for the constituent ethnic groups. Ethnicity in Bosnia and Herzegovina is described as 'ethnic/national affiliation' and language is noted as 'mother tongue'. It is not permissible to tick more than one answer box, and therefore not possible to declare multi-ethnicity or more than one religion.

\footnotetext{
23 This observation includes only the English translation of the census form. In another language the statement about the alphabetical order might not be true.
} 
Above these answer boxes, it is stated that the questions on ethnicity and religion are not obligatory, but it should be pointed out that an answer does need to be given: "[If] the answer cannot be obtained, the enumerator shall write down "Unknown"' (Director of the Agency for Statistics of Bosnia and Herzegovina, n.d., p. 156). Here, children whose parents have different ethnic and/or religious backgrounds need to decide which side they are on. From an outsider perspective, this seems strange in a country which contains several ethnic groups with intermarriages between them. This practice also goes against the CES recommendations, according to which respondents should be free to declare more than one ethnic affiliation (United Nations Economic Commission for Europe, 2006, p. 96). The methodological guidelines allow the declaration of more than one 'mother tongue', but only in 'exceptional cases, when the enumerated person declares that s/he has two mother tongues' (Director of the Agency for Statistics of Bosnia and Herzegovina, n.d.). In such an instance, this has to be put in the open-answer field. Though language can be taken as an indicator of national identity, as described above, Bosnia, it seems, allows more leeway with regard to this aspect than it does with the other ethnic and cultural categories. The language categories offered in the census questionnaire-'Bosnian', 'Croatian' and 'Serbian'-are not as different as might appear, since they all developed from the same linguistic origin (Greenberg, 2004). Another aspect taken into account in the Croatian census methodology but not taken up in this one is that, in Croatia, people can declare their 'regional, religious or any other affiliation' in the category of ethnicity (Croatian Bureau of Statistics, n.d.). There is no mention of such an opportunity in the Bosnian census law and methodology. This is indeed surprising, since the category 'Bosniak' is a somewhat recent invention. Before the break-up of Yugoslavia 'Muslim' was the term used (Bringa, 1993). This may cause confusion among the Bosniak population, who in the last Yugoslav census (1991) had to declare themselves ethnic Muslims, but now find themselves referred to as 'Bosniak'.

A further divergence in these census questions from those of Croatia is that language is treated differently from religion and ethnicity. While the questions on ethnicity and religion are not mandatory, the language question must be answered. Here there is no direct option allowing respondents to avoid declaration of their mother tongue. What the CES recommendations insist should not appear is any link between ethnicity and national affiliation (United Nations Economic Commission for Europe, 2006, p. 96). But this recommendation is ignored: the category for ethnicity is called 'ethnic/national affiliation'. There seems altogether to be a preference for the set ethnic packages of 'Bosniak', 'Croat' and 'Serb' in the census form.

These ethnic packages clearly represent the three constituent ethnic peoples included in the Dayton Agreement (Marko, 2013): if a person ticks the box 'Bosniak', it is expected that 'Islamic' and speaking 'Bosnian' will 
follow. The same seems to be the case for the combination 'Croat', 'Catholic' and 'Croatian'; and, in turn, for 'Serb', 'Orthodox' and 'Serbian'. It comes as no surprise that the publication of the census data for ethnicity, language and religion only mentions the categories connected to these three constitvent groups (Agency for Statistics Bosnia and Herzegovina [Agencija za statistiku Bosne i Hercegovine], 2016). Initially, there was concern that the data from the census in Bosnia might affect the power-sharing structures in the country, which, following the Dayton Agreement, divide representation proportionally among the constituent (ethnic) peoples-Bosniaks, Croats and Serbs-as they appear in the census results of 1991 (Marko, 2013). However, the population numbers given in the 2013 census do not differ significantly from the 1991 figures (Perry, 2016). Though the census was supervised by the EU through an International Monitoring Operation, the census results have been questioned by the ethnic Serbs (Perry, 2013). This challenge, indirectly connected with a potential increase in ethnic numbers, is part of a political impasse in Bosnia on how to count the resident population (Recknagel, 2016). The whole issue is still causing debates. Even though the results have been published, Republika Srpska authorities do not recognize them (Recknagel, 2016; Toe, 2016b, 2016e).

\subsubsection{Macedonia}

Macedonia conducted censuses in 1994 and 2002. In the 2010 census round, a new census was planned for early October 2011 (Eurostat, 2014). However, on the tenth day of the enumeration process, the Macedonian Parliament annulled the Census Law it had adopted earlier and cancelled the census altogether. This was due to political disagreements, especially on whether or not to include the diaspora population of the country in the count (Daskalovski, 2013).

Macedonia's 2011 census questionnaire is the only one of the three studied here that gives the title 'ethnic characteristics' to a section (Republic of Macedonia State Statistical Office, n.d.). The order of questions on ethnic and cultural characteristics is the same as in the Croatian questionnaire-a question on ethnicity, followed by questions on language and religion. As in the Bosnian questionnaire, the ethnic and cultural questions are not grouped in the same answer section as the question on citizenship. However, unlike the other questionnaires, the Macedonian one does not give any preselected answer categories for the questions on ethnicity, language, and religion: it offers open-answer fields for all. In addition, it provides three questions about language: 'mother tongue', 'language usually spoken', and 'knowledge of foreign languages'. There is one question each for 'ethnic affiliation' and 'religious affiliation' (Republic of Macedonia State Statistical Office, n.d.). Apart from the question on 'knowledge of foreign languages', none of these are mandatory. Though there is no direct option offered to 
avoid declaration in these categories, the census methodology states that the enumerators may fill in that the person did not declare, or put 'I do not know' (Republic of Macedonia State Statistical Office, 2011, p. 54). In short, this questionnaire is the only one making all three ethnic and cultural categories voluntary, and is thus the sole example fully in line with CES recommendations.

Another differentiating feature is that the Macedonian census law allows the collection of census data in a language other than Macedonian and a script other than Cyrillic. The law does not mention the name of the language (Albanian) but refers to it as 'the official language used by a minimum 20\% of the citizens of the Republic of Macedonia' (Republic of Macedonia State Statistical Office, 2010, p. 19).

As all the Macedonian census questions only offer open-answer options, the questionnaire potentially allows the declaration of more than one ethnicity. This questionnaire is thus the only one without a prominent ethnic preference. It is remarkable that, although this census form was most in line with CES recommendations, it was the one that did not go through with the enumeration. The Macedonian census form did not suggest any ethnic preference, but the census failed due to lack of trustworthy data (Daskalovski, 2013; Vrgova, 2015). The census was stopped because there was an inconsistent implementation of the accompanying methodology (Eurostat, 2014). This revolved around the issue of whether to include the diaspora population to boost ethnic (and linguistic) numbers, or whether to exclude this group (Marusic, 2011a). Already one year before the census operation started, Albanian politicians were proclaiming that they would not accept the census results (Interview 2: OSCE official). Then, throughout the census process, ethnic Albanians wanted to increase their own numbers in the survey, while ethnic Macedonians were just as eager to play these numbers down (Marusic, $2011 \mathrm{~b}$ ). Following the Ohrid Framework Agreement, language rights should be given to communities if the language is spoken by more than $20 \%$ of the population. Also, proportional representation in the police and in the bureaucracy depends on recorded population numbers (Brunnbaver, 2002, p. 5). Since the census of 2002, the only ethnic group meeting the threshold of $20 \%$ has been the Albanian group. It was the political struggle between the ethnic Albanians, who wanted to boost population numbers so as to keep their rights and standards, and the ethnic Macedonians, who wanted to decrease Albanian influence, that led to the cancellation of the census operation. 


\subsection{Comparison}

Since there are EU and international guidelines for census-taking, one might expect that countries would harmonise their practices in this area. However, when we look at the ethnic and cultural questions in the census forms of the case countries, we see diverging approaches. In all the census forms, the questions on ethnicity and religion are not obligatory (table 9), and this, at least, is in line with the CES recommendations. While Croatia had closedanswer categories presented first, and then an additional open-answer field, Bosnia offered these open and closed fields the other way round. Macedonia, by contrast, offered open-answer fields only. Macedonia also differed on the language question: while in Croatia and Bosnia the question on language was mandatory, the Macedonian census form did not insist on this. It did, however, present several questions about language, and, for a question on 'foreign languages' spoken, made an answer obligatory. The only questionnaire fully in line with the CES recommendations was the one Macedonia produced. Ironically, the Macedonian census was also the only one to be aborted. Meanwhile, the census operations in Croatia and Bosnia were completed, despite these countries' suggesting preferred ethnic packages in their questionnaires. Indeed, Croatia, which produced the questionnaire least in line with the CES recommendations, was the most successful of the three states in completing the census operation. Bosnia was more in line with the recommendations than was Croatia, but since this country's questionnaire suggested categories and included a much-debated question on entity citizenship, it emphasised a linking of the political with ethnic and cultural identities. All this shows that there is far more to a census than a simple population count. As has been shown in Macedonia and Bosnia, a census can be highly politicised.

Table 9: Comparison of ethnic and cultural questions in the census questionnaires of Croatia, Bosnia and Herzegovina and Macedonia

\begin{tabular}{|c|c|c|c|}
\hline & Croatia & Bosnia and Herzegovina & Macedonia \\
\hline Ethnicity & $\begin{array}{l}\square \quad \text { 'Croat', open- } \\
\text { answer field } \\
\square \quad \text { Not obligatory }\end{array}$ & $\begin{array}{l}\square \quad \text { Open-answer field, } \\
\text { 'Bosniak', 'Croat', 'Serb' } \\
\square \quad \text { Not obligatory }\end{array}$ & $\begin{array}{ll}\square \quad \text { Open-answer field } \\
\square \quad \text { Not obligatory }\end{array}$ \\
\hline Language & $\begin{array}{l}\square \quad \text { 'Croatian', open- } \\
\text { answer field } \\
\square \quad \text { Obligatory }\end{array}$ & $\begin{array}{l}\square \quad \text { Open-answer field, } \\
\text { 'Bosnian', 'Croatian', } \\
\text { 'Serbian' } \\
\square \quad \text { Obligatory }\end{array}$ & $\begin{array}{l}\square \quad \text { Open-answer field } \\
\square \quad \text { Not obligatory } \\
\square \quad \text { Several questions on } \\
\text { language (only one } \\
\text { obligatory) }\end{array}$ \\
\hline Religion & $\begin{array}{l}\square \quad \text { 'Catholic', 'Atheist', } \\
\text { open-answer field } \\
\square \quad \text { Not obligatory }\end{array}$ & $\begin{array}{l}\square \quad \text { Open-answer field, } \\
\text { 'Islam', 'Catholic', } \\
\text { 'Orthodox' } \\
\quad \text { Not obligatory }\end{array}$ & $\begin{array}{l}\square \quad \text { Open-answer field } \\
\square \quad \text { Not obligatory }\end{array}$ \\
\hline
\end{tabular}




\subsection{Conclusion}

Because political participation and mandate representation quotas have become linked to the political structure of West Balkan countries, ethnic and cultural characteristics need to be collected. But there are no EU conditions on how to manage this, and international recommendations are only partially followed, even though enquiry into ethnic and cultural categories often forms part of the population censuses in the Balkan region. Recognizing this problem, Chapter 3 has used survey data to provide an international framework to review these categories. The results, based on the survey data and the census questionnaires of three sample countries, clearly demonstrate that there is no one-size-fits-all approach on how to collect ethnic and cultural data. Some subsidiary points have emerged. First, there seems to be a difference in the degrees of sensitivity attached to different aspects: ethnicity and religion are highly sensitive and citizenship and language are less so. Second, since there is no coherent EU approach on how to deal with ethnic and cultural data, it is not possible to speak of Europeanisation in this policy area.

In each of the three case countries the main paradox surrounding the collection of ethnic and cultural data is present: in order to be recognized, minority groups need to have their presence known, but the collection of data about their existence can cause discrimination or bring about other negative consequences. The negative implications are already visible in the politicisation of censuses and census outcomes. This politicisation was somewhat weaker in Croatia, where the debate on ethnic and cultural characteristics came up largely after the census, when, following the results, about thirty municipalities were allowed to introduce Cyrillic script for their official language. This led to major protests and even a referendum on whether to change the constitution to increase the numerical threshold (Hoh, 2015, p. 78). The Bosnian census categories recognized three constituent ethnic groups, which all had (and have) their own agendas for ethnic national state-building (Keil, 2013b; Keranen, 2013). Intense political debate on the census definitions was the main reason why the publication of the census results was so seriously delayed. Even now, after the results have been published, the Serb authorities do not recognise them (Recknagel, 2016; Toe, 2016b, 2016c). In Macedonia, the census was highly politicised, as both the main ethnic groups-Macedonian and Albanian-wanted to maintain or increase their political influence. The linking of language rights to numerical thresholds led to the spread of different methodologies in the census operation, ultimately causing it to fail altogether.

Thus, in all three countries studied, the inclusion of questions on ethnic and cultural characteristics in the census has had political repercussions. Moreover, these have been divergent in character. This thesis does not at- 
tempt to provide a solution, but highlights the further paradox that including ethnic and cultural questions in a census shapes ethnic preferences, which may influence policy-making and the distribution of rights; but these ethnic preferences may also be used for ethnic nation-building (Anderson, 2006). The influence of ethnic preferences has so far been underestimated by the EU. Lack of attention to how it is addressed in census-taking flaws the current EU approach to state-building and enlargement (Keil, 2013b). There is no coherent European approach on how to collect ethnic and cultural data, and we cannot speak of Europeanisation of census-taking.

As minority rights and political representation in the Western Balkans are connected to the results shown in its censuses, further research is needed on the possible outcomes of this linkage, which so far have been unanticipated. That this is one of the important challenges the EU faces in the Western Balkans is made clear by the ongoing debate on the definition of 'usual residence' in Bosnia and the current political crisis in Macedonia. 



\section{Chapter 5 'When counting counts': Europeanisation of census-taking in Croatia, Bosnia and Macedonia}

A slightly different version of this chapter has been published as Hoh, A.-L. (2017b). 'When Counting Counts': Europeanisation of Census-Taking in Croatia, Bosnia and Herzegovina and the Former Yugoslav Republic of Macedonia. Journal of Contemporary European Research, 13(1), 980-996. 


\title{
Chapter 5
}

\begin{abstract}
In 2000, the European Union extended the membership perspective to the Western Balkans; however these countries have taken different political paths towards EU accession at different speeds. The population census is one of the conditions for EU accession and part of the $18^{\text {th }}$ acquis chapter on statistics. This chapter seeks to explain the variation in census-taking in the 2010 census round in Croatia, Bosnia and Herzegovina and the former Yugoslav Republic of Macedonia considering two Europeanisation mechanisms: (a) the conditionality and (b) the legitimacy of the EU regulations in the area of census-taking. While conditionality assesses the cost/benefit calculation between the EU rewards/pressure and domestic adoption costs, legitimacy analyses whether the EU census regulations will be accepted based on their perception of appropriateness. Congruence analysis is used to compare the effectiveness of the Europeanisation mechanisms on the censuses in the countries under investigation. The study concludes that in Croatia legitimacy had the most impact, whereas the cases of Bosnia and Herzegovina and the former Yugoslav Republic of Macedonia can be better explained by conditionality. Therewith this work contributes to the recent findings that conditionality as well as legitimacy matter for research on Europeanisation.
\end{abstract}




\subsection{Introduction}

More than a decade after the European Union extended the membership perspective to the Western Balkans in 2000, these countries have taken different political paths towards EU accession, and at different speeds. The pathway of EU accession is tied to conditions and depends on compliance with EU rules and norms by the candidate countries. The process of alignment with EU rules and norms has been described as a major challenge for the countries in the Balkan region (Noutcheva, 2012; Prifti, 2013). The population and housing census (hereafter census) is one of the aspects which represents a challenge in some of the enlargement countries.

Within the acquis communautaire the census is part of the $18^{\text {th }}$ chapter on statistics and outlined in the statistical compendium (European Commission, 2014c). Census-taking is crucial for the production and dissemination of population data and serves as a backbone for official statistics. The census is the tool for a state to gain information about its population and their living standards. Census data is important for the sample designs to conduct statistical surveys. As the EU is very keen on using statistics for evidence-based decision making, a reliable population count is a crucial element in the EU accession process. However, in the Balkan region, the collection of the data for the population and housing census is an exceedingly sensitive issue as important decisions over the distribution of public funds and/or the allocation of institutional quotas for various societal (ethnic/linguistic) groups are based on census data (Everaers, 2015). Essentially, census-taking is often highly politicised in multi-ethnic and multi-lingual societies and especially in the Western Balkans (Bieber, 2015).

Censuses in the Western Balkan region were conducted long before EU accession. The last census of Yugoslavia was collected shortly before its break-up in 1991. Now within the framework of EU enlargement, accession countries have to comply with EU conditions for census-taking. Except for Bosnia and Herzegovina, whose census took place in 2013, all Western Balkan countries conducted their censuses in 2011 , the reference year of the EU population count (Eurostat, 2014). Although all Western Balkan countries have the same EU conditions to comply with, three cases were chosen based on the different outcomes with regard to census-taking: ranging from aborted (the former Yugoslav Republic of Macedonia, hereafter Macedonia), to delayed (Bosnia and Herzegovina, hereafter Bosnia) and relatively timely, with minor contestation (Croatia). In addition to the different census outcomes, these are also countries in different stages of EU accession; whereas Croatia became an EU member in 2013, Macedonia is a candidate country and Bosnia a potential candidate.

Earlier scholars have researched the censuses in the region, but focused foremost on the construction of national identity through the census catego- 
ries (Bieber, 2015) or the aspect of ethnicity (Daskalovski, 2013; Visoka \& Gjevori, 2013). Recently, more attention has been paid to the politics of numbers behind the population count (Daskalovski, 2013; Keil \& Perry, 2015), but so far there is little research on the impact of the EU on the censuses in the Western Balkans (Keil, 2015).

This chapter assesses whether the impact of the EU enlargement process can explain the variation in census-taking outcomes in Bosnia, Croatia and Macedonia. This will be done by using congruence analysis to test the impact on census-taking of two mechanisms of Europeanisation: conditionality and legitimacy. Legitimacy focuses on the acceptance and implementation of the EU census regulations, as well as the nature of debates and contestations surrounding the census processes. This will show whether countries comply with the EU rules because they see it as appropriate and legitimate to do so. Conversely, conditionality, which is based on the logic of consequences, assesses the rational cost/benefit incentives behind the differences of countries in EU accession (Schimmelfennig \& Sedelmeier, 2004, 2005a, 2007) and, in particular, whether the benefits of complying with EU conditions (EU rewards) outweigh the domestic adoption costs. The chapter explores which of the two Europeanisation mechanisms is more likely to explain compliance.

\subsection{Census-taking within Europeanisation}

Europeanisation has many definitions, from broader ones looking at 'processes of a) construction, b) diffusion, and c) institutionalisation of formal and informal rules, procedures, policy paradigms, styles and "ways of doing things"' (Radaelli, 2006, p. 59), to more concrete ones, which see Europeanisation as a shorthand definition for the domestic influence of the EU (Elbasani, 2013a, p. 5). As this research is only looking into a rather small aspect of the acquis and how this influences the censuses in the enlargement countries, Europeanisation is defined here as the influence of the EU on the Western Balkan countries (Elbasani, 2013a, p. 5). Earlier research on Europeanisation has looked into EU member state building (Bieber, 2011 ; Keil, 2013b) but also the effectiveness of the acquis conditionality in South Eastern Europe (Trauner, 2009) and the normative and strategic dimensions of EU external power (Noutcheva, 2009, 2012). Recently more attention has been paid to domestic factors which affect Europeanisation in the region, such as the lack of 'stateness' (Elbasani, 2013a), and human rights and corruption (Glüpker, 2013).

Within the framework of Europeanisation, census-taking is underresearched. The EU developed the EU census regulations to harmonise statistical data in all (potential) member states and uses this data 'evidence- 
based decision making' (Everaers, 2015, p. 185). Thereby, census data becomes crucial for policy-making and the distribution of, for example, subsidies. What differentiates censuses in the Western Balkans from those in most European countries is that the distribution of rights (such as minority rights) and political power can depend on the population data (Keil, 2015). In most Western European countries, census-taking is primarily a technical statistical exercise, however in the Balkan countries the census is a tool to know the numbers of the different population groups present (Interview 3: Eurostat official; Interview 4: EU delegation Sarajevo official).

After Yugoslavia dissolved, issues of ethnicity and ethnic group size, as well as geography, were important tools used in the conflicts for bargaining new borders, rights and representation schemes in the newly established states in the Western Balkans (Visoka \& Gjevori, 2013, p. 6). Bieber (2015) has shown that the census constitutes a site to negotiate national identities, to represent majority and minority groups. Since rights and the representation of power in the cases under investigation depend on the census results of ethnic groups, the process of census-taking is highly political (Kertzer \& Arel, 2002b, p. 36). Particularly political are the census questions on ethnicity, language and religion, place of usual residence and whether or not to include the diaspora in the census. These aspects have been identified as the most contested issues in the Western Balkans (Everaers, 2015, p. 192) because these questions can be used and potentially manipulated to increase ethnic numbers. ${ }^{24}$ Even though it is important in the Western Balkan countries, the EU does not require collecting data on the sensitive ethno-cultural characteristics (ethnicity, language and religion). Also in the Conference of European Statisticians Recommendations for the 2010 Censuses of Population and Housing (CES recommendations) ${ }^{25}$ these aspects are only part of the noncore categories (United Nations Economic Commission for Europe, 2006, p. 162). Nonetheless, in the 2010 census round, all Western Balkan countries included these topics in their census questionnaires (Eurostat, 2014). ${ }^{26}$

The EU has high stakes in the stability of the region and wants to develop reliable statistics in its potential member states (Bieber, 2015, p. 11). In the 2010 census round almost all the Western Balkan countries were financially and/or technically supported by the European Commission, through for example Eurostat, the statistical office of the EU. Even though it is highly recommended that candidate countries follow the EU census regulations, they

\footnotetext{
24 This is not only important in the case countries but is also an issue in Montenegro (Vuković, 2015), Serbia (Nikolić \& Trimajova, 2015), Slovenia (Josipovič, 2015) and Kosovo (Musaj, 2015).

25 The CES recommendations form the international guidelines for census-taking. These are formulated by the United Nations Economic Commission for Europe in collaboration with Eurostat (United Nations Economic Commission for Europe, 2006).

26 Earlier research has shown that this is also important for cultural politics in Spain (Urla, 1993) and used for ethnic exclusion in Israel (Leibler \& Breslau, 2005).
} 
are not legally obliged to comply. However, compliance does increase their chance of EU membership.

\subsection{Europeanisation of census-taking: Conceptual framework}

Earlier research on the transformative power of the EU has shown that EU conditionality can explain patterns of EU rule transfer to candidate countries in Central and Eastern Europe (Schimmelfennig \& Sedelmeier, 2004). However, in the Western Balkans, Noutcheva (2009) has shown that the lack of perceived legitimacy of the EU rules leads to different outcomes in compliance with EU conditions. While the aspect of conditionality looks at the (dis)incentives the EU offers in light of a cost/benefit calculation, the aspect of legitimacy will be analysed by looking at the implementation of the EU census rules in addition to the nature of the debates and contestations surrounding the censuses.

\subsubsection{Conditionality}

Schimmelfennig and Sedelmeier (2004, p. 662) describe conditionality as 'a bargaining strategy of reinforcement by reward, under which the EU provides external incentives for a target government to comply with its conditions'. The EU rewards accession countries that comply with its conditions and withholds rewards in the case of noncompliance. Within the literature, a differentiation is made within the democratic and acquis conditionality of the EU, asserting that the domestic political costs are more important for democratic conditionality, which is connected to compliance with the Copenhagen Criteria (Schimmelfennig \& Sedelmeier, 2007, pp. 91-92). In the case of census-taking, which is part of the acquis conditionality, however, the aspect of domestic adoption costs is also of importance. Since the census data is used to establish numerical thresholds (for example, for minority rights, as well as political representation), it can affect the adoption costs for the domestic political elite. Therefore, the EU rewards for having a census need to be stronger than the potential losses of the domestic political elite. In order to tip the balance towards compliance, the EU can also pressure candidates by withdrawing pre-accession funds or setting short-term conditions within the accession process, through, for example, the Stabilisation and Association Agreements.

Conditionality will be assessed by looking at the cost/benefit calculation of EU rewards/pressure versus domestic adoption costs. The EU rewards will be assessed by looking at the material and social rewards the accession countries receive or lose in case of compliance or noncompliance, and the pressure the EU puts on its enlargement countries for them to comply with the EU census regulation. The domestic adoption costs will be assessed ac- 
cording to the potential gains/losses of rights for the domestic political elite, such as numerical thresholds connected to the census results. Following the logic of consequences, it is expected that the credibility of threats and promises from the EU, as well as EU pressure, can make a difference with regard to the successful implementation of conditions for the population and housing censuses, if they outweigh the domestic adoption costs.

\subsubsection{Legitimacy}

Numerous authors have shown that in the Western Balkan countries compliance with the EU conditions cannot be fully explained when only taking into account the rational choice idea of conditionality (Bieber, 2011 ; Freyburg \& Richter, 2010; Noutcheva, 2009). Therefore, the aspect of the perceived legitimacy of the EU conditions will also be considered. This mechanism is based on the acceptance of norms, values and identities, and follows the logic of appropriateness, which assumes that actors choose the most appropriate (legitimate) course of action (March \& Olsen, 1989; Schimmelfennig \& Sedelmeier, 2004, p. 667). If external actors accept the authority of the EU and are convinced of the legitimacy and appropriateness of EU rules, they adopt and comply with them (Schimmelfennig, 2014, p. 20). In respect to census-taking, the acceptance of the EU census regulations, as well as the contestation surrounding the census, will be used as indicators for legitimacy. To be perceived as fully legitimate, the EU conditions must not only be accepted by the Statistical National Institute of the accession country but also by its political elite, because domestic actors can have a crucial role as, for example, veto players in post-communist countries (Mendelski, 2013). Conversely, if there is contestation and opposition against the appropriateness of the EU census regulations, the country is likely not to comply with the EU conditions for census-taking. The contestation of the censuses will be taken into account because this will show whether and to what extent the EU census regulations are accepted by the public/political elite. It is expected that if the EU census regulations are accepted as legitimate, there will be no contestation of the census process and there will be full compliance with the EU census regulations.

To measure the effect of legitimacy on compliance with the EU census regulations, it will be assessed whether the National Statistical Institutes of the case countries, as well as their political elites, accept and implement the EU census regulations and whether or not there is public/political contestation of the census. The latter will be assessed by looking at public/political debates and their outcomes surrounding the censuses. If the census is highly contested (strongly debated) it is expected that compliance with the EU census regulations is not due to the mechanism of legitimacy. If there is little or no debate and the EU census regulations are accepted and implemented, the mechanism of legitimacy is regarded as strong. However, the nature 
of the debate also matters; for example, if the outcome of the debate is to comply with the EU census regulations and this is implemented and accepted, compliance is also expected to be due to legitimacy.

\subsection{Method, case selection and data}

To compare the mechanisms of EU conditionality and legitimacy, congruence analysis will be used. This method is a small-N research design which uses case studies to contrast and compare the explanatory relevance of theoretical approaches (Blatter \& Haverland, 2012, p. 144). This approach is also known as systematic process analysis (Hall, 2006). To compare the mechanisms of Europeanisation, empirical data collected via semistructured interviews, conducted with people at the National Statistical Institutes, international census experts and EU officials, as well as the census laws, questionnaires and methodologies of the case countries will be analysed and compared with the EU regulations on census-taking (European Parliament \& Council of the European Union, 2008). These documents will be complemented with data from the EU progress reports and newspaper articles.

The countries have been chosen because although they have to comply with the same EU conditions, they show a variation with regard to census operations and outcomes. Croatia, by now an EU member, has conducted two censuses since independence from Yugoslavia, in 2001 and in 2011 respectively. The last census in 2011 was conducted after the acquis chapter on statistics was already closed but before the accession date of July 2013. Macedonia, an EU candidate country since 2005, however without opening membership negotiations, has also conducted two censuses since independence, one in 1994 and one in 2002. Another was planned for 2011, but aborted after a few days of enumeration due to unequal implementation of the methodology. Bosnia submitted its application for EU membership in 2016 and is considered a potential candidate country. The country conducted its first census since 1991 in October 2013 and the results were published, after a long delay, in June 2016.

Here we will focus foremost on the 2010 census round, which following the international definition includes all censuses conducted in the time period from 2005 up to 2014 (United Nations Statistics Division, 2013). This census round was chosen because throughout the previous round (the 2000 cycle, from 1995 to 2004) there were as yet no EU conditions with regard to censustaking. Since then, attention accorded to the collection, harmonisation and dissemination of population data has increased; in the enlargement package of 2015 the chapter on statistics was even included in the list of aspects that are part of strengthened reporting (European Commission, 2015a). 


\subsection{When counting counts: Case analysis}

\subsubsection{Bosnia and Herzegovina}

In October 2013, Bosnia conducted its first census since independence from the former Yugoslavia. This census was long expected as the preparations had already started in 2008. As it was the first census since independence from Yugoslavia and the armed conflict (1992-1995), there was an urgent need for reliable population data. The census law was adopted in February 2012. The Agency for Statistics is officially responsible for the census but cooperates with the Statistical Institutes of the Entities: the Republika Srpska (RS) and the Federation of Bosnia and Herzegovina (Director of the Agency for Statistics of Bosnia and Herzegovina, n.d., p. 13). An International Monitoring Operation (IMO), led by Eurostat, started in April 2012, shortly after the adoption of the census law. Since then, the IMO has conducted more than 20 missions in Bosnia. From the beginning of the census project, there was a strong commitment from the EU towards this census. Without EU help and guidance it would have been very difficult to carry it out (Interview 5: DG NEAR official). Of the approximately 23 million EUR census costs (Eurostat, 2014), more than 13 million was paid by the EU (Interview 4: EU Delegation Sarajevo official). Next to this, the Swedish International Development Cooperation contributed about 1.85 million EUR to the census exercise via the Instrument for Pre-Accession Assistance (AAM Consulting, 2013; Eurostat, 2014). The enumeration process took place in October 2013 and was in line with international standards (Durr et al., 2013). There were some reports of irregularities (Perry, 2013), however, most of these, related to diaspora enumeration, were expected to be sorted out during the data processing (Durr et al., 2013, p. 12). There was indeed a lengthy interim period in which data processing remained on hold (Interview 8: Statistical Agency official) due to a missing agreement on the definition of 'place of usual residence' (Interview 6: Statistical Agency official). The EU urged Bosnia to publish the population data by July 2016 (Toe, 2016d). Even though the IMO estimated that Bosnia was not likely to meet this deadline (Durr \& Demirci, 2016, p. 8), the data was finally published on 30 June 2016. However, debates continued after the publication, as the RS still does not accept the definition of 'place of usual residence' (Toe, 2016b).

Regarding the Europeanisation mechanism of conditionality, the rewards and the pressure for complying with the $\mathrm{EU}$ conditions are high. Particularly since Bosnia submitted its membership application in February 2016, the publication of the census data has been made a condition for Bosnia's EU accession process (RFE/RL, 2016). This was emphasised in April 2016, when the European Parliament called 'for the results of the population and housing census to be published without further delay' (European Parliament, 2016). 
The successful completion of the census has been emphasised in the proposed Reform Agenda for 2015 to 2018 by the European Commission (European Commission, 2015c) and the importance of the acquis chapter on statistics is mentioned in the Stabilisation and Association Agreement (SAA), in force since July 2015 (Official Journal of the European Union, 2015). The publication of the census data had the potential, furthermore, to attract international funding and support (Interview 7: Eurostat official). The ultimate reward bestowed by the EU would be acceptance of the Bosnian membership application, giving the EU an additional opportunity to press for the publication of the census results. The SAA, the Reform Agenda and the membership application itself can thus all be considered as rewards as well as instruments to pressure Bosnia to comply with EU conditions for census-taking.

The domestic adoption costs for complying with EU census regulations are high as well, since the census results can be used to certify the death toll and ethnic cleansing during the war (1992-1995) (Interview 4: EU delegation Sarajevo official). It was expected that the census outcome might affect the political system, which distributes power among the three constituent ethnic groups: Bosniaks, Croats and Serbs (Armakolas \& Maksimovic, 2014; Bieber, 2004). The government and the parliament are constituted by the three ethnic groups and within the parliament there is parity at the state level, based on the 1991 population distribution (Bieber, 2004, p. 6). If the census of 2013 had strongly diverged from the 1991 population numbers, this could have sparked debate about the current constitutional design based on the constituent ethnic groups. This increased the political and domestic adoption cost for Croatian politicians especially, as it was expected that their numbers would have decreased and they might lose the legitimacy of basing their power on the constituent group structure. In the end, the overall census numbers did not differ much from the 1991 population but still caused debates (Recknagel, 2016). In addition to this, there are concerns that the aspect of 'entity citizenship', which was included in the census questionnaire, could pave the way for a referendum of independence in the RS (Armakolas \& Maksimovic, 2014; Perry, 2015; Popis, 2013). The RS "hopes to "ratify" ethnic cleansing through the census and to confirm that the RS is a proto-nation state [however] a larger share of non-Serbs would challenge this ambition' (Bieber, 2013). By now a referendum for a Serb national holiday has taken place, which is seen as a test run for secession of RS from Bosnia (Deutsche Welle, 2016). Overall, there are concerns that the new population data will not only be used for socio-economic purposes but misused for political purposes (Interview 4: EU delegation Sarajevo official; Interview 6: Statistical Agency official; Interview 8: Statistical Agency official). When the Director of the Statistical Agency, Velimir Jukic, announced in May 2016 that the Agency would publish the census results before the deadline on 1 July 2016, following the EU regulations without consensus among the statistical institutes, 
the President of the RS, Milorad Dodik, declared that he would refuse to accept the results (Toe, 2016a). Given that Bosnia published the data one day before the deadline of July 1, the balance of the cost/benefit calculation ultimately tipped in favour of compliance with the EU census regulations, meaning that EU pressure and rewards outweighed the domestic adoption costs.

The debate between the RS and the Statistical Agency is also important when looking at the impact of legitimacy. This debate caused the delay in data processing, which rested on the definition of 'place of usual residence' (Interview 4: EU delegation Sarajevo official). Although this is clearly defined in the EU regulations, the RS wanted to include an additional question on place of work/education, as a control to check whether people actually reside in Bosnian territory (Interview 4: EU delegation Sarajevo official; Interview 6: Statistical Agency official; Interview 5: DG NEAR official). The adjusted definition shows the intent of the RS to "'legalise the ethnic cleansings from the 1990s" and create conditions for its separation from the Bosnian state' (Armakolas \& Maksimovic, 2014, p. 86). Although fully in line with the IMO recommendations (Interview 10: International Census Consultant), the data processing was still on hold during the interviews with study informants in 2015, as the statistical institute of the RS continued to oppose the definition of the resident population provided by the EU (Interview 6: Statistical Agency official). In brief, the debate demonstrates that the census in Bosnia is contested. Even though in the end the Statistical Agency implemented the EU census regulations, the ongoing contestation of the census definitions (Toe, $2016 \mathrm{~b})$ suggests that the instrument of legitimacy is not very strong in Bosnia and, as such, cannot be considered an important factor that contributes to the publication of the census data.

\subsubsection{The Former Yugoslav Republic of Macedonia}

Macedonia had already gathered population data in 1994 and in 2002. The 1994 census was 'hotly contested' (Daskalovski, 2013, p. 8) and observers were surprised when they discovered how political the census operation was (Friedman, 2002). This was the first census conducted after independence from Yugoslavia in 1991. A year before the second census, an armed ethnic conflict between ethnic Albanians and ethnic Macedonians broke out. This was stopped with the Ohrid Framework Agreement in August 2001. The 2002 census was also disputed by Macedonians, Albanians and other ethnic groups, but assessed as fair and accurate by the international community (Vrgova, 2015, p. 116). The 2011 census was planned for April, then delayed to October (Marusic, 2011c). After the EU delegation in Macedonia had warned Eurostat of difficulties with the preparations for the census (Interview 11: EU Delegation Skopje official), Eurostat set up a light monitoring operation after an official request from Macedonia (Everaers, 2015, p. 185). The IMO 
started in October 2010 (Interview 9: International Census Consultant). Following the advice of the IMO the census enumeration was delayed, but a green light was given for the census data collection in October 2011 (Interview 12: Eurostat official). Nonetheless, the census was stopped due to an increase of unreliable census forms, signed by only one of the two enumerators (according to the census law both must sign) and/or applying different methodologies (Interview 13: State Statistical Office official). Although the 2011 census in Macedonia was observed by the IMO, there was no guarantee of reliable population data. The census was officially stopped because of the unequal implementation of census methodologies and disagreements about counting the diaspora population (European Commission, 2013b, p. 13; Eurostat, 2014, p. 21).

With regard to conditionality, there are no concrete EU rewards, nor strong EU pressure for complying with the regulations on census-taking, and in the overall accession process Macedonia is 'at an impasse' (European Commission, 2015b, p. 2). Even though Macedonia is already an EU candidate country, there are currently no significant developments regarding EU accession. The European Commission first recommended opening membership negotiations in 2009 but they still have not been opened. In 2015, the recommendation was only extended under the condition that the "urgent reform priorities' and the political agreement to overcome the current political crisis, following a huge wire-tapping scandal, were implemented (Balkans in Europe Policy Group, 2015; European Commission, 2015b, p. 14; Marusic, 2016). Therefore, there are neither reliable EU rewards, nor pressure from the EU to push for a census complying with the EU census regulations.

In addition to the lack of EU rewards/pressure, the domestic adoption costs for holding a census are high, since in Macedonia (as in Bosnia) the political system has institutionalised ethnicity. According to the Ohrid Framework Agreement (OFA), if minorities make up more than $20 \%$ of the population, language rights as well as the 'equitable representation of persons [...] in public bodies at all levels and in other areas of public life' (OSCE, 2001) depend on the population numbers. Following the 2002 census, the only minority making up more than $20 \%$ of the population is ethnic Albanians (Vrgova, 2015, p. 116). Throughout the census process, ethnic Albanians wanted to increase their numbers and ethnic Macedonians wanted to decrease the numbers of the ethnic Albanians (Marusic, $2011 \mathrm{~b}$ ). In the end, the enumeration process was problematic, as different methodologies on how to count the resident population circulated and a lot of census questionnaires were signed by only one of the two enumerators (Interview 13: State Statistical Office official). These aspects made it impossible to guarantee reliable data and when the State Census Commission resigned four days before the enumeration was finished, the census operation was cancelled (Jordanovski \& Dimevski, 2011 ; Marusic, 201 la). The whole census operation 
was highly politicised and political representation depended on the census outcomes. In this case, the domestic adoption costs clearly outweighed the non-existent EU rewards/pressure for complying with the EU census regulations. This indicates that conditionality may have had a strong negative impact on compliance with the EU census regulations.

When looking at the mechanism of legitimacy, this seems to have only limited influence on compliance with the EU rules. The EU census regulations were only partially accepted and the reasons for having a census were at least in part political rather than socio-economic. As described above, the OFA clearly sets a threshold of $20 \%$ for the official use of other languages, but also proportional representation in the public bodies depends on the population numbers (Brunnbauer, 2002, p. 5; OSCE, 2001; Vasilev, 2013). In 2010, a year before the census enumeration started, politicians proclaimed that they would not accept the census methodology (Interview 2: OSCE official). This debate was also visible when the State Census Commission, which consisted of 25 members 'appointed by the Government of the Republic of Macedonia' (Republic of Macedonia State Statistical Office, 2010, p. 15), influenced the census operation, to such an extent that they tried to impose different methodologies on how to count the diaspora population. The State Census Commission was responsible for appointing half the regional instructors; the other half would be appointed by public announcement (Republic of Macedonia State Statistical Office, 2010, p. 17). This arrangement led to difficulties and delays in hiring sufficient enumerators; when the enumeration started, in some areas there was a lack of well-trained enumerators and staff, which delayed the enumeration (Interview 13: State Statistical Office official). Three days before the enumeration started, the representative of the Albanian Party Democratic Union for Integration still wanted to include the diaspora population in the population count. When this request was not accepted, since it was not in line with the Eurostat recommendations, he and another Albanian representative resigned from the State Census Commission (Jordanovski \& Dimevski, 2011; Marusic, 2011b). Despite recurring disputes about the census methodology and difficulties with hiring staff, Eurostat confirmed that the State Statistical Office was technically ready for the census operation (Interview 12: Eurostat official). Overall, the methodology and the questionnaire were described as being in line with the EU census regulations (Interview 13: State Statistical Office official). Nonetheless, the census was captured by political forces trying to influence the population count to increase ethnic numbers (Interview 11: EU Delegation Skopje official; Interview 2: OSCE official). Even though the EU census regulations were accepted by the State Statistical Office, there was a strong contestation of the 2011 census, which shows a low level of legitimacy. 


\subsubsection{Croatia}

Croatia's separation from Yugoslavia in 1991 was followed by violent conflict (1991-1995). As a result of this conflict, the country is ethnically relatively homogeneous, with Serbs as the biggest minority ethnic group with 186,633 people or about $4 \%$ of the population (Hoh, 2015, p. 78). The census in 2011 was Croatia's second since independence, and was conducted without any major problems (Hoh, 2015). The 2001 census, according to the European Commission, was 'in line with the UNECE/Eurostat recommendations for the 2000 censuses of population and housing in the ECE region' (European Commission, 2006, p. 9). The costs for the census were calculated up front and addressed in the census law. A census budget of 21 million EUR was calculated, but in the end the approximate costs were only about 16 million EUR (Eurostat, 2014). Unlike in Bosnia, the costs were all covered by the Croatian government. Only one small part of the Post Enumeration Survey was covered by the EU through the Instrument for Pre-Accession Assistance (Eurostat, 2014, p. 10). There was a delay concerning the publication of the census data (Pavelic, 2012), which was caused due to difficulties in hiring staff. The government did not allow the Statistical Office to hire the best census enumerators for the data processing phase; instead the Statistical Office had to hire people who had been unemployed for a long period (Interview 1: Croatian Bureau of Statistics official). The census results were finally published on 8 November 2013 (Croatian Bureau of Statistics, 2013). Today, the census data of Croatia is part of the Eurostat census hub, which can be considered as a sign of the high quality of the data.

With regard to conditionality, back in 2007 the Croatian population statistics were regarded as being compliant with the acquis (European Commission, 2007, p. 7). In the year of the 2011 census, Croatia also concluded its accession negotiations (Elbasani, 2013a, p. 5). Actually, the chapter on statistics had already been closed in October 2009, before the census law was finalised. Therefore the 2011 census was not followed as closely by the EU as, for example, the Bosnian census (Interview 14: DG NEAR official). Since Croatia had already demonstrated its ability to conduct a census, it was expected that it could do so again (Interview 14: DG NEAR official). In the end, the 2011 census was described as 'harmonised with international standards $[\ldots]$ in order to provide the international comparability of data' (Croatian Bureau of Statistics, 201 1, p. 8). Bearing in mind that by the time of the census the acquis chapter on statistics was already closed, it was expected that Croatia would comply with the EU census regulations. Thus the census did not form a subject of the accession negotiations and because of this EU rewards and pressure can be considered low.

As political representation in Croatia depends to a lesser extent on the census outcomes, the domestic adoption costs for complying with the EU 
census regulations were not as high as in Bosnia or Macedonia. Even though rights for minorities in Croatia also depend on the population numbers, the numerical threshold of $1.5 \%$ to guarantee representative seats for minorities (Petričušić, 2002; Tatalović, 2006, p. 55) is much lower than the $20 \%$ threshold in Macedonia. In addition, between 1991 and 2001 the share of ethnic minorities decreased by $50 \%$ (Tatalović, 2006), with the result that Croatia is ethnically more homogeneous than Bosnia or Macedonia. Therefore, the domestic adoption costs were low and even though the rewards for complying with the EU conditions were low as well, Croatia was compliant. Conditionality therefore does not provide a firm explanation for Croatia's full compliance with the EU census regulations.

The impact of legitimacy was by contrast very high. Despite the lack of EU rewards, Croatia implemented the EU census regulations before it was a member of the European Union. The EU census regulation (European Parliament \& Council of the European Union, 2008), together with the CES recommendations, are mentioned as two of the most important documents for international standards on the website of the Croatian Bureau of Statistics (CBS) (Croatian Bureau of Statistics, 2011, p. 9). The enumeration process was 'carried out successfully and according to international standards in April 2011 ' (European Commission, 2011 a, p. 40). As mentioned above in relation to conditionality, Croatia had a proven ability to conduct a census (Interview 14: DG NEAR official). The CBS was very firm on using the international definitions, for example for the category of 'place of usual residence'-this, in spite of concern by demographers and politicians, who wanted to keep the former definitions in order to compare the data over time or wanted to include the diaspora (Interview 1: Croatian Bureau of Statistics official). There was no public/political debate on the census and thus the Croatian census can be regarded as not contested. After the results were published, the potential introduction of the Cyrillic script, used by the Serb minority, in about 20 municipalities sparked protests (Pavelic, 2013, 2014). However, the census itself was not contested and there were no big gains or losses for political parties with regard to ethnic proportional representation after the census. The lack of contestation and the CBS acceptance of the EU census regulations show that in the case of Croatia the impact of legitimacy is much stronger than the impact of conditionality.

\subsection{Conclusion}

This chapter assessed the effectiveness of the Europeanisation mechanisms of conditionality and legitimacy on the compliance of Croatia, Bosnia and Macedonia with the EU census regulations. The cases of Bosnia and Macedonia show that the impact of the domestic adoption costs on the mecha- 
nism of conditionality should be taken seriously, and that these costs can even influence the mechanism of legitimacy. High domestic adoption costs in Bosnia and in Macedonia contributed to debates and contestation of the EU census regulations and resulted in a low level of legitimacy in these cases. In Bosnia, EU rewards and pressure were much higher than for Macedonia and this tipped the balance of the cost/benefit calculation in favour of complying with the EU census regulations. Whereas in the case of Bosnia the empirical findings suggest a strong influence of the mechanism of conditionality on compliance with the EU census regulation, legitimacy can provide a further explanation for the delay of the census operation. In Croatia, the mechanism of conditionality cannot explain compliance with the EU census regulations, as although the domestic costs were rather limited, Croatia did not benefit from EU rewards. In the case of Croatia, however, the empirical findings show that legitimacy can have a strong positive impact on compliance with the EU regulations. The noncompliance of Macedonia, as evidence shows, can be explained by either conditionality, as domestic adoption costs outweighed EU rewards and pressure, or legitimacy, since there was strong contestation of the EU census regulation. The mechanism of legitimacy can explain the cases of Croatia and Macedonia. It might not provide strong explanations in Bosnia, but even in this case it provides insights as to why the census process was delayed. Therefore, this research confirms earlier studies which concluded that conditionality alone cannot fully explain compliance with the EU rules. In order to understand fully the influence of the EU on its enlargement countries, both mechanisms need to be considered. Due to the variation these cases show, it is not possible to generalise how these mechanisms would affect the other countries in the Western Balkans. This thesis focuses on the Europeanisation mechanisms, but further research could address the role of other domestic factors such as domestic veto players, and the inclusion of sensitive data on ethnicity, language and religion in the census questionnaire.

Nonetheless, this analysis does demonstrate that when the political representation and/or rights depend on the population numbers, census-taking is connected to the Copenhagen Criteria, in particular minority rights and democratic conditionality. This is not only important for the Western Balkans but can be crucial in other countries where aspects of ethnicity/identity are connected to census data (see also Simon, 2011), such as Spain (Urla, 1993). This research has shown that acquis conditionality is not only a technical exercise but is in fact highly political, and that, especially with regard to census-taking, this aspect should not be underestimated. 
Chapter 6

Census-taking in the Western Balkans:

A matter of state capacity or the influence of domestic and external actors?

A slightly different version of this chapter is currently under review. 


\begin{abstract}
Limited statehood has been identified as an obstacle for integration of the Western Balkan countries. Even though enlargement countries are all required to comply with the same conditions, they show significant variation. This chapter contributes to the debate on whether it is institutional factors or the agency of actors that matter most in Europeanisation processes. The analysis shows that state capacity is insufficient in explaining the variation in census outcomes, and that the influence of external actors can potentially be very strong. The influence of domestic actors is in general underestimated and can be of crucial importance.
\end{abstract}




\subsection{Introduction}

Since 2003 the Western Balkan countries have been on the path towards becoming EU member states. Although there is talk of 'enlargement fatigue' and the future of EU enlargement seems insecure, EU Commissioner for enlargement Johannes Hahn recently gave the assurance that all Western Balkan countries should sooner or later become EU member states (Ladurner, 2017). Currently these countries are in very different stages of the EU enlargement process and are moving at different speeds toward EU membership. Croatia received membership in 2013; Serbia and Montenegro have started membership negotiations; Macedonia and Albania are official candidate countries, without having started membership negotiations; and finally, Bosnia submitted its membership application in February 2016 but is still, like Kosovo, regarded as a potential candidate.

The process of EU enlargement rests upon the principle of conditionality, where EU rewards are conditional upon the countries' compliance with EU conditions (Bieber, 2011; Elbasani, 2013a). The EU conditions for membership consist of the Copenhagen Criteria, which lay out the key factors for compliance, such as democracy and a functioning market economy, and the acquis communautaire, the enforcement of all current EU rules (European Commission, 2014b). One of the preconditions for EU membership is the population and housing census (hereafter census), which is part of the $18^{\text {th }}$ acquis chapter on statistics. In essence, a census is an approximately decennial population count in a country; nonetheless, census-taking can be highly political, especially if the census outcomes are connected with proportional representation as in the Western Balkans. As accession countries, the Western Balkan countries are strongly recommended to follow the EU census regulations, but there have been different outcomes with regard to the population census-ranging from successful (Croatia, Serbia) to long delayed and/or partly boycotted (Bosnia and Kosovo) to aborted (Macedonia). Census data is used as the backbone of national statistics, but increasingly also on the EU level as the EU needs harmonised statistical data for evidence-based decision making (Everaers, 2015).

Vachudova (2014) argues that the EU continues to have an effect on the democratisation processes in the Western Balkans. However, according to Mendelski (2013, p. 101), the transformative power of the EU is weaker than sometimes assumed by Europeanisation research. Recent research (Börzel, 2013; Elbasani, 2013a, p. 6) suggests that limited statehood-the lack of structures to enable the execution of EU rules-is one of the main obstacles for the Western Balkans' compliance with EU regulations. While much research has been done on the EU's enlargement strategy (Börzel \& Schimmelfennig, 2017; Keil, 2013b; Schimmelfennig \& Sedelmeier, 2006), little research has been conducted to analyse the agency that influences EU 
integration and census-taking processes. Within the literature on statebuilding, institutional factors (such as state capacity but also the agency of actors, both domestic and external) are mentioned as potential capacity builders (Risse, 2011; Schneckener, 2011). This chapter will therefore answer the following research question: How important are state capacity and domestic and external actors, for compliance with the EU census regulations in Croatia, Bosnia and Macedonia? The chapter argues that state capacity cannot fully explain the variation in census-taking outcomes. The analysis shows that the influence of external actors, in this case the EU, potentially can be very strong. More importantly, the influence of domestic actors is in general underestimated and can be of crucial importance.

State capacity will be assessed by comparing the World Bank Governance Indicators over the period of the 2010 census round, which spans the period 2005-2014 (United Nations Statistics Division, 2013). In order to analyse the influence of domestic and external actors, data from in-depth interviews and newspaper articles will be used.

\subsection{Census-taking in the Western Balkans}

Census-taking is bound up with the formation of states (Curtis, 2001, p. 3) and is inherently political. Historically, census data has been used for colonial domination (Anderson, 2006, pp. 163-164), to conscript citizens into military service, and to ensure payment of taxes (Nobles, 2000, p. 3). Statistics are seen as a description of the state, 'by and for itself' (Desrosières, 1998, p. 147), as they provide the state with an overview of its population, which is used not only to oversee and conscribe its citizens, but also serves them through (for example) the distribution of subsidies and policy-making. Since 'census making is itself a practice of state formation, an assertion of sovereign authority over people and social relations' (Curtis, 2001, p. 36), ${ }^{27}$ the process of census-taking is closely connected to state institutions. For example, Lee and Zhang (2017) measured the legibility of a state by looking at its population census. In this chapter, however, it will be tested whether state capacity, but also the influence of domestic and external actors, can explain the variation in the outcomes in census-taking in the Western Balkans.

Since all Western Balkan countries are considered future EU member states, they are expected to meet EU standards for statistical data. The EU uses the population data for evidence-based decision making. Pieter Everaers, Director of the Department for Cooperation in the European Statis-

\footnotetext{
${ }^{27}$ According to Curtis $(2001$, p. 33), censuses are made and not taken, because they 'do not simply report aspects of social relations existing [. . .]. Rather, census making configures social relations in keeping with particular political and cultural objectives and interests in order that such relations may be known and governed'.
} 
tical System at Eurostat, the statistical agency of the EU, describes evidencebased decision-making as "an important cornerstone of European society" (Everaers, 2015, p. 185). In order to comply with the EU census regulations, (future) member states need to follow the EU regulation for census-taking (European Parliament \& Council of the European Union, 2008). Even though enlargement countries have the same EU conditions to follow, their last censuses had very different outcomes and consequently the EU has increased its attention to the population census in its enlargement countries.

To analyse the compliance of enlargement countries with the EU census regulation, Croatia, Bosnia and Macedonia have been chosen as case countries. Besides the fact that all of these countries are considered (or in the case of Croatia, are) EU members, they also share a similar history with regard to census-taking, since before its breakdown they all were part of Yugoslavia where the last census took place in 1991. Nonetheless, there is a strong variation in census outcomes: Croatia had a relatively successful census in 2011; the 2013 census in Bosnia was marked by serious delays and the data was published only in 2016; and the 2011 census in Macedonia was aborted a couple of days into the enumeration process.

\subsection{State capacity and census-taking}

Academic literature has addressed the enlargement process of the Western Balkans from the Europeanisation perspective (Aybet \& Bieber, 2011 ; Bieber, 2011; Elbasani, 2013a; Keil, 2013a; and Chapter 4 of this thesis). Scholars (Denti, 2014; Keil, 2013a) also use the term 'EU member state building', because the EU has tried to build functional states as well as to integrate them. This approach creates a paradox, as on the one hand the process of statebuilding aims at sovereign states, whereas on the other hand, the integration process also undermines the sovereignty of the new states (Chandler, 2010; Juncos, 2012; Woelk, 2013). According to Krasner (2001, pp. 7-12) there are four aspects of sovereignty that can be problematic: (1) Interdependence sovereignty, the ability of a state to control trans-border activities; (2) domestic sovereignty, the effective control of state territory; (3) international legal sovereignty, which is whether or not a state is internationally recognised; and (4) Westphalian sovereignty, whether states have autonomous governing structures. Papadimitriou and Petrov (2012, p. 749) have identified Kosovo's sovereignty as problematic on more than one of the aspects of Krasner's typology. This is also the case when looking at the minimalist state of Bosnia (Bieber, 2011). Limited statehood has been identified as an obstacle for and a missing link in the EU integration process of the Western Balkans (Börzel, 2013; Elbasani, 2013a). In areas of limited statehood, international sovereignty is intact, but domestic sovereignty, the effective control of state territory, is 
missing (Risse, 2011 , p. 2). According to Börzel and Risse (201 1b, p. 201), states with limited statehood are unlikely to comply with rules from supranational institutions, 'simply because they lack the enforcement capacity to implement these policies'.

Within the broader concept of governance-'the institutionalised modes of social coordination to produce and implement collectively binding rules, or to provide public goods' (Risse, 2011, p. 9) -this chapter will look at the capacity of a state to penetrate society and extract resources (Migdal, 1988, p. 8). In order to assess the state capacity of the case countries, the study makes use of the World Bank Governance (WBG) indicators, selecting four of the indicators as appropriate to measure state capacity. ${ }^{28}$ 'Government effectiveness' is the first of these, and measures the quality and independence of the public and civil service, the quality of policy formulation and implementation, and the credibility of a government's commitment to such policies (Kaufmann et al., 2010, p. 4). Second, the indicator for 'regulatory quality' measures the ability of a government to formulate and implement policies and regulations that permit and promote private sector development (Kaufmann et al., 2010, p. 4). The third indicator, 'control of corruption', assesses the extent to which public power is exercised for private gain and whether a state is 'captured' by private interests (Kaufmann et al., 2010, p. 4). The fourth is 'political stability', which measures the likelihood of the government being destabilised or overthrown by unconstitutional means (Kaufmann et al., 2010, p. 4).

\footnotetext{
28 Fukuyama (2013, pp. 348-349) identified these four indicators to measure state capacity. The other two WBG indicators were not selected, because within the broader framework of governance the focus remains on structural and process dimensions (Risse, 2011, p. 9), rather than citizen participation (which is covered by the indicator 'voice and accountability') or confidence in the rules of the society (which is measured by the indicator for 'rule of law') (Kaufmann, Kraay, \& Mastruzzi, 2010). It should be noted that although there is debate about whether or not these are the right measurements for state capacity (Fukuyama, 2013; Lottholz \& Lemay-Hébert, 2016; Skocpol, 1985, p. 28), this thesis does not take into account potential alternatives (Holt \& Manning, 2014) as these are still the measurements most often used for state capacity (for example by Börzel \& Schimmelfennig, 2017; Mendelski, 2013; Noutcheva \& Aydin-Düzgit, 2012) and most of the critique on the WBG indicators has been refuted by Kaufmann, Kraay, and Mastruzzi (2007).
} 


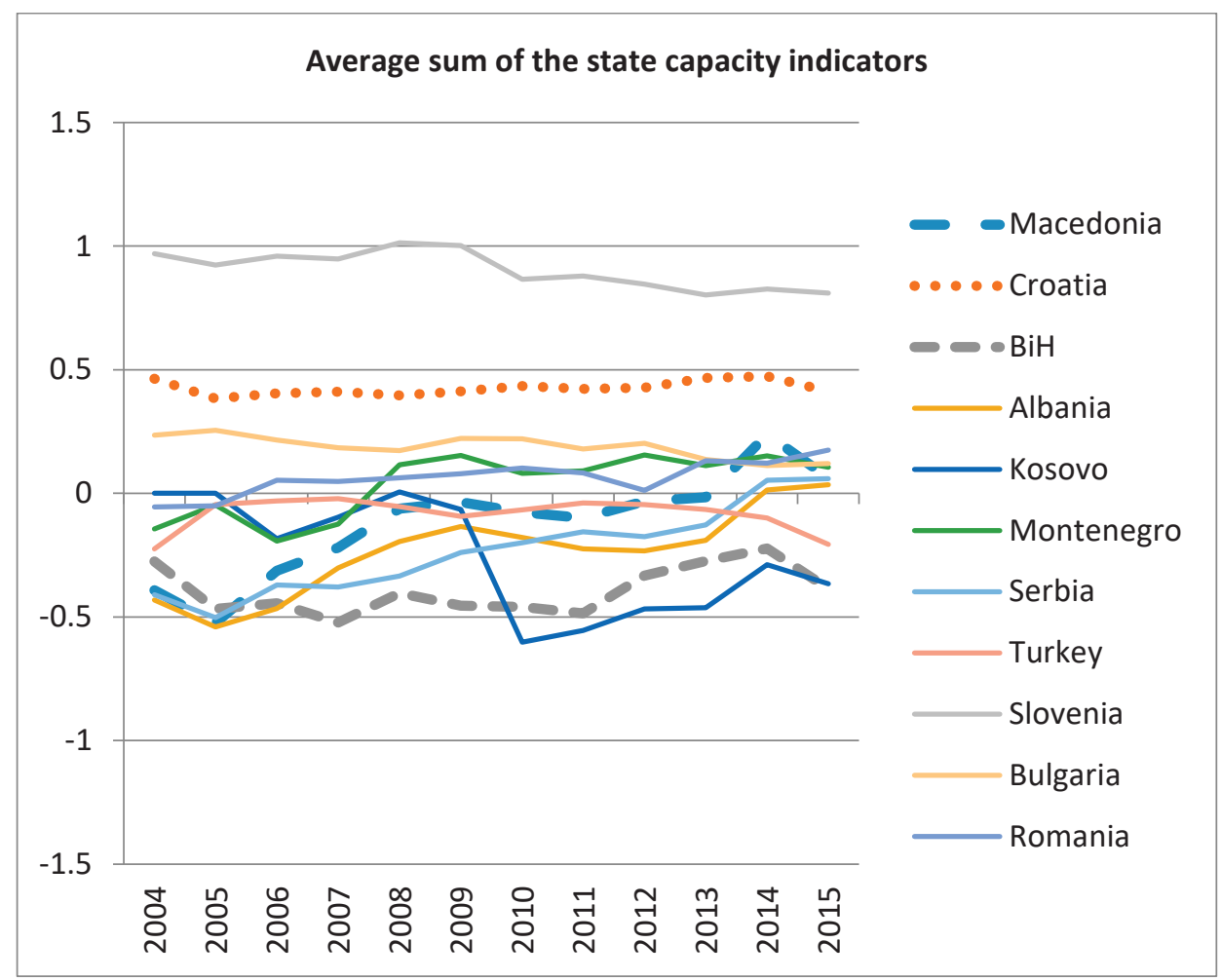

Figure 5: Average sum of Indicators for State Capacity (Government Effectiveness, Regulatory Quality, Political Stability, and Control of Corruption) for 2004-2015

Figure 5 shows an average score of all four indicators ${ }^{29}$ for the Western Balkan countries, but also for EU members Slovenia, Romania, Bulgaria and neighbouring Turkey, in order to provide a bigger picture of the region including countries that are already EU members. Looking at the comparison of these indicators, one can see that Croatia scores best overall among the case countries; only Slovenia's scores are better. Notably, Croatia's scores are superior to those of Romania and Bulgaria. In the region, the lack of state capacity manifests also in the contestations of geographical borders and political authority (Börzel, 2013, p. 178). Serbia and Croatia are regarded as consolidated (Börzel, 2013, p. 179), but other countries in the region, such as Bosnia and Kosovo, are still seen as unconsolidated states with weak capacity. Macedonia's scores were rather negative in the beginning (with -0.52 in 2005), but since then have slowly increased (to 0.24 in 2014) albeit with a

\footnotetext{
29 These scores can range from -2.5 to 2.5. The correlation between these indicators for the three case countries was strong and significant at the 0.01 level and therefore the average score of the indicators is presented in one figure. The individual scores of the indicators for state capacity (government effectiveness, regulatory quality, political stability and control for corruption) for the case countries Croatia, Bosnia and Macedonia can be found in Table 12 in Appendix 6.
} 
slight drop in 2015 (when the average score was 0.06). Bosnia's scores for all years are below 0 , and this country showed the worst scores overall for state capacity (with only Kosovo scoring worse, between 2010 and 2014). ${ }^{30}$

When comparing the average scores of the indicators with the census outcomes of the 2010 census round, 31 state capacity alone does not explain the variation in census outcomes. Croatia has, compared to the other Western Balkan countries, the highest average score for state capacity and also conducted a complete census in 2011 . The Croatian census data was harmonised with international standards (Croatian Bureau of Statistics, 2011) and there were no major irregularities during the census process. Since the data is also part of the European census hub, ${ }^{32}$ the Croatian census can be regarded as fully compliant with the EU census regulations. Regarding Croatia's high scores for state capacity this is not very surprising. However, when we compare the census outcomes of Macedonia and Bosnia with their state capacity scores we see a different picture. Considering the state capacity scores, from 2010 onwards the only country with worse scores than Bosnia is Kosovo. Bosnia started the census process in 2008, but was only able to conduct the census in 2013. The data processing was delayed, but in the end the data was published in June 2016. Although there were some deviations, Eurostat declared the census data valid and observed that 'the entire process was conducted in compliance with international standards' (Croatian News Agency, 2016). In line with the conclusion that Bosnia's census was eventually compliant with international standards, it will be regarded as delayed compliance with EU census regulations, because of the hold-up and the disagreements regarding data processing. Macedonia, which compared to Croatia and Bosnia has a medium average score on state capacity indicators, in theory should have the capacity to conduct a census. Certainly, the process of census-taking should have been smoother than in Bosnia. Nonetheless Macedonia's 2011 census was stopped a couple of days

\footnotetext{
30 These scores are also mirrored in the EU progress reports. Whereas Croatia met the political criteria of the EU in 2011, 'core challenges' were mentioned with regard to the political criteria in Macedonia (European Commission, 2011 b, p. 38). In 2011, Bosnia was described as making only 'limited progress' in meeting the political criteria (European Commission, 2011b, p. 58). In 2014 Bosnia was described as 'once again' making 'very limited progress' (European Commission, 2014a, p. 1). Comparing these measures to the 2017 Freedom House report (Freedom House, 2017), Croatia managed to retain its status as 'free' in 2017, although its 2016 Freedom of the Press status was assessed as only 'partly free'. Macedonia and Bosnia retained their 'partly free' status; whereas Bosnia's Freedom of Press status in 2016 was marked as 'partly free', Macedonia's press was 'not free' in 2016.

31 The 2010 census round includes all censuses collected between 2005 and 2014 (United Nations Statistics Division, 2013). Within the EU, the reference year for the census was 2011 (European Parliament \& Council of the European Union, 2008).

32 The census hub (European Statistical System, n.d.) is created by the European Statistical System to disseminate the population data of all member states. Initially it was also the plan to include enlargement countries, but this did not work out.
} 
into the enumeration process. Because the Macedonian census was aborted, it will be regarded as non-compliant with the EU census regulations.

Even though consolidated statehood has been described as a precondition for advancing EU membership negotiations (Börzel, 2013, p. 180), this analysis shows that state capacity is insufficient in explaining the variation in census outcomes and compliance with the EU census regulations. Therefore, next to this institutional factor, the influence of domestic and external actors will be assessed in the next sections.

\subsection{Domestic and external actors}

Following Migdal (1988, p. 19), the state's leadership has the power to make and implement rules, as well as the power to create the parameters for rule making. Local agency is a factor often hidden or unrecognised in peacebuilding processes. However, local agency is a great resource for sustaining peace in the long term (Chandler, 2013; Qehaja \& Prezelj, 2017). Peacebuilding processes are closely connected with state-building (Barnett \& Zürcher, 2008). Usually local agency is perceived in terms of veto players, where actors either accept or hinder the implementation of EU regulations depending on potential gains and losses (Schimmelfennig \& Sedelmeier, 2004, pp. 666-667). In the accession process for Central and Eastern Europe countries the influence of veto players was considered small (Schimmelfennig \& Sedelmeier, 2004, p. 667), whereas in the Western Balkans political actors are important when looking at the divergent compliance responses (Noutcheva, 2009). Domestic strategies of ethnic and economic clientelism can hinder EU conditionality and capacity-building (Börzel, 2013, p. 182). Census outcomes are connected to political representation and minority rights via numerical thresholds, potentially increasing the adoption costs to domestic political elites to such an extent that they prefer to opt for noncompliance. Such is the situation in the three case countries (see also Chapter 3 of this thesis). In Croatia, minority rights depend on the census data. In Bosnia, parliamentary representation of the constituent groups is based on the census outcomes of 1991 (Bieber, 2004, p. 6), and in Macedonia the Ohrid Framework Agreement guarantees language rights to minorities making up more than $20 \%$ of the population. Therefore, alongside the aspect of state capacity, the interest of the domestic actors in the census, and in complying or not with the EU census regulations, becomes important for the analysis.

With regard to the census, the domestic actors taken into account for the analysis are the National Statistical Institutes and domestic politicians. Census bureaus, which are embedded in the National Statistical Institutes, are not only simple producers of statistical data, as they are involved in the process 
of categorising they are political actors (Nobles, 2000, p.1). Domestic politicians are relevant as their influence can either support or hinder the census process. Their willingness to comply with the EU census regulations is of high importance, as will be shown by the examples of Macedonia and Bosnia. The influence of the domestic actors is assessed by in-depth interview data and contextualised with official documents and newspaper articles.

In addition to the influence of domestic actors, external actors, in this case the EU, can also influence the census processes and compliance. In countries with contested statehood, such as Kosovo or Bosnia, external actors can exercise authority (Börzel, 2013, p. 182; Krasner \& Risse, 2014). Even though there is critique on the EU's approach to member state building, the EU has been described as the most important external actor in the Western Balkans (Vachudova, 2015, p. 522). All of the Western Balkan countries have been part of a series of technical cooperation meetings led by Eurostat (Everaers, 2015, p. 185) to assist and prepare the accession countries for EU integration and if needed to help them with (for example) the population census. The censuses in Macedonia in 2011, as well as in Bosnia in 2013, were observed by International Monitoring Operations (IMOs) led by Eurostat. In the event that a country requests a monitoring mission, it depends on this mission to guarantee 'fair and transparent census-taking' (Everaers, 2015, p. 185 ) and therewith legitimise the census results. This already shows that these countries do not have the capacities to conduct the census on their own. Since the EU is a very important actor in the Western Balkans, its influence as an external actor will be taken into account in the analysis.

The influence of the EU as external actor will also be analysed through indepth interview data, as well as official documents.

\subsection{Case analyses}

\subsubsection{Croatia}

The 2011 census in Croatia took place in April 2011. Looking first at the actors involved in the census-taking process, responsibilities concerning the Croatian census are outlined in the country's census law (Croatian Parliament, 2010). The main responsibility lies with the Croatian Bureau of Statistics (CBS) (Croatian Parliament, 2010). Five other institutions (the Ministry of Foreign Affairs and European Integrations, the Ministry of Interior, the Ministry of Defence, the Ministry of Justice and the State Geodetic Administration) are designated in the census law to help within their area of competence, and their tasks are clearly outlined (Croatian Parliament, 2010). The CBS relied on the infrastructure of these institutions to conduct the census, but the census was otherwise not influenced by them (Interview 1: Croatian Bureau of Statistics official). There were no difficulties regarding the outline of the census law 
or the enumeration process. Some local politicians, academics and demographers wanted to keep the former definitions of the census categories, but the CBS insisted on adjusting these definitions in line with the EU census regulations (Interview 1: Croatian Bureau of Statistics official). After the data collection process, the government prohibited the CBS from hiring the best census enumerators for the data processing; instead they were to hire people who had been unemployed for a longer period (Interview 1: Croatian Bureau of Statistics official). The director of the CBS, Ivan Kovac, blamed the Croatian government for not allowing the CBS to hire additional administrative staff to process the data in a more timely manner (Pavelic, 2012). This caused delays in the processing of the census data; however this was not as serious as in for example Bosnia. The Croatian census data was published in November 2013 (Croatian Bureau of Statistics, 2013). The Serbian National Council, the local authority of the ethnic Serbs in Croatia, was very critical of the census and mentioned 'serious irregularities' in the census process (Pavelic, 2012). In Croatia, minority rights depend on the census outcomes (Petričušić, 2002), therefore ethnic minorities have an increased interest in the census. Overall, the census process in Croatia was not significantly affected by domestic actors and there were not many reports of irregularities during the census process. After the census results were published, however, there were protests by Croatian war veterans, as in some areas the Serb minority had gained rights to use the Cyrillic alphabet in public places (Pavelic, $2013,2014)$. The protesters even called for a referendum to change the rights of minorities, but they were not successful (Pavelic, 2014). Thus, while domestic actors were interested in the census, they did not influence the census process. In sum, as mentioned above, the Croatian census complied with EU census regulations.

With regard to external actors, there was little to no influence, apart from the technical cooperation meetings organized by Eurostat for the whole region of the Western Balkans (Everaers, 2015, p. 185). In these meetings the national census experts exchanged best practices among themselves and with the European Commission in order to harmonise their data collection. All Western Balkan countries participated in these meetings and therefore all of them had the same influence. However, in contrast to Macedonia and Bosnia there was no IMO mission in Croatia. Also, with regard to finances the census was independent of external actors. The whole operation was financed by Croatia. The census budget of 21 million EUR was already established in the census law (Croatian Parliament, 2010) and in the end the census costs were estimated much lower, at about 16 million EUR (Eurostat, 2014). Thus, the influence of external actors on the 2011 census in Croatia can be considered as low. 


\subsubsection{Bosnia and Herzegovina}

In Bosnia, the State Statistical Agency (SSA) conducted the census together with the statistical agencies of the federations of Bosnia and Herzegovina and the Republika Srpska (RS). The census process started in 2008. The census law however was only adopted in 2012. The enumeration process was initially planned for April 2013, but was then delayed until October. Officially the census was in line with the international standards (Durr et al., 2013), but there were reports of irregularities (Perry, 2013). The 2013 census was the first census in independent Bosnia, and because of this there was substantial concern already before the census. It was expected that the census data could be used to certify the death toll and ethnic cleansing of the war (1992-1995) (Interview 4: EU delegation Sarajevo official). Another concern was the inclusion of the census question on 'entity citizenship', which could pave the way for a referendum on the independence of the RS (Armakolas \& Maksimovic, 2014; Perry, 2015; Popis, 2013). The adjusted definition of place of usual residence was perceived by the Bosniak diaspora as intent of the RS to "'legalise the ethnic cleansings from the 1990s" and to create conditions for its separation from the Bosnian state' (Armakolas \& Maksimovic, 2014, p. 86). Because of the continued disagreement on the definition of 'place of usual residence', the data processing was on hold from February 2015 until June 2016 (Interview 8: Statistical Agency official). Although there is a clear definition of this category in the EU census regulations, the RS wanted to include the aspect of place of work/education, to control whether people actually reside in Bosnian territory (Interview 4: EU delegation Sarajevo official; Interview 6: Statistical Agency official; Interview 14: DG NEAR official). The Statistical Institute of the Republika Srpska was very critical of the approach of the Statistical Agency and the IMO mission, and even published an open book of 72 pages (Republika Srpska Institute of Statistics, 2016) to explain why they do not accept the census results. The Statistical Institute of the Republika Srpska wants to include the extra question to control whether people actually reside in Bosnia (Republika Srpska Institute of Statistics, 2016). They are convinced that there is an overcount of about 400,000 people and that the census 'cannot be verified as fair or unbiased' (Republika Srpska Institute of Statistics, 2016, p. 3). In May 2016, the Director of the Statistical Agency, Velimir Jukic, announced that the census results would be published before the deadline set by the EU, which was 1 July 2016. Therewith the data was published in line with the EU census regulations, but without consensus among the statistical institutes, since the Statistical Institute of the Republika Srpska did and still does not agree with the definitions handled by Eurostat. In the end, then, the Statistical Agency and its Director decided to publish the census data, even though the president of the RS, Milorad Dodik, declared that he will not accept the results (Toe, 2016a). This shows that in 
Bosnia the domestic actors pursue different interests when it comes to the census.

When looking at the external actors in Bosnia, one must acknowledge that the EU played an important role. From the beginning on, the EU delegation in Sarajevo was strongly committed to the census (Interview 4: EU Delegation Sarajevo official). Also with regard to finances the external influence of the EU on the census in Bosnia was rather high, as the EU financed more than $50 \%$ of the census costs: the total cost of the census was approximately 23 million EUR (Eurostat, 2014), of which more than 13 million was paid by the EU (Interview 4: EU Delegation Sarajevo official). In addition, the Swedish International Development Cooperation contributed about 1.85 million EUR to the census via the Instrument for Pre-Accession Assistance (AAM Consulting, 2013; Eurostat, 2014). As another external influence, the census was observed by an IMO mission. This IMO had 23 missions and consisted of six experts. ${ }^{33}$ The IMO started shortly after the adoption of the census law in April 2012. Since Bosnia submitted its membership application in February 2016, the EU was able to push for the publication of the census data, by making this one of the preconditions for the accession process (RFE/RL, 2016). This was also emphasised by the European Parliament in April 2016 (European Parliament, 2016), the Reform Agenda published in 2015 (European Commission, 2015c) and the Stabilization and Association Agreement (SAA), which entered into force in July 2015 (Official Journal of the European Union, 2015). By declaring the published population data valid and in line with the international standards, Eurostat also legitimises the data. Thus the EU was able to influence the census, not only via direct involvement through the IMO and Eurostat, but also via external pressure through the enlargement process. Nevertheless even the IMO did not succeed in ensuring full acceptance of the census data, since the RS still does not recognize the results and questions their reliability (Republika Srpska Institute of Statistics, 2016).

\subsubsection{Macedonia}

Like in Bosnia, the census in Macedonia was highly politicised. This was mainly because the census outcome is connected to proportional representation. Due to the Ohrid Framework Agreement, minorities making up more than $20 \%$ of the population receive language rights and proportional representation in the police and bureaucracy (Brunnbaver, 2002, p. 5). The only ethnic minority meeting this threshold is the ethnic Albanians. Therefore political groups, which are mostly structured along ethnic lines, were very interested in the census numbers. For example, Albanian political parties wanted to

${ }^{33}$ The IMO reports can be accessed at http://www.bhas.ba/census/. 
move the census date to July in order enable expatriates to participate in the census (Lutovska, 2010; Vrgova, 2015, p. 117).

In Macedonia, the National Statistical Institute and the State Statistical Office conducted the census together with the State Census Commission, which consisted of 25 members and was appointed by the government (Republic of Macedonia State Statistical Office, 2010). The State Census Commission had a multi-ethnic make-up based on the data from the 2002 census (Republic of Macedonia State Statistical Office, 2010, p. 15). The census was planned for April, but in the end took place in October 2011. However, there were still debates, for example within the State Census Commission about the census methodology and especially the definition of "place of usual residence' and the question of whether or not to include the diaspora in the total population count. In addition there were difficulties between the State Census Commission and the State Statistical Office. The State Census Commission was responsible for appointing half of the regional instructors (Republic of Macedonia State Statistical Office, 2010, p. 17). However, when the enumeration started there was a lack of enumerators, which in some areas delayed the process (Interview 13: State Statistical Office official). Three days before the start of the enumeration, the representative of the Albanian Party Democratic Union for Integration still wanted to include the diaspora population in the population count. When this was not accepted he and another Albanian representative resigned from the State Census Commission (Jordanovski \& Dimevski, 2011; Marusic, 2011b). The census enumeration still started, however different methodological approaches and definitions were spread and troubled the collection of the census data. The enumeration process was stopped, because too many forms came in signed by only one of the two enumerators (under law the form had to be signed by both enumerators), and the collection of reliable population data could not be guaranteed (Interview 13: State Statistical Office official). From the beginning there was a lot of domestic interest in the census process. One year before the census took place, some politicians already proclaimed that they would not accept the census results (Interview 2: OSCE official). In the end the unwillingness of domestic actors to accept the international census regulations-and definition for place of usual residence in particular-made a reliable population count impossible.

The EU delegation in Skopje had warned Eurostat of difficulties in the census preparations (Interview 9: EU Delegation Skopje official). After Macedonia requested the IMO, it was set up as a 'light' mission in October 2010 (Everaers, 2015, p. 185; also confirmed by Interview 9: International Census Consultant). Compared to the IMO mission with Bosnia, the one in Macedonia was rather short, with only five or six meetings and two experts. Beyond this 'light' monitoring mission, Macedonia did not receive much external support. For example, it did not have any international financial help 
(Eurostat, 2014) and since the enlargement process is at a standstill, the EU cannot pressure the country to comply with the EU census regulations via other means. The OSCE in Skopje, as well as the EU delegation in Skopje, criticized Eurostat and the IMO for underestimating the difficulties and political climate of the census (Interview 2: OSCE official; Interview 11: EU Delegation Skopje official). The census was aborted, because domestic actors from the State Census Commission, as well as politicians, disagreed over rules on how to collect the population data. Unlike in Bosnia, where the EU could use the enlargement process to press for the population data, in Macedonia it had only limited abilities, which were not sufficient to overcome the domestic problems.

\subsection{Comparison}

When comparing the three cases (Table 10) and their scores for state capacity, only Croatia shows a good score. Macedonia and Bosnia both have rather weak scores. In the absence of a strong state capacity, other factors can better explain the census outcomes. In Croatia the domestic and the external actors were not as interested in the census as were the actors in Bosnia and Macedonia. The 2011 census in Croatia can be regarded as a relatively technical exercise and there was not much domestic interest in the census process; whereas the cases of Bosnia and Macedonia show that if there is a lack of state capacity this needs to be overcome by other means. In these countries the political elites were very interested in the census outcomes, especially since these can have effect on the proportional representation of the ethnically organised political parties. This interest made the censuses in these countries highly political. Even though external actors did not take over the census operations, considering it important that the countries be able to conduct the census by themselves, there was a difference between the levels of assistance the countries received. Croatia had no assistance, but still was able to conduct a census in line with the EU census regulations. In Bosnia the level of assistance was high, considering both the financial help and the 23 IMO missions. Macedonia did not receive as much external assistance, but here the census failed. Thus state capacity cannot sufficiently explain the variance in compliance with the EU census regulations. In the case of domestic disputes, the case of Bosnia shows that the EU can be a strong actor and this external influence can be the decisive factor for compliance. However if there are domestic disputes hindering compliance with the EU regulations and the EU has little leverage, census processes can also be aborted, as was the case in Macedonia. These cases show that domestic agency is important in census-taking processes and should not be underestimated. 
Table 10: Comparison of state capacity, domestic actors and external actors, by country

\begin{tabular}{|c|c|c|c|c|}
\hline & State capacity & Domestic actors & External actors & Census outcome \\
\hline Croatia & Strong & $\begin{array}{l}\text { Willingness to } \\
\text { comply }\end{array}$ & $\begin{array}{l}\text { Very little } \\
\text { influence/interest }\end{array}$ & Compliant \\
\hline $\begin{array}{l}\text { Bosnia and } \\
\text { Herzegovina }\end{array}$ & Very weak & $\begin{array}{l}\text { Domestic disputes } \\
\text { hindering } \\
\text { compliance }\end{array}$ & $\begin{array}{l}\text { High interest, high } \\
\text { influence (EU carrot) }\end{array}$ & $\begin{array}{l}\text { Delayed } \\
\text { compliance }\end{array}$ \\
\hline Macedonia & Weak & $\begin{array}{l}\text { Domestic disputes } \\
\text { hindering } \\
\text { compliance }\end{array}$ & $\begin{array}{l}\text { Medium interest, little } \\
\text { influence (no EU } \\
\text { carrot) }\end{array}$ & Non-compliant \\
\hline
\end{tabular}

\subsection{Conclusion}

Vachudova $(2015$, p. 524) has already noted that 'the great variation in outcomes even across the EU's ten new post-communist members underscores that many details of domestic reform have largely been determined by domestic factors'. This seems also to be the case when we look at the census processes in Croatia, Bosnia and Macedonia. In all of these countries the census outcomes are used for proportional representation, which led to different degrees of census politicisation. Whereas in Croatia there was very little debate, there were long and still ongoing disputes in Bosnia and the Macedonian census was cancelled due to disagreements on the methodology. These outcomes are also almost mirrored when looking at the levels of state capacity. While Croatia has better scores than EU member states Romania and Bulgaria, Macedonia's scores are weak and those of Bosnia are very weak. The analysis has shown that state capacity is insufficient to explain the variation in compliance with the EU census regulations.

Even though Croatia was close to EU accession before the last census, there was no strong external pressure with regard to the census. The censuses in Bosnia and Macedonia were both observed by an International Monitoring Observation. In Bosnia the IMO was quite extensive and also EU pressure was high. This was less the case in Macedonia where there was only a 'light' IMO and there was not much pressure from the EU since accession negotiations are at a standstill. The case of Bosnia shows that strong external influence can tip the balance in favour of a complete census, which however is still internally contested. The case of Macedonia demonstrates that in the absence of a strong push from external actors, domestic actors are in a position to block the census process.

In Croatia, the political domestic actors did not have much influence in the census. The cases of Bosnia and Macedonia, however, show that domestic actors can have a negative influence on census processes, especially if political actors want to hijack the census process and/or its results for their advantage. In Bosnia there was and still is a dispute on how to define the total residence population as the outcomes might influence the ethnic 
homogeneity of the territories of the Federations. In Macedonia, there was also no clear definition of the total population and the in- or exclusion of the diaspora population. This is connected to the threshold outlined in the Ohrid Framework Agreement according to which minorities making up more than $20 \%$ are granted more rights.

This analysis shows that state capacity is insufficient to explain the variation in compliance with the EU census regulations. This means that structural issues alone cannot explain compliance patterns. Agency, especially of domestic actors, can be very strong and should not be underestimated. In the case of Bosnia, the EU as external actor was able to tip the balance in favour of compliance, but in Macedonia, the EU had very little power to overcome the discrepancies which occurred during the census enumeration. 

Chapter 7

Conclusion 


\subsection{Introduction}

On the path of EU enlargement the Western Balkan countries have the same conditions to comply with. These consist of the political-the Copenhagen Criteria-as well as the technical conditions-the acquis communautaire, which outlines the full body of EU rules and norms. These countries, however, show very different compliance patterns. This is particularly the case when looking at their population and housing census, which is part of the $18^{\text {th }}$ acquis chapter on statistics. Whereas some countries had few complications with the collection of population data and included all the EU regulations (such as Croatia), others had to cope with serious delays throughout the process and discussion about which definitions should be used (Bosnia) or even failed to finish the census enumeration data due to methodological differences (Macedonia). This thesis has looked into the reasons why there is such a variation when it comes to compliance with the EU census regulations in Croatia, Bosnia and Macedonia even though they all had the same EU conditions to comply with. The overall research question is thus: What accounts for the variation in compliance with the EU census regulations in Croatia, Bosnia and Macedonia?

Looking at the variation in census-taking is important, as the census is the backbone of most statistics, as well as being used for policy-making within the national context and the EU, for example for the distribution of funds and subsidies (Everaers, 2015, p. 185). As such the population census is part of the preconditions for European membership. However, as the census data is also used to allocate resources, ultimately some profit more than others, which makes census processes highly political-even more so, when rights of minority and ethnic groups are connected to the census outcomes, as is the case in the Western Balkans (see also Chapter 4).

The analysis of the variation in census-taking within the context of Europeanisation provides more insights into the compliance behaviour of enlargement countries using the example of one particular aspect of the acquis communautaire. To achieve this, first the Europeanisation and the operationalisation of compliance with the EU census regulations has been outlined (see chapter 2). Several sub-questions have been investigated using the additional coverage mixed methods model (Morgan, 2014), which combined in-depth interviews and expert survey data (see Chapter 3). The first sub-question analysed whether in the absence of EU rules on collecting ethno-cultural data, it is possible to speak of the Europeanisation of censustaking (Chapter 4). The second sub-question analysed the mechanisms of Europeanisation (conditionality and legitimacy) in order to assess their effectiveness (Chapter 5) and the third sub-question compared the influence of structural aspects of state capacity with the influence of domestic and external agency (Chapter 6). 
This conclusion will first elaborate the main findings of the overall thesis and its separate chapters. Second, it will put these findings together in order to answer the overall research question. Third, the contribution to the academic literature will be outlined in more detail, as well as the generalisability of the findings. Fourth, it will reflect on the limitations of this research and suggest further avenues of enquiry; finally, policy recommendations will be presented.

\subsection{Main findings}

The main findings of this thesis unfold in three steps. First, the analysis shows that especially if rights and proportional representation of power are connected to the census outcomes, this can politicise and seriously hinder census processes. Second, by accepting or disputing the EU census regulations, domestic actors can respectively either facilitate or obstruct the compliance with the EU census regulations. This is related to the first aspect, because the acceptance of the EU census regulations depends on the potential gain or loss of power based on the census outcomes for the domestic actors. Third, depending on the available rewards and direct pressure of the EU, the EU might be able to overcome domestic disputes and tip the balance in favour of compliance. These findings will now be elaborated within the frameworks of the separate sub-questions and chapters in more detail.

Chapter 2 introduced the theoretical background of Europeanisation and in particular what needs to be taken into account when it comes to external Europeanisation, the influence of the EU on non-members of the EU, in this case enlargement countries. This chapter also outlined the EU census regulations and how compliance is assessed in this thesis.

Chapter 3 described the overall research design which is based on a mixed methods approach. The data collection strategy of this thesis is innovative and provides an excellent example of mixed methods research. It combines 28 in-depth interviews with an expert survey, collected among 75 census experts in two rounds with a response rate of $69 \%$ and $50 \%$ respectively. The use of the additional coverage mixed methods model as research design enabled the analysis of the phenomenon of census-taking from the broader perspective of 'Europeanisation', as well as from the local perspective of the case countries, Croatia, Macedonia and Bosnia.

Chapter 4 addressed the fact that with regard to sensitive census questions on ethno-cultural data (ethnicity, language and religion), there is no coherent EU approach. This chapter answered the first sub-question of this thesis (Can we speak of Europeanisation of census-taking, in the absence of concrete rules on collecting ethno-cultural data?). Even though data on ethno-cultural characteristics is not required by the EU, all Western Balkan 
countries asked for ethno-cultural data in their census questionnaires. Simon (2011) has shown that there is a wide variety of practices within Europe on how to collect identity data. That there is no direct agreement on how to collect data on ethnicity and cultural characteristics has been confirmed by the expert survey. The survey also demonstrated that there are different degrees in sensitivity in ethno-cultural data: ethnicity and religion are seen as most sensitive, whereas language and citizenship-data often used for policy-making-are regarded as less sensitive. A comparison of the three countries' census questionnaires and methodologies showed that they have very different approaches on how to collect ethno-cultural data, not always in line with the international recommendations of the UNECE (United Nations Economic Commission for Europe, 2006). Croatia's census questionnaire was the least in line with the UNECE census recommendations, as the questionnaire provided answer categories, before an open-answer field, whereas the Bosnian census questionnaire was a bit more in line with the recommendations as it first presented an open-answer field and only afterwards provided answer categories. The Macedonian census questionnaire was in line with the UNECE census recommendations; however this is also the only census that failed due to domestic disputes on the census methodology.

In addition, Chapter 4 highlighted the paradox of counting ethnic and cultural data. Population groups that are not acknowledged by data officially do not exist and do not get a voice. Defining groups and linking their categories to proportional representation can lead to the politicisation and delay (in the case of Bosnia) or even failure of census processes (in the case of Macedonia). In all of the case countries, census outcomes are not only linked to policy-making, but also to rights: in Croatia these are linked to minority rights; in Bosnia, the Dayton Peace Agreement divided the political system among the three constituent ethnic groups ('Bosniak', 'Croat' and 'Serb') based on the 1991 census; and in Macedonia, the Ohrid Framework Agreement outlines that ethnic groups making up more than $20 \%$ of the population are granted language and minority rights. In Croatia and Bosnia there seems to be a preference for the national 'ethnic' packages. ${ }^{34} \mathrm{Col}$ lecting data on ethno-cultural characteristics is thus very problematic. By making the census a condition for enlargement, the EU requires the countries to engage in the process of census-taking and its consequences. Chapter 4 showed that there are no EU concrete rules (explicit compliance) and no agreement among census experts (implicit compliance) on how to collect ethno-cultural data, and therefore it is not possible to speak of Europeanisation with regard to this aspect. While Europeanisation in that chapter was assessed through the explicit and implicit compliance with the EU census

\footnotetext{
34 For Croatia, this is Croatian and in Bosnia these are the constituent ethnic groups of Bosniaks (formerly also known as ethnic Muslims (Đečević, Vuković-Ćalasan, \& Knežević, 2017)), Bosnian Serbs and Bosnian Croats.
} 
regulations, the following chapters (5 and 6) analysed Europeanisation as the direct influence of the EU on the census processes.

Chapter 5 analysed the impact of the EU with regard to compliance with the EU census regulations in Croatia, Bosnia and Macedonia. In order to do so, it looked at the effectiveness of two Europeanisation mechanisms (conditionality and legitimacy) while analysing the compliance of the three case countries with the EU census regulations. This was assessed on the one hand via a rational-choice cost/benefit calculation, in which the EU rewards and pressure were weighed against the costs and potential losses of domestic actors, in the Europeanisation mechanism of conditionality. In counterpoint, this chapter also assessed the perceived legitimacy, the acceptance and/or the contestation behind compliance with the EU census regulations, in the Europeanisation mechanism of legitimacy. Congruence analysis (Blatter \& Haverland, 2012) was used to compare these two mechanisms. In Bosnia and Macedonia the domestic adoption costs were high. In Macedonia, where there were few EU rewards or pressure and very high domestic adoption costs, the census failed. In Bosnia, however, the EU rewards and pressure through the recent membership application tipped the balance towards compliance with the EU census regulations and meeting the deadline for the publication of the census results. The mechanism of legitimacy had very little influence in Bosnia and Macedonia, but Croatia had a strong focus on following the EU census regulations. However, there the mechanism of conditionality could not explain the compliance with the EU census regulations. Both mechanisms therefore are considered as important, which confirms that conditionality alone cannot fully explain the compliance with the EU regulations. However, the analysis also showed that in all cases the effectiveness of the mechanisms differed and there is no one-size-fits-all model of Europeanisation that can explain compliance with the EU census regulations. Nonetheless these findings also highlight the importance of investigating the domestic aspects in more detail, which was then done in Chapter 6.

This chapter analysed the structural aspect of state capacity, but also the agency of domestic and external actors in Croatia, Bosnia and Macedonia to assess the importance of these factors for the compliance with the EU census regulations. This chapter used four of the World Bank Governance Indicators to compare the state capacity of the case countries. As expected for an EU member state, Croatia had rather high scores for state capacity and fully met the EU requirements. However, although Macedonia had higher scores for state capacity than Bosnia, this census completely failed, while Bosnia in the end managed to publish its census data in line with the international regulations and within the deadline given by the EU. The analysis showed that unlike what the literature (Börzel, 2013; Elbasani, 2013a) suggests, state capacity is not able to fully explain the variance in census outcomes in the case countries, and in order to provide a fuller explanation of 
the census processes, this chapter also analysed the agency of the domestic and external actors. Domestic agency is often a hidden and unrecognised factor in state-building processes-and as the analysis showed, is also underestimated in census-taking processes. With the exception of Croatia, there was a high interest in the census process and results on the part of domestic actors. In Macedonia, domestic actors even tried to circumvent the international census recommendations in order to increase the census results to their advantage. In Bosnia, the Statistical Institute of the Republika Srpska still does not accept the published census results (Republika Srpska Institute of Statistics, 2016). This chapter also analysed the influence of the EU as an external actor. This influence varied, depending on the carrots and sticks at the EU's disposal. For Croatia, which at the time of the census already had a set date for its accession, there was little or no influence by the EU. In Macedonia, the EU did not have sufficient influence to guarantee reliable results nor to stop the census from failing. In Bosnia, however, the EU was able to push the long-delayed census process towards the publication of the census data by July 2016. The analysis thus showed the importance of domestic actors in facilitating or obstructing census processes. Not only the National Statistical Institutes, but also the local politicians can seriously hinder and/or prolong the census processes, as in Bosnia and Macedonia. In such instances the EU can intervene, which in the case of Bosnia led to delayed compliance with the EU regulations, which considering timeliness is denoted as partial compliance. In Macedonia, the EU rewards and pressure were not strong enough to counter the local contestations surrounding the census. These varying cases demonstrate that domestic actors should not be underestimated and can be crucial in census-taking.

Table 11: Relevant factors for census-taking in Croatia, Bosnia and Macedonia

\begin{tabular}{|c|c|c|c|c|c|c|}
\hline & $\begin{array}{l}\text { Compliance } \\
\text { with EU } \\
\text { regulations }\end{array}$ & $\begin{array}{l}\text { Ethno-cultural } \\
\text { characteristics }\end{array}$ & $\begin{array}{l}\text { Europeanisation } \\
\text { mechanism }\end{array}$ & $\begin{array}{l}\text { State } \\
\text { capacity }\end{array}$ & $\begin{array}{l}\text { Domestic } \\
\text { actors }\end{array}$ & $\begin{array}{l}\text { EU as external } \\
\text { actor }\end{array}$ \\
\hline Croatia & $\begin{array}{l}\text { Full } \\
\text { compliance }\end{array}$ & Yes & Legitimacy & Strong & $\begin{array}{l}\text { Little } \\
\text { interest }\end{array}$ & Little interest \\
\hline Bosnia & $\begin{array}{l}\text { Partial } \\
\text { compliance }\end{array}$ & Yes & Conditionality & $\begin{array}{l}\text { Very } \\
\text { weak }\end{array}$ & $\begin{array}{l}\text { High } \\
\text { interest }\end{array}$ & High interest \\
\hline Macedonia & $\begin{array}{l}\text { Non- } \\
\text { compliance }\end{array}$ & Yes & $\begin{array}{l}\text { None of them } \\
\text { strong enough }\end{array}$ & Weak & $\begin{array}{l}\text { High } \\
\text { interest }\end{array}$ & $\begin{array}{l}\text { Medium } \\
\text { interest }\end{array}$ \\
\hline
\end{tabular}

The findings of these empirical chapters reveal important insights into the factors that can influence census processes (see also Table 11). So what accounts for the variation in compliance with the EU census regulations?

Croatia's compliance with the EU census regulations can be best explained by the strong positive impact of the Europeanisation mechanism of legitimacy, and by the fact that the census was not much contested. There 
was little pressure by the EU to complete this census, but Croatia's scores for state capacity are even higher than the ones for EU member states Romania and Bulgaria, and compared to Bosnia and Macedonia, there was little interest in the census outcomes on the part of domestic actors. Even though the collection of ethno-cultural characteristics was least in line with the international recommendations of the UNECE, Croatia did comply with the EU census regulations and its census is also part of the EU census hub, which collects the population data of all EU member states.

The census processes in Bosnia and Macedonia were much more complicated than the one in Croatia. In Bosnia the process was long delayed due to domestic disputes on first the census law and later the census methodology. Although the country has very weak scores for state capacity, it managed to in the end publish the population data. This was however not possible without help from the EU. Besides financing a large part of the census, the EU also put pressure on Bosnia's authorities to advance the census process. This is why in Bosnia the Europeanisation mechanism of conditionality was able to outweigh the domestic adoption cost and the EU is an important external actor. However, the census results are still not fully accepted by all domestic actors in the country, which shows that the domestic circumstances, in this case the ethnic make-up of the population and the background of the Dayton Peace Agreement, as well as the interest in the census data by domestic actors, should not be underestimated in census processes.

With better state capacity scores than Bosnia, Macedonia might be expected to have the capacity to successfully collect population data, however its 2011 census was aborted a couple of days after the enumeration started. Neither one of the two Europeanisation mechanisms was very strong, as the enlargement process of Macedonia is at a standstill. Domestic interest in the census results, however, was very high. Although most in line with the UNECE census recommendations on how to collect ethno-cultural data, the whole census process was highly politicised and could not guarantee a reliable population count. Linking census outcomes to proportional representation made the census an instrument of manipulation to potentially increase/decrease political power.

\subsection{Contribution to the literature}

By analysing census-taking in the Western Balkans within EU enlargement, this thesis contributes to literature on census and categorisation practices, and the framework of Europeanisation. Chapter 2 of this thesis highlighted the difference between internal and external Europeanisation, the influence of the EU on members and non-members respectively and broadened the scope of Europeanisation research by analysing compliance of enlargement 
countries with the specific requirements of the acquis communautaire. By using different angles of Europeanisation this thesis shows the explicit compliance with the EU census regulations, but also the differences when it comes to implicit compliance, such as the collection of ethno-cultural data. By analysing the direct influence of the EU through the Europeanisation mechanisms of conditionality and legitimacy it builds on the literature of for example Noutcheva (2012); Schimmelfennig and Sedelmeier (2004), but by analysing compliance with one particular aspect of the acquis, this thesis opens up a new research arena for Europeanisation research. In addition, research on Europeanisation has neglected the influence of domestic processes (Elbasani, 2013a; Mastenbroek, 2005). By analysing the domestic factors this thesis brings the domestic perspective back into Europeanisation research.

Chapter 3 is an example of how mixed methods research, in particular the additional coverage model of Morgan (2014), can be applied as research design. This chapter showed how in-depth interview data can be combined with data collected via a two-round expert survey.

By building on the existing literature on the construction of categories (Hacking, 2007; Kertzer \& Arel, 2002b; Nobles, 2000; Ruppert, 2011; Yanow, 2003), Chapter 4 highlighted the paradox of collecting ethno-cultural data, which addresses the need and complications that can occur when collecting this sensitive data. All case countries collected data on ethno-cultural characteristics, which are not required by the EU; however as minority and language rights are linked to the proportional representation of the population, the collection of this data becomes a necessity. This chapter adds to recent research on censuses in the Western Balkans which focuses on the construction of national identity through the census categories (Bieber, 2015), the aspect of ethnicity (Daskalovski, 2013; Visoka \& Gjevori, 2013) as well as the politics behind the population count (Daskalovski, 2013; Keil \& Perry, 2015). Such politics are also relevant in other geographical contexts (Leibler \& Breslau, 2005; Urla, 1993), and confirm the importance of the domestic context in census processes.

In addition, the analysis in Chapter 4 shows that census processes are never purely technical, but highly political. Nonetheless the census is part of the seemingly technical requirements for EU enlargement, the acquis communautaire. EU enlargement is embedded within the academic literature on Europeanisation. This strand of literature has so far focused on models for how to analyse the transformative power of the EU (Grabbe, 2006; Schimmelfennig \& Sedelmeier, 2004) and general compliance behaviour (Noutcheva, 2009; Schimmelfennig, 2005), or has looked into the political criteria for EU accession (Glüpker, 2013; Mendelski, 2013). By analysing census-taking, one specific aspect of the acquis, this research provides insights into the compliance behaviour of accession countries with the seemingly technical conditions for membership. The analysis in Chapter 5 strengthens 
previous Europeanisation research, which states that with regard to the mechanisms of Europeanisation, the rational-choice model of conditionality alone cannot fully explain the compliance behaviour of accession countries and that the perceived legitimacy of the EU rules is also an important factor (Noutcheva, 2009). In addition, it shows that there is no one-size-fits-all Europeanisation model, as the effectiveness of conditionality and legitimacy varies in each case.

Chapter 6 builds on the literature on Europeanisation, but also on the importance of the domestic factors in EU enlargement processes (Elbasani, 2013b). By analysing the influence of domestic and external actors, this chapter contributes to the debate on whether institutional factors or the agency of actors matters in Europeanisation processes. Unlike what other scholars (Börzel, 2013; Elbasani, 2013a) have suggested, the analysis showed that the institutional aspect of state capacity was not sufficient in explaining the difference in census outcomes; the influence of actors, however, and especially the domestic ones, was very strong in Bosnia and Macedonia. Depending on the strength of the EU pressure and rewards, the EU as an external actor can potentially also influence the compliance with the census regulations. The analysis, especially in the cases of Bosnia and Macedonia, has shown that the importance of the domestic actors should not be underestimated in Europeanisation research.

\subsection{Generalisability of the findings}

The variations in census outcomes show that, especially because the domestic circumstances are so significant to the census outcomes, it is not possible to generalise directly from the findings with regard to the Europeanisation mechanisms. The findings of this research are very context-specific and only to some extent generalisable to other cases. However, there are some aspects that can be taken from this research. One of them is that the domestic circumstances and actors play an important role and should be taken into account in research assessing the mechanisms of Europeanisation.

Another aspect this thesis has highlighted by analysing one specific aspect of the acquis is that even though the acquis is regarded as rather technical, the process of census-taking is highly political and is indirectly connected to the political criteria of EU membership, the Copenhagen Criteria. This is an important aspect and can be taken as an example when studying other chapters of the acquis, for example Chapter 19 which focuses on social policy and employment, or the aspect of anti-discrimination, which is also connected to minority rights and therewith the Copenhagen Criteria.

With regard to the broader context of census-taking, it has already been shown that the collection of ethno-cultural data does not only have serious 
consequences in the Western Balkan countries, but for example also in Spain (Urla, 1993) and Israel/Palestine (Leibler \& Breslau, 2005). The finding of this thesis that the domestic context (where, for example, rights are linked to census outcomes as is the case with the Ohrid agreement) and actors (here mainly ethnically based politicians) are important, is not only generalisable to research on Europeanisation, but also to research on censuses.

Finally, also with regard to the methods used in this project, there is limited generalisability. The application of the two rounds of questions, the Delphi method, in the expert survey provided for interesting exploratory insights and the possibility for feedback which would not have been possible with only one questionnaire. In addition, the interviews provided crucial explanatory insights into the different cases. The use of the additional coverage mixed methods design of this study provides an example for researchers who would like to engage in mixed methods research by combining and collecting indepth interview and survey data.

\subsection{Limitations and suggestions for further research}

This research project faced some limitations, mostly methodological but sometimes more practical considerations.

The first limitation is related to access to interviewees, which is a practical consideration. Since census experts are a rather select group, it was not always possible to speak to the National Statistical Institutes, however in such cases former employees of these institutes and people from other international organisations were interviewed. Nonetheless due to the finite number of census experts, there might be a potential bias of the people directly involved in the census processes. In order to prevent this bias from affecting the results of this research, also people working in the EU institutions, for example at the EU Delegations and Eurostat, were interviewed and official documents and reports as well as newspaper articles were consulted.

The second limitation is also connected to the fact that there are not many census experts. The survey was administered to some of the same people who gave interviews, and instead of selecting a sample the whole population of census exerts was approached. The survey questions differed from the questions asked in the interview, but asking the same people for an in-depth interview and a two-round survey put considerable pressure on the respondents. Nonetheless a vast majority of the approached census experts were willing to fill in the first round of the survey questionnaire, and half of them also participated in the second round. Consequently the response rate was rather high with $69 \%$ in the first and $50 \%$ in the second round.

Besides these limitations, there are also aspects which are worthy of further investigation, such as how the different modes of data collection used in 
census-taking affect the population data. The EU allows for different modes of collecting population data, such as the register-based census in the Netherlands, a mixed mode census in Germany and the traditional census which is applied in the Western Balkans. This has been researched from a methodological point of view in order to ensure the comparability of the findings, but it would be interesting to analyse whether and how these different modes of data collection can for example influence the collection and harmonisation of sensitive data on ethnicity, language and religion or be used for a cross-country comparison of, for example, migration statistics.

Another avenue for further research relates to the use of census data. The focus of this project was mostly on the difficulties of collecting population data; but it was not possible to further investigate how this data is actually used in the domestic, but also the EU context. It is known that the connection of rights to census outcomes leads to the politicisation of the census and can lead to domestic contestation; however less is known about the consequences which derive from this. Not only is this relevant in the case countries, but also for example when looking at the censuses in Kosovo and Moldova, where due to territorial disputes and boycotts the census did not cover all of the municipalities. Research on the use and consequences of census data can be done qualitatively, but also by a mixed methods research design. For example the survey collected for this project could be adjusted into a longitudinal panel design with multiple waves in order to investigate the dynamics on attitudes towards census-related issues and practices in the EU and the UNECE region. Such a survey could also include the Russian-speaking experts, in order to widen the scope of the research.

The last suggestion for further research concerns the implications of census data on policy processes, as well as the other way around: how policymaking can potentially influence census processes. Examples of similar research investigate the constructs of race and ethnicity in the United States (Yanow, 2003) and the nexus between the census, racial categories and citizenship (Nobles, 2000). Most of these empirical examples however focus on the United States or Brazil and only little research has been done in the European context or with regard to other census categories, for example country of origin. More research on these aspects is highly recommended.

\subsection{Policy recommendations}

Beyond the academic implications highlighted above, this research also raises interesting aspects for the 2020 census round ${ }^{35}$ and policy-making.

Within the current EU enlargement policy there is a lack of attention given to the domestic context and actors. Identifying that "civil society and stake-

35 This round includes all censuses from 2015 until 2024. 
holders' require a stronger role in the accession process in the enlargement strategy of 2016 (European Commission, 2016b) was a step in the right direction, however more can be done to take into account other domestic actors, besides the civil society and also the domestic context. This thesis has shown that the influence of domestic actors involved in the census processes should not be underestimated, as since the census data is connected to rights and numerical thresholds, political domestic actors can potentially gain or lose power. The direct influence of the EU on census processes depends very much on the means at the EU's disposal and the domestic willingness to comply with the EU rules. This was especially visible in Bosnia and Macedonia, where there was strong influence of the domestic actors in the census processes. Within the enlargement strategy, the EU and Eurostat should pay even more attention to the domestic context and actors, especially when it comes to census-taking.

If domestic contestation of the census is likely, there should be additional attention on the census law and the definitions in the census methodology and questionnaire. Not only has this been problematic in Macedonia, where there was no clear definition on 'place of usual residence', but also in Bosnia, where although there is a clear definition, the question on 'place of usual residence' still seems to be an issue of debate. The census law and methodology should contain exact definitions of the census questions and categories, but the domestic actors involved should also agree with these, in order to prevent contestation and protest.

The analysis has shown that better scores on state capacity or previous experience in census-taking cannot be taken as a guarantee for a good population count. This was highlighted by the case of Macedonia, where even though the country had experience with census-taking, politicians doubted the census results even before it had taken place. Therefore international observers and the EU need to pay more attention to the domestic developments and potential contestations of the census processes in the Western Balkans.

In general, there should be more awareness that censuses are always political processes and can feed existing tensions. Since census data is used for policy-making ultimately some will profit and others will lose on the basis of the census data. There should also be more awareness of the political implications that are inherent to census-taking, especially if the census results are linked to peace agreements and minority rights. Especially if rights and proportional representation are linked to the census outcomes, appropriate measures, for example additional supervision through monitoring missions and/or a clear agreement on the census regulations by all actors involved, should be taken in order to ensure a reliable census. This thesis has shown that, although the census is based on statistical procedures and regulations, it ultimately remains highly politicised. 
References 
AAM Consulting. (2013). Technical assistance to population and housing census - Phase II - Final report.

Agency for Statistics Bosnia and Herzegovina [Agencija za statistiku Bosne i Hercegovine]. (2013). Multilingual forms. Sarajevo. Retrieved from www.bhas.ba/Popis\%202013/ BHAS_Visejezicna_zbirka_BH.pdf

Agency for Statistics Bosnia and Herzegovina [Agencija za statistiku Bosne i Hercegovine]. (2016). Census of population, households and dwellings in Bosnia and Herzegovina, 2013 Final results. Sarajevo.

Aichholzer, G. (2009). Das ExpertInnen-Delphi: Methodische Grundlagen und Innovationen im Bereich 'Technology-Foresight'. In A. Bogner, B. Littig, and W. Menz (Eds.), Experteninterviews: Theorien, Methoden, Anwendungsfelder. Wiesbaden: VS Verlag für Sozialwissenschaften.

Anastasakis, O. (2008). The EU's political conditionality in the Western Balkans: Towards a more pragmatic approach. Southeast European and Black Sea Studies, 8(4), 365-377. doi:10.1080/14683850802556384

Anderson, B. (2006). Imagined communities: Reflections on the origin and spread of nationalism. London and New York: Verso.

Arel, D. (2002). Language categories in censuses: Backward- or forward-looking? In D. I. Kertzer \& D. Arel (Eds.), Census and identity: The politics of race, ethnicity, and language in national censuses. Cambridge University Press.

Armakolas, I., \& Maksimovic, M. (2014). Memory and the uses of the wartime past in contemporary Bosnia and Herzegovina: The case of the Bosniak campaign for the October 2013 popu-

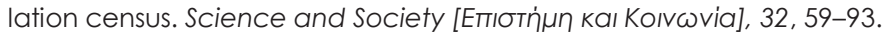

Atanasova, G., \& Bache, I. (2010). Europeanization and F.Y.R. Macedonia: Towards a compound polity? Southeast European and Black Sea Studies, 10(1), 85-96. doi:10.1080/146838510 03606762

Aybet, G., \& Bieber, F. (2011). From Dayton to Brussels: The impact of EU and NATO conditionality on state building in Bosnia \& Hercegovina. Europe-Asia Studies, 63(10), 1911-1937. doi:10.1080/09668136.2011.618706

Balkans in Europe Policy Group. (2015). Unraveling the political crisis in Macedonia: Toward resolution or calm before the storm? Retrieved from http://www.suedosteuropa.unigraz.at/biepag/ node/158

Barnett, M., \& Zürcher, C. (2008). The peacebuilder's contract: How external statebuidling reinforces weak statehood. In R. Paris \& T. D. Sisk (Eds.), The dilemmas of statebuilding: Confronting the contradictions of postwar peace operations (pp. 23-52). New York: Taylor \& Francis.

Bieber, F. (2004). Institutionalizing ethnicity in the Western Balkans. Managing change in deeply divided societies. European Centre for Minority Issues Working Paper, 19, 1-27.

Bieber, F. (2011). Building impossible states? State-building strategies and EU membership in the Western Balkans. Europe-Asia Studies, 63(10), 1783-1802. doi:10.1080/09668136.2011.618679

Bieber, F. (2013). Bosnia census: When counting counts. Retrieved from Balkan Insight, http://www.balkaninsight.com/en/blog/when-counting-counts-the-bosnian-census

Bieber, F. (2015). The construction of national identity and its challenges in Post-Yugoslav censuses. Social Science Quarterly, 96(3), 873-903. doi:10.1111/ssqu.12195

Blatter, J., \& Haverland, M. (2012). Designing case studies: Explanatory approaches in small-n research. Basingstoke: Palgrave Macmillan.

Bochsler, D., \& Schläpfer, B. (2015). An indirect approach to map ethnic identities in post-conflict societies. Ethnopolitics, 15(5), 467-486. doi:10.1080/17449057.2015.1084744

Boeije, H. (2005). Analyseren in kwalitatief onderzoek: denken en doen. Amsterdam: Boom onderwijs.

Bogner, A., Littig, B., \& Menz, W. (2009). Interviewing experts. Palgrave Macmillan UK.

Böhmelt, T., \& Freyburg, T. (2017). Forecasting candidate states' compliance with EU accession rules, 2017-2050. Journal of European Public Policy, 1-19. doi:10.1080/13501763.2017.1348385

Börzel, T. A. (2002). Member state responses to Europeanization. JCMS: Journal of Common Market Studies, 40(2), 193-214. doi:10.11111/1468-5965.00351 
Börzel, T. A. (2013). When Europeanization hits limited statehood: The Western Balkans as a test case for the transformative power of Europe. In A. Elbasani (Ed.), European integration and transformation in the Western Balkans: Europeanization or business as usual? London and New York: Routledge Chapman \& Hall.

Börzel, T. A., Hofmann, T., Panke, D., \& Sprungk, C. (2010). Obstinate and enefficient: Why member states do not comply with European law. Comparative Political Studies, 43(11), 13631390. doi:10.1177/0010414010376910

Börzel, T. A., \& Lebanidze, B. (2017). "The transformative power of Europe" beyond enlargement: the EU's performance in promoting democracy in its neighbourhood. East European Politics, 33(1), 17-35. doi:10.1080/21599165.2017.1280473

Börzel, T. A., \& Risse, T. (2000). When Europe hits home: Europeanization and comestic Change. European Integration online Papers (EloP), 4(15).

Börzel, T. A., \& Risse, T. (2003). Conceptualizing the domestic impact of Europe. In K. Featherstone \& C. M. Radaelli (Eds.), The Politics of Europeanization. Oxford: Oxford University Press.

Börzel, T. A., \& Risse, T. (201 la). From Europeanisation to diffusion: Introduction. West European Politics, 35(1), 1-19. doi:10.1080/01402382.2012.631310

Börzel, T. A., \& Risse, T. (2011b). When Europeanisation meets diffusion: Exploring new territory. West European Politics, 35(1), 192-207. doi:10.1080/01402382.2012.634543

Börzel, T. A., \& Schimmelfennig, F. (2017). Coming together or drifting apart? The EU's political integration capacity in Eastern Europe. Journal of European Public Policy, 24(2), 278-296. doi:10.1080/13501763.2016.1265574

Bourne, A., \& Cini, M. (2006). Introduction. In M. Cini \& A. Bourne (Eds.), Palgrave Advances in European Union Studies. Basingstoke: Palgrave Macmillan.

Bringa, T. R. (1993). Nationality categories, national identification and identity formation in "multinational" Bosnia. Anthropology of East Europe Review, 11 (1\&2), 80-89.

Broeders, D., \& Dijstelbloem, H. (2016). The Datafication of Mobility and Migration Management: the Mediating State and its Consequences. In I. v. d. Ploeg \& J. Pridmore (Eds.), Digitizing Identities: Doing Identity in a Networked World (pp. 242-260). London: Routledge.

Brunnbaver, U. (2002). The implementation of the Ohrid Agreement: Ethnic Macedonian resentments. Journal on Ethnopolitics and Minority Issues in Europe (1), 1-24.

Bulmer, S. (2007). Theorizing Europeanization. In P. Graziano \& M. Vink (Eds.), Europeanization: New Research Agendas. Basingstoke and New York: Palgrave Macmillan.

Bundeszentrale für politische Bildung. (2013). Bevölkerung nach demografischen Strukturmerkmalen. Retrieved from http://www.bpb.de/nachschlagen/zahlen-und-fakten/soziale-situationin-deutschland/169557/themengrafik-demografische-merkmale

Caporaso, J. (2007). The three worlds of regional integration theory. In P. Graziano \& M. Vink (Eds.), Europeanization: New Research Agendas. Basingstoke and New York: Palgrave Macmillan.

Chandler, D. (2010). The EU and Southeastern Europe: The rise of post-liberal governance. Third World Quarterly, 31 (1), 69-85. doi:10.1080/01436590903557330

Chandler, D. (2013). Peacebuilding and the politics of non-linearity: Rethinking 'hidden' agency and 'resistance'. Peacebuilding, 1 (1), 17-32. doi:10.1080/21647259.2013.756256

Commission of the European Communities. (2009). Commission Regulation (EC) No 1201/2009 of 30 November 2009 implementing Regulation (EC) 763/2008 of the European Parliament and the Council on population and housing censuses as regards the technical specifications of the topics and of their breakdowns. Brussels: Official Journal of the European Union.

Cooley, L., \& Mujanović, J. (2016). Population politics in Bosnia and Herzegovina: A reply to Bochsler and Schläpfer. Ethnopolitics, 15(5), 487-492. doi:10.1080/17449057.2016.1190159

Creswell, J. W., \& Plano Clark, V. L. (2011). Designing and conducting mixed methods research. Los Angeles: SAGE Publications.

Creswell, J. W., Plano Clark, V. L., Gutmann, M. L., \& Hanson, W. E. (2003). Advanced mixed methods research designs. In A. Tashakkori \& C. Teddlie (Eds.), Handbook of Mixed Methods in Social \& Behavioral Research (pp. 209-240). Thousand Oaks, London, New Delhi: SAGE Publications. 
Croatian Bureau of Statistics. (2011). Census of population, households and dwellings 2011, first results by settlements. Zagreb.

Croatian Bureau of Statistics. (2013a). Press release on releasing the results of the census of population, households and dwellings in the Republic of Croatia in 2011 [Press release]. Retrieved from www.dzs.hr/Eng/important/PressCorner/PressRelease/census201 1_3.pdf

Croatian Bureau of Statistics. (n.d.). Census of population, households and dwellings 2011 : Notes on methodology. Retrieved from http://www.dzs.hr/default_e.htm

Croatian News Agency. (2016, 12 October). Eurostat: Bosnia census results valid. EBL News. Retrieved from https://eblnews.com/news/balkan/eurostat-bosnia-census-results-valid-40062

Croatian Parliament. (2010). Decision on the adoption of the act on the Census of Population, Households and Dwellings in the Republic of Croatia in 2011. Zagreb. Retrieved from http://www.dzs.hr/Eng/censuses/census2011/regulations/censusact.htm

Curtis, B. (2001). The politics of population: State formation, statistics, and the census of Canada, 1840-1875. University of Toronto Press.

Daskalovski, Z. (2013). Census taking and inter-ethnic relations in Macedonia. Southeast European and Black Sea Studies, 13(3), 365-379. doi:10.1080/14683857.2013.812773

Đečević, M., Vuković-Ćalasan, D., \& Knežević, S. (2017). Re-designation of ethnic Muslims as Bosniaks in Montenegro. East European Politics and Societies, 31(1), 137-157. doi:10.1177/0888 325416678042

Delcour, L. (2013). Meandering Europeanisation. EU policy instruments and policy convergence in Georgia under the Eastern Partnership. East European Politics, 29(3), 344-357. doi:10.1080/2159 9165.2013.807804

Denti, D. (2014). The Europeanisation of candidate countries: The case for a shift to the concept of EU member-state building. Contemporary Southeastern Europe, 1 (1), 9-32.

Desrosières, A. (1998). The politics of large numbers: A history of statistical reasoning. Cambridge and London: Harvard University Press.

Deutsche Welle. (2016, 25 September). Bosnian Serbs defy Sarajevo with referendum for a national holiday. Deutsche Welle. Retrieved from http://dw.com/p/2QZTf

Dillman, D. A., Smyth, J. D., \& Christian, L. M. (2014). Internet, phone, mail, and mixed-mode surveys: The tailored design method. Hoboken: Wiley.

Director of the Agency for Statistics of Bosnia and Herzegovina. (n.d.). Methodology for preparation, organization and taking the 2013 census in BiH. Retrieved from http://www.bhas.ba/ Popis\%202013/Metodology\%20-\%20eng.pdf

Durr, J.-M., Bianchini, R., Demirci, M., Kostadinova-Daslakovska, K., \& Pieraccini, G. (2013). Steering committee of the international monitoring operation on the population and housing censuses in Bosnia and Herzegovina: Thirteenth assessment report, 27 September-18 October 2013.

Durr, J.-M., \& Demirci, M. (2016). Steering committee of the international monitoring operation on the population and housing censuses in Bosnia and Herzegovina: Twenty-second assessment report.

Elbasani, A. (2013a). Europeanization travels to the Western Balkans: Enlargement strategy, domestic obstacles and diverging reforms. In A. Elbasani (Ed.), European integration and transformation in the Western Balkans: Europeanization or business as usual? (pp. 3-21). London and New York: Routledge Chapman \& Hall.

Elbasani, A. (Ed.) (2013b). European integration and transformation in the Western Balkans: Europeanization or business as usual? London and New York: Routledge Chapman \& Hall.

Eigmüller, M. (2013). Europeanization from below: The influence of individual actors on the EU integration of social policies. Journal of European Social Policy, 23(4), 363-375. doi:10.1177/095892 8713507467

European Commission. (2006). Screening report Croatia.

European Commission. (2007). Accession Negotiations - Croatia - Draft Common Position. Brussels.

European Commission. (2010a). Commission Regulation (EU) No 519/2010 of 16 June 2010 adopting the programme of the statistical data and of the metadata for population and housing 
census provided for by Regulation (EC) No 763/2008 of the European Parliament and of the Council. Brussels: Official Journal of the European Union.

European Commission. (2010b). Commission Regulation (EU) No 1151/2010 of 8 December 2010 implementing Regulation (EC) No 763/2008 of the European Parliament and of the Council on population and housing censuses, as regards the modalities and structure of the quality reports and the technical format for the data transmission. Brussels: Official Journal of the European Union.

European Commission. (2011 a). Croatia 2011 progress report. Brussels.

European Commission. (2011b). Enlargement strategy and main challenges 2011-2012. Brussels. Retrieved from http://ec.europa.eu/enlargement/pdf/key_documents/2013/package/strategy_ paper_2013_en.pdf

European Commission. (2013a). Chapters of the acquis. EU enlargement. Retrieved from http://ec.europa.eu/enlargement/policy/conditions-membership/chapters-of-the-acquis/ index_en.htm

European Commission. (2013b). The former Yugoslav Republic of Macedonia 2013 progress report.

European Commission. (2014a). Bosnia and Herzegovina progress report.

European Commission. (2014b). Conditions for membership. Retrieved from http://ec.europa.eu/ enlargement/policy/conditions-membership/index_en.htm

European Commission. (2014c). Statistical requirements compendium. Luxembourg: Publications Office of the European Union.

European Commission. (2015a). 2015 enlargement package. Retrieved from http://europa.eu/ rapid/press-release_MEMO-15-6040_en.htm

European Commission. (2015b). EU Enlargement Strategy. Retrieved from https://ec.europa.eu/ neighbourhood-enlargement/sites/near/files/pdf/key_documents/2015/20151110_strategy_ paper_en.pdf

European Commission. (2015c). Reform agenda for Bosnia and Herzegovina 2015-2018.

European Commission. (2016a). From 6 to 28 members. Retrieved from https://ec.europa.eu/ neighbourhood-enlargement/policy/from-6-to-28-members_en

European Commission. (2016b). 2016 Communiation on EU enlargement policy. Brussels. Retrieved from https://ec.europa.eu/neighbourhood-enlargement/sites/near/files/pdf/key_documents/ 2016/20161109_strategy_paper_en.pdf

European Commission. (2018a). Bosnia and Herzegovina 2018 Report. Retrieved from https://ec.europa.eu/neighbourhood-enlargement/sites/near/files/20180417-bosnia-andherzegovina-report.pdf

European Commission. (2018b). Communication from the Commission to the European Parliament, the Council, the European Economic and Social Committee and the Committee of the Regions - A credible enlargement perspective for and enhanced EU engagement with the Western Balkans.

European Parliament. (2016). European Parliament Resolution of 14 April 2016 on the 2015 Report on Bosnia and Herzegovina (2015/2897(RSP)).

European Parliament \& Council of the European Union. (2008). Regulation (EC) No 763/2008 of the European Parliament and the Council of 9 July 2008 on Population and Housing Censuses. Official Journal of the European Union.

European Statistical System. (n.d.). Census hub. Retrieved from https://ec.europa.eu/Census Hub2/query.do?step=selectHyperCube\&qhc=false

Eurostat. (2014). 2011 Population census framework: Factsheet on population censuses in the Enlargement countries. Retrieved from https://circabc.europa.eu/sd/a/aa6b9065-45f5-48f79262-0a067584b48b/EU_Enlargement_countries_census_Factsheets_upd-Mar2014.pdf

Everaers, P. (2015). The 2011 round of population and housing censuses in the Western Balkans: A comparative analysis with a focus on ethnicity and citizenship. Contemporary Southeastern Europe, 2(2), 184-194.

Featherstone, K. (2003). Introduction: In the name of 'Europe'. In K. Featherstone \& C. M. Radaelli (Eds.), The Politics of Europeanization. Oxford: Oxford University Press. 
Featherstone, K., \& Radaelli, C. M. (Eds.). (2003). The Politics of Europeanization. Oxford: Oxford University Press.

Freedom House. (2017). Freedom in the world 2017. Retrieved from https://freedomhouse.org/ sites/default/files/FH_FIW_2017_Report_Final.pdf

Freyburg, T., \& Richter, S. (2010). National identity matters: The limited impact of EU political conditionality in the Western Balkans. Journal of European Public Policy, 17(2), 263-281. doi:10.1080/13501760903561450

Friedman, V. (2002). Observing the observers: Language, ethnicity, and power in the 1994 Macedonian census and beyond. Political Essays, 3(4).

Fukuyama, F. (2013). What is governance? Governance, 26(3), 347-368. doi:10.1 111 /gove.12035

Gawrich, A., Melnykovska, I., \& Schweickert, R. (2010). Neighbourhood Europeanization through ENP: The case of Ukraine. JCMS: Journal of Common Market Studies, 48(5), 1209-1235. doi:10.1111/j.1468-5965.2010.02110.x

George, A. L., \& Bennett, A. (2005). Case studies and theory development in the social sciences. Cambridge and London: MIT Press.

Georgescu, C. M. (2014). Europeanization imagology, historical institutionalism and integration: Comparative politics of institutional change in governance. The Free Library.

Glüpker, G. (2013). Effectiveness of EU conditionality in the Western Balkans: Minority rights and the fight against corruption in Croatia and Macedonia. Journal of Contemporary European Research, 9(2), 223-241.

Goldschneider, C. (2002). Ethnic categorization in censuses: comparative observations from Israel, Canada, and the United States. In D. I. Kertzer \& D. Arel (Eds.), Census and identity: The politics of race, ethnicity, and language in national censuses. Cambridge University Press.

Grabbe, H. (2003). Europeanization goes East: Power and uncertainty in the EU accession process. In K. Featherstone \& C. M. Radaelli (Eds.), The Politics of Europeanization. OUP Oxford.

Grabbe, H. (2006). The EU's transformative power: Europeanization through conditionality in Central and Eastern Europe. Palgrave Macmillan.

Graziano, P., \& Vink, M. (2007). Europeanization: New research agendas. Basingstoke and New York: Palgrave Macmillan.

Graziano, P., \& Vink, M. (2013). Europeanization: Concept, theory, and methods. In S. Bulmer \& C. Lesquene (Eds.), The member states of the European Union (pp. 31-54). Oxford University Press.

Greenberg, R. D. (2004). Language and identity in the Balkans: Serbo-Croatian and its disintegration. Oxford: Oxford University Press.

Haas, E. B. (1958). The uniting of Europe: Political, social, and economic forces, 1950-1957. Stanford University Press.

Hacking, I. (2007). Kinds of people: Moving targets. Proceedings of the British Academy, 151, 285318.

Hall, P. A. (2006). Systematic process analysis: When and how to use it. European Management Review, 3(24), 24-31.

Hartlapp, M., \& Falkner, G. (2009). Problems of operationalization and data in EU compliance research. European Union Politics, 10(2), 281-304. doi:10.1177/1465116509103370

Hoh, A.-L. (2015). The 2011 census in Croatia: A (partial) role model for the Western Balkans? Contemporary Southeastern Europe, 2(2), 65-83.

Hoh, A.-L. (2017a). Counting for what purpose? The paradox of including ethnic and cultural questions in the censuses of Croatia, Bosnia and Macedonia. Südosteuropa, 65(1), 125-148.

Hoh, A.-L. (2017b). 'When counting counts': Europeanisation of census-taking in Croatia, Bosnia and Herzegovina and the Former Yugoslav Republic of Macedonia. Journal of Contemporary European Research, 13(1), 980-996.

Holt, J., \& Manning, N. (2014). Fukuyama is right about measuring state quality: Now what? Governance, 27(4), 717-728. doi:10.1111/gove.12109

Hsu, C.-C., \& Sandford, B. A. (2007). The Delphi technique: Making sense of consensus. Practical Assessment, Research \& Evaluation, $12(10)$. 
Huddleston, T., Niessen, J., \& Tjaden, T. J. (2013). Using EU indicators of immigrant integration: Final report for Directorate General for Home Affairs. Brussels.

Ivankova, N. V., Creswell, J. W., \& Stick, S. L. (2006). Using mixed-methods sequential explanatory design: From theory to practice. Field Methods, 18(1), 3-20. doi:10.1177/1525822X05282260

Jepperson, R. L. (1991). Institutions, institutional effect, and institutionalism. In W. W. Powell \& P. J. DiMaggio (Eds.), The New Institutionalism in Organizational Analysis. University of Chicago Press.

Johnson, R. B., Onwuegbuzie, A. J., \& Turner, L. A. (2007). Toward a definition of mixed methods research. Journal of Mixed Methods Research, 1 (2), 112-133. doi:10.1177/1558689806298224

Jordanovski, Z., \& Dimevski, S. (2011, 18 October). Ethnischer Zwist stoppt Volkszählung in Mazedonien. Deutsche Welle. Retrieved from http://www.dw.com/de/ethnischer-zwist-stopptvolksz\%C3\%A4hlung-in-mazedonien/a-15466103

Josipovič, D. (2015). Slovenia and the census: From the 20. century Yugoslav counts to the register-based census of 2011. Contemporary Southeastern Europe, 2(2), 159-175.

Jukic, E. M. (2013, 3 October). Bosnian NGO's call for boycott of census. Balkan Insight. Retrieved from http://www.balkaninsight.com/en/article/bosnian-ngos-call-for-census-boycott

Juncos, A. E. (2012). Member state-building versus peacebuilding: The contradictions of EU statebuilding in Bosnia and Herzegovina. East European Politics, 28(1), 58-75. doi:10.1080/13523 279.2011 .635650

Kaufmann, D., Kraay, A., \& Mastruzzi, M. (2007). Worldwide Governance Indicators project: Answering the critics. World Bank Policy Research Working Paper Series, 4149.

Kaufmann, D., Kraay, A., \& Mastruzzi, M. (2010). The Worldwide Governance Indicators: Methodology and analytical Issues. World Bank Policy Research Working Paper, 5430.

Keil, S. (2013a). Europeanization, state-building and democratization in the Western Balkans. In S. Keil (Ed.), State-building in the Western Balkans: European approaches to democratization. New York: Routledge.

Keil, S. (Ed.) (2013b). State-building in the Western Balkans: European approaches to democratization. London and New York: Routledge.

Keil, S. (2015). Conclusion: The politics of numbers-Censuses in the post-Yugoslav states. Contemporary Southeastern Europe, 2(2), 176-183.

Keil, S., \& Perry, V. (2015). Introduction: The politics of numbers in the post-Yugoslav states. Contemporary Southeastern Europe, 2(2), 43-49.

Keranen, O. (2013). International statebuilding as contentious politics: The case of post conflict Bosnia and Herzegovina. In S. Keil (Ed.), State-building in the Western Balkans: European approaches to democratization. London and New York: Routledge.

Kertzer, D. I., \& Arel, D. (2002a). Censuses, identity formation, and the struggle for political power. In D. I. Kertzer \& D. Arel (Eds.), Census and identity: The politics of race, ethnicity, and language in national censuses. Cambridge University Press.

Kertzer, D. I., \& Arel, D. (Eds.). (2002b). Census and identity: The politics of race, ethnicity, and language in national censuses. Cambridge University Press.

Kohler-Koch, B. (1996). Catching up with change: The transformation of governance in the European Union. Journal of European Public Policy, 3(3), 359-380. doi:10.1080/13501769608407039

Kraler, A., Reichel, D., \& Entzinger, H. (2015). Migration statistics in Europe: a core component of governance and population research. In P. Scholten, H. Entzinger, R. Penninx, \& S. Verbeek (Eds.), Integrating Immigrants in Europe: Research-Policy Dialogues (pp. 39-58). Cham: Springer International Publishing.

Kraske, M. (2017). State capture in the Balkans: L'état c'est nous! Perspectives_Political Analysis and Commentary, 3.

Krasner, S. D. (Ed.) (2001). Problematic sovereignty: Contested rules and political possibilities. New York: Columbia University Press.

Krasner, S. D., \& Risse, T. (2014). External actors, state-building, and service provision in areas of limited statehood: Introduction. Governance, 27(4), 545-567. doi:10.1111/gove.12065 
Ladurner, U. (2017, 10 February). Es reicht ein Streichholz. Zeit Online. Retrieved from http://www.zeit.de/politik/ausland/2017-02/johannes-hahn-kommissar-eu-erweiterungwestbalkanstaaten

Lee, M. M., \& Zhang, N. (2017). Legibility and the informational foundations of state capacity. The Journal of Politics, 79(1), 118-132. doi:10.1086/688053

Leech, N. L., \& Onwuegbuzie, A. J. (2009). A typology of mixed methods research designs. Quality \& Quantity, 43(2), 265-275. doi:10.1007/s1 $1135-007-9105-3$

Leibler, A., \& Breslau, D. (2005). The uncounted: Citizenship and exclusion in the Israeli census of 1948. Ethnic and Racial Studies, 28(5), 880-902. doi:10.1080/01419870500158919

Lightfoot, S., \& Szent-Iványi, B. (2014). Reluctant donors? The Europeanization of international development policies in the new member states. JCMS: Journal of Common Market Studies, 52(6), 1257-1272. doi:10.1111/jcms.12141

Linstone, H. A., \& Turoff, M. (2002). The Delphi method: Techniques and applications. AddisonWesley Pub. Co.

Lottholz, P., \& Lemay-Hébert, N. (2016). Re-reading Weber, re-conceptualizing state-building: From neo-Weberian to post-Weberian approaches to state, legitimacy and state-building. Cambridge Review of International Affairs, 1-18. doi:10.1080/09557571.2016.1230588

Lutovska, K. (2010). A tale of two censuses. Southeast European Time.

March, J. G., \& Olsen, J. P. (1983). The new institutionalism: Organizational factors in political life. American Political Science Review, 78(3), 734-749. doi:10.2307/1961840

March, J. G., \& Olsen, J. P. (1989). Rediscovering institutions: The organizational basis of politics. New York: The Free Press.

Marko, J. (2013). Ethnopolitics and constitutional reform in Bosnia-Herzegovina. In O. Listhaug \& S. P. Ramet (Eds.), Bosnia-Herzegovina since dayton: Civic and uncivic values. Ravenna: Longo Angelo.

Marusic, S. J. (2011a, 13 October). Macedonia scraps 'failed' census. Balkan Insight. Retrieved from http://www.balkaninsight.com/en/article/macedonian-population-census-fails

Marusic, S. J. (2011b, 11 October). Macedonian census commission resigns. Balkan Insight. Retrieved from http://www.balkaninsight.com/en/article/macedonian-census-commissionresigns

Marusic, S. J. (2011C, 15 August). Macedonian population census planned for October. Balkan Insight. Retrieved from http://www.balkaninsight.com/en/article/all-set-for-macedonianhead-count-in-october

Marusic, S. J. (2016, 16 May). Activists' enthusiasm powers Macedonia's 'colourful revolution'. Balkan Insight. Retrieved from http://www.balkaninsight.com/en/article/activist-senthusiasm-drives-macedonia-s-colorful-revolution--05-13-2016

Mastenbroek, E. (2005). EU compliance: Still a 'black hole'? Journal of European Public Policy, 12(6), 1103-1120. doi:10.1080/13501760500270869

Mendelski, M. (2013). Where does the European Union make a difference? Rule of law development in the Western Balkans and beyond. In A. Elbasani (Ed.), European integration and transformation in the Western Balkans: Europeanization or business as usual? London and New York: Routledge Chapman \& Hall.

Meuser, M., \& Nagel, U. (2009). Experteninterviews und der Wandel der Wissensproduktion. In A. Bogner, B. Littig, \& W. Menz (Eds.), Experteninterviews: Theorien, Methoden, Anwendungsfelder. Wiesbaden: VS Verlag für Sozialwissenschaften.

Migdal, J. S. (1988). Strong societies and weak states: State-society relations and state capabilities in the Third World. Princeton, N.J.: Princeton University Press.

Milekic, S. (2014, 13 August). Croatia referendum ruling less clear than it seems. Balkan Insight. Retrieved from http://www.balkaninsight.com/en/blog/croatia-referendum-ruling-less-clearthan-it-seems

Moravcsik, A. (1993). Preferences and power in the European Community: A liberal intergovernmentalist approach. JCMS: Journal of Common Market Studies, 31 (4), 473-524. doi:10.1111/ j.1 1468-5965.1993.tb00477.x 
Moravcsik, A. (2005). The European constitutional compromise and the neofunctionalist legacy. Journal of European Public Policy, 12 (2), 349-386. doi:10.1080/13501760500044215

Morgan, D. L. (2014). Integrating qualitative and quantitative methods: A pragmatic approach. Thousand Oaks: SAGE Publications.

Musaj, M. (2015). Kosovo 2011 census: Contested census within a contested state. Contemporary Southeastern Europe, 2(2), 84-98.

Nikolić, M. D., \& Trimajova, L. (2015). A tale of two Serbias? Census-taking in 2002 and 2011. Contemporary Southeastern Europe, 2(2), 142-158.

Nobles, M. (2000). Shades of citizenship: Race and the census in modern politics. Stanford: Stanford University Press.

Nobles, M. (2002). Racial categorization and censuses. In D. I. Kertzer \& D. Arel (Eds.), Census and identity: The politics of race, ethnicity, and language in national censuses. Cambridge University Press.

Noutcheva, G. (2009). Fake, partial and imposed compliance: The limits of the EU's normative power in the Western Balkans. Journal of European Public Policy, 16(7), 1065-1084. doi: $10.1080 / 13501760903226872$

Noutcheva, G. (2012). European foreign policy and the challenges of Balkan accession: Conditionality, legitimacy and compliance. New York: Routledge.

Noutcheva, G., \& Aydin-Düzgit, S. (2012). Lost in Europeanisation: The Western Balkans and Turkey. West European Politics, 35(1), 59-78. doi:10.1080/01402382.2012.631313

Noutcheva, G., \& Bechev, D. (2008). The successful laggards: Bulgaria and Romania's accession to the EU. East European Politics \& Societies, 22 (1), 1 14-144. doi:10.1177/0888325407311793

Official Journal of the European Communities. (2000). Council Directive 2000/43/EC of 29 June 2000 implementing the principle of equal treatment between persons irrespective of racial or ethnic origin.

Official Journal of the European Union. (2015). Stabilisation and Association Agreement between the European Communities and their Member States, of the one part, and Bosnia and Herzegovina, of the other part.

Onwuegbuzie, A. J., \& Leech, N. L. (2005). Taking the "Q" out of research: Teaching research methodology courses without the divide between quantitative and qualitative paradigms. Quality and Quantity, 39(3), 267-295. doi:10.1007/s1 1135-004-1670-0

OSCE. (2001). Ohrid Framework Agreement. Skopje: Organization for Security and Co-operation in Europe. Retrieved from: www.osce.org/skopje/100622?download=true

OSCE High Commissioner on National Minorities. (2012). The Ljubljana Guidelines on Integration of Diverse Societies. Retrieved from: www.osce.org/hcnm/ljubljana-guidelines? download=true

Papadimitriou, D., \& Petrov, P. (2012). Whose rule, whose law? Contested statehood, external leverage and the European Union's rule of law mission in Kosovo. JCMS: Journal of Common Market Studies, 50(5), 746-763. doi:10.1111/j.1468-5965.2012.02257.x

Pavelic, B. (2012, 18 December). Croatia sees population drop over decade. Balkan Insight. Retrieved from http://www.balkaninsight.com/en/article/census-croatia-lost-150-thousandin-a-decade

Pavelic, B. (2013, 3 January). Croatia to introduce Cyrillic script to Vukovar. Balkan Transitional Justice. Retrieved from http://www.balkaninsight.com/en/article/croatia-to-introducecyrillic-to-vukovar

Pavelic, B. (2014, 12 August). Croatia's language dispute leaves minorities nervous. Balkan Transitional Justice. Retrieved from http://www.balkaninsight.com/en/article/croatia-s-languagedispute-leaves-minorities-nervous-1

Perry, V. (2013). The 2013 census in Bosnia and Herzegovina. DPC, Policy Note (New Series \#3).

Perry, V. (2015). To count or not to count? That is the question. Retrieved from http://www.democratizationpolicy.org/to-count-or-not-to-count--that-is-the-question

Perry, V. (2016). Some census findings that caught my eye. Retrieved from http://dpc.djikic.com/ some-census-findings-that-caught-my-eye

Petričušić, A. (2002). Constitutional law on the rights of national minorities in the Republic of Croatia. European Yearbook of Minority Issues, 2 (3), 607-629. 
Petričušić, A. (2008). Nation-building in Croatia and the treatment of minorities: Rights and wrongs. L'Europe en Formation, 3, 135-1 45.

Plano Clark, V. L., Garrett, A. L., \& Leslie-Pelecky, D. L. (2010). Applying three strategies for integrating quantitative and qualitative databases in a mixed methods study of a nontraditional graduate education program. Field Methods, 22 (2), 154-174. doi:10.1177/1525822X09357174

Popis. (2013). Popis stanovništva priprema za referendum u Republici Srpskoj. Retrieved from http://popis2013.net/index.php?docid=968

Prifti, E. (Ed.) (2013). The European future of the Western Balkans: Thessaloniki@10 (2003-2013). Paris: European Union Institute for Security Studies.

Qehaja, F., \& Prezelj, I. (2017). Issues of local ownership in Kosovo's security sector. Southeast European and Black Sea Studies, 1-17. doi:10.1080/14683857.2017.1324279

Radaelli, C. M. (2000). Whither Europeanization? Concept stretching and substantive change. European Integration online Papers (EloP), 4 (8).

Radaelli, C. M. (2002). The domestic impact of European Union Public Policy: notes on concepts, methods, and the challenge of empirical research. Politique européenne, 5(1), 105-136. doi:10.3917/poeu.005.0105

Radaelli, C. M. (2006). Europeanization: Solution or problem? In M. Cini \& A. Bourne (Eds.), Palgrave advances in European Union Studies (pp. 56-76). Basingstoke: Palgrave USA.

Radaelli, C. M., \& Pasqiver, R. (2007). Conceptual Issues. In P. Graziano \& M. Vink (Eds.), Europeanization: New Research Agendas. Basingstoke and New York: Palgrave Macmillan.

Recknagel, C. (2016, 30 June). Bosnia erupts in feuding over new census data. Radio Free Europe/Radio Liberty. Retrieved from http://www.rferl.org/content/bosnia-census-results-sparkfeuding/27831 183.html

Republic of Croatia, \& Croatian Bureau of Statistics. (2011). Personal questionnaire census 2011. Retrieved from www.dzs.hr/Eng/censuses/census2011/forms/P1-WEB.pdf

Republic of Macedonia State Statistical Office. (2010). Law on census of population, households and dwellings in the Republic of Macedonia, 2011.

Republic of Macedonia State Statistical Office. (2011). Methodology for preparing, organizing and implementing the census of population, households and dwellings in the Republic of Macedonia, 2011. Skopje.

Republic of Macedonia State Statistical Office. (n.d.). Enumeration form.

Republika Srpska Institute of Statistics. (2016). Open book on the census in BiH 2013. Retrieved from: www2.rzs.rs.ba/static/uploads/bilteni/popis/otvorena_knjiga/Open_book_on_Census_ web.pdf

RFE/RL. (2016, 27 May). EU urges Bosnia to publish census figures to gain membership. Radio Free Europe/ Radio Liberty. Retrieved from http://www.rferl.org/content/eu-urges-bosnia-publishcensus-figures-gaim-membership-ethnic-dispute-/27760330.html

Risse, T. (2011). Governance in areas of limited statehood: Introduction and overview. In T. Risse (Ed.), Governance without a state? Policies and politics in areas of limited statehood. New York: Columbia University Press.

Rubin, H. J., \& Rubin, I. S. (2011). Qualitative interviewing: The art of hearing data. Thousand Oaks: SAGE Publications.

Ruppert, E. (2007). Producing population. CRESC Working Paper No. 37, 1-32.

Ruppert, E. (2011). Population objects: Interpassive subjects. Sociology, 45(2), 218-233. doi:10.1177/0038038510394027

Ruppert, E., Isin, E., \& Bigo, D. (2017). Data politics. Big Data \& Society, 4(2), 1-7. doi:10.1 177/20539 51717717749

Salentin, K., \& Schmeets, H. (2017). Sampling immigrants in the Netherlands and Germany. Comparative Migration Studies, 5(1), 21. doi:10.1186/s40878-017-0062-2

Schimmelfennig, F. (2005). Strategic calculation and international socialization: Membership incentives, party constellations, and sustained compliance in Central and Eastern Europe. International Organization, 59(04), 827-860. doi:10.1017/\$0020818305050290 
Schimmelfennig, F. (2014). Enlargement and integration capacity: A framework of analysis. MAXCAP Working Paper Series. Retrieved from userpage.fu-berlin.de/kfgeu/maxcap/system/ files/enlargement_and_integration_capacity-a_framework_for_analysis.pdf

Schimmelfennig, F., \& Sedelmeier, U. (2004). Governance by conditionality: EU rule transfer to the candidate countries of Central and Eastern Europe. Journal of European Public Policy, 11 (4), 661-679. doi:10.1080/1350176042000248089

Schimmelfennig, F., \& Sedelmeier, U. (2005a). The Europeanization of Central and Eastern Europe. Ithaca and London: Cornell University Press.

Schimmelfennig, F., \& Sedelmeier, U. (2005b). The politics of EU enlargement: Theoretical and comparative perspectives. In F. Schimmelfennig \& U. Sedelmeier (Eds.), The politics of European Union enlargement. London and New York: Routledge.

Schimmelfennig, F., \& Sedelmeier, U. (2006). The study of EU enlargement: Theoretical approaches and empirical findings. In M. Cini \& A. Bourne (Eds.), Palgrave Advances in European Union Studies: Palgrave Macmillan.

Schimmelfennig, F., \& Sedelmeier, U. (2007). Candidate countries and conditionality. In P. Graziano \& M. Vink (Eds.), Europeanization: New research agendas. Basingstoke and New York: Palgrave Macmillan.

Schmeets, H. (forthcoming 2018). How World Bank Governance Indicators may predict the assessment of elections by international observers: Evidence from the OSCE region. Nordic Journal of Human Rights, 38(1).

Schneckener, U. (2011). State building or new modes of governance? The effects of international involvement in areas of limited statehood. In T. Risse (Ed.), Governance without a state? Policies and politics in areas of limited statehood (pp. 232-261). New York: Columbia University Press.

Schulte Nordholt, E. (2014). Introduction to the Dutch census 2011. In Statistics Netherlands (Ed.), Dutch census 2011: Analysis and methodology. Den Haag/Heerlen: Statistics Netherlands. Retrieved from https://www.cbs.nl/NR/rdonlyres/5FDCE1B4-0654-45DA-8D7E-807A0213DE66/ 0/2014b57pub.pdf.

Schulte Nordholt, E., Ossen, S., \& Haas, P. (2013). Research on the quality of registers to make data decisions in the Dutch Virtual Census. Revista de Demografía Histórica, 89-105.

Sedelmeier, U. (201 1). Is Europeanisation through conditionality sustainable? Lock-in of institutional change after EU accession. West European Politics, 35(1), 20-38. doi:10.1080/014023 82.2012.631311

Sekulic, D., Massey, G., \& Hodson, R. (1994). Who were the Yugoslavs? Failed sources of a common identity in the former Yugoslavia. American Sociological Review, 59(1), 83-97.

Shaw, S. J. (1978). The Ottoman census system and population, 1831-1914. International Journal of Middle East Studies, 9(03), 325-338. doi:10.1017/\$0020743800033602

Simmons, B. A. (1998). Compliance with international Aagreements. The Annual Review of Political Science, 1 .

Simon, P. (2005). The measurement of racial discrimination: The policy use of statistics. International Social Science Journal, 57(183), 9-25. doi:10.111 1/j.0020-8701.2005.00528.x

Simon, P. (2008). The choice of ignorance: The debate on ethnic and racial statistics in France. French Politics, Culture \& Society, 26(1), 7-31. doi:10.3167/fpcs.2008.260102

Simon, P. (2011). Collecting ethnic statistics in Europe: A review. Ethnic and Racial Studies, 35 (8), 1366-1391. doi:10.1080/01419870.2011.607507

Simon, P., \& Piché, V. (2011). Accounting for ethnic and racial diversity: The challenge of enumeration. Ethnic and Racial Studies, 35(8), 1357-1365. doi:10.1080/01419870.2011.634508

Skocpol, T. (1985). Bringing the state back in: Strategies of analysis in current research. In P. B. Evans, D. Rueschemeyer, \& T. Skocpol (Eds.), Bringing the State Back In. Cambridge: Cambridge University Press.

Spendzharova, A. B., \& Vachudova, M. A. (2012). Catching up? Consolidating liberal democracy in Bulgaria and Romania after EU accession. West European Politics, 35(1), 39-58. doi:10.1080/01402382.2012.631312 
Steinmo, S. (2008). Historical institutionalism. In D. Della Porta \& M. Keating (Eds.), Approaches and Methodologies in the Social Sciences: A Pluralist Perspective (pp. 118-138). Cambridge: Cambridge University Press.

Steunenberg, B., \& Dimitrova, A. (2007). Compliance in the EU enlargement process: The limits of conditionality. European Integration online Papers, 11.

Strelkov, A. (2016). The EU and rule of law promotion in Western Balkans: A new role for candidate states' parliaments. East European Politics, 1-20. doi:10.1080/21599165.2016.1228529

Tashakkori, A., \& Teddlie, C. (2003). Handbook of mixed methods in social \& behavioral research. Thousand Oaks, London, New Delhi: SAGE Publications.

Tatalović, S. (2006). National minorities and Croatian demoracy. Politička misao, 43(5), 45-59.

Teddlie, C., \& Tashakkori, A. (2003). Major issues and controversies in the use of mixed methods in the Social and Behaviorial Sciences. In A. Tashakkori \& C. Teddlie (Eds.), Handbook of mixed methods in social \& behavioral research. Thousand Oaks, London, New Delhi: SAGE Publications.

Toe, R. (2016a, 19 May). Bosnia Statistics Agency vows to publish census. Balkan Insight. Retrieved from http://www.balkaninsight.com/en/article/bosnia-s-statistical-agency-approves-programto-publish-census-results-05-18-2016

Toe, R. (2016b, 30 June). Bosnia to publish census without Serb agreement. Balkan Insight. Retrieved from http://www.balkaninsight.com/en/article/bosnia-to-release-long-awaitedcensus-results-on-thursday-06-29-2016

Toe, R. (2016c, 30 June). Census reveals Bosnia's changed demography. Balkan Insight. Retrieved from http://www.balkaninsight.com/en/article/new-demographic-picture-of-bosnia-finallyrevealed-06-30-2016

Toe, R. (2016d, 12 January). Publish 2013 census data, EU urges Bosnia. Balkan Insight. Retrieved from http://www.balkaninsight.com/en/article/eu-urges-bosnia-to-publish-data-from-censusin-light-of-future-application-01-11-2016

Toe, R. (2016e, 11 March). Squabbles over data put Bosnian census at risk. Balkan Insight. Retrieved from http://www.balkaninsight.com/en/article/still-no-agreement-on-publication-ofresults-bosnian-census-03-10-2016

Trauner, F. (2009). From membership conditionality to policy conditionality: EU external governance in South Eastern Europe. Journal of European Public Policy, 16(5), 774-790. doi:10.1080/135017 60902983564

Turoff, M. (2002). The policy Delphi. In H. A. Linstone \& M. Turoff (Eds.), The Delphi method: Techniques and applications (pp. 80-96). Addison-Wesley Pub. Co.

United Nations Economic Commission for Europe. (2006). Conference of European Statisticians recommendations for the 2010 censuses of population and housing. New York and Geneva: United Nations Publication.

United Nations Economic Commission for Europe. (2014). Measuring population and housing Practices of UNECE countries in the 2010 round of censuses. Geneva: United Nations Publication.

United Nations Economic Commission for Europe. (n.d.). Geographical scope. Retrieved from http://www.unece.org/oes/nutshell/region.html

United Nations Statistics Division. (2013). 2010 world population and housing census programme. Retrieved from http://unstats.un.org/unsd/demographic/sources/census/censusdates.htm

Urla, J. (1993). Cultural politics in an age of statistics: Numbers, nations, and the making of Basque identity. American Ethnologist, 20(4), 818-843. doi:10.2307/646233

Vachudova, M. A. (2005). Europe undivided: Democracy, leverage, and integration after communism. Oxford: Oxford University Press.

Vachudova, M. A. (2014). EU leverage and national interests in the Balkans: The puzzles of enlargement ten years on. Journal of Common Market Studies, 52(1), 122-138. doi:10.1111/jcms.12081

Vachudova, M. A. (2015). External actors and regime change: How post-communism transformed comparative politics. East European Politics and Societies and Cultures, 29(2), 519530 . 
Valente, P. (2010). Census taking in Europe: How are populations counted in 2010? Population and Societies, 467, 1-4.

van der Plank, P. H. (2012). Effects of Habsburg edcuational policies measured by census statistics. Jezikoslovlje, 13(2), 373-393.

Vasilev, G. (2013). Multiculturalism in post-Ohrid Macedonia: Some philosophical reflections. East European Politics \& Societies, 27(4), 685-708. doi:10.1177/0888325413484924

Versluis, E. (2004). Explaining variations in implementation of EU directives. European Integration online Papers, 8(19).

Versluis, E. (2007). Even rules, uneven practices: Opening the 'black box' of EU law in action. West European Politics, 30(1), 50-67. doi:10.1080/01402380601019647

Vink, M., \& Graziano, P. (2007). Challenges of a new research agenda. In P. Graziano \& M. Vink (Eds.), Europeanization: New Research Agendas. Basingstoke and New York: Palgrave Macmillan.

Visoka, G., \& Gjevori, E. (2013). Census politics and ethnicity in the Western Balkans. East European Politics, 29(4), 1-20. doi:10.1080/21599165.2013.819349

Vos, K. J. (2006). Europeanization and convergence in industrial relations. European Journal of Industrial Relations, 12 (3), 31 1-327. doi:10.1177/0959680106068915

Vrgova, R. (2015). Census, identity, and the politics of numbers: The case of Macedonia. Contemporary Southeastern Europe, 2(2), 107-125.

Vuković, I. (2015). Population censuses in Montenegro: A century of national identity "repacking". Contemporary Southeastern Europe, 2(2), 126-141.

Woelk, J. (2013). EU member state-building in the Western Balkans: (Prolonged) EU-protectorates or new model of sustainable enlargement? Conclusion. Nationalities Papers, 41 (3), 469-482. doi:10.1080/00905992.2013.768978

Yanow, D. (2003). Constructing "race" and "ethnicity" in America: Category-making in public policy and administration. New York: M.E. Sharpe.

Yousuf, M. I. (2007). Using experts' opinions through Delphi technique. Practical Assessment, Research \& Evaluation, 12(4). 

Appendices 


\section{Appendix 1: Regulation (EC) No 763/2008 of the European Parliament and the Council of 9 July 2008 on Population and Housing Censuses}

REGULATION (EC) No 763/2008 OF THE EUROPEAN PARLIAMENT AND OF THE COUNCIL

of 9 July 2008

on population and housing censuses

(Text with EEA relevance)

THE EUROPEAN PARLIAMENT AND THE COUNCIL OF THE EUROPEAN UNION,

Having regard to the Treaty establishing the European Community, and in particular Article 285(1) thereof,

Having regard to the proposal from the Commission,

Acting in accordance with the procedure laid down in Article 251 of the Treaty $\left({ }^{1}\right)$

Whereas:

(1) The Commission (Eurostat) needs to be in possession of sufficiently reliable, detailed and comparable data on the population and housing, in order to enable the Community to fulfil the tasks assigned to it, in particular by Articles 2 and 3 of the Treaty. Sufficient comparability must be ensured at Community level as regards methodology, definitions and the programme of the statistical data and the metadata.

(2) Periodic statistical data on the population and the main family, social, economic and housing characteristics of persons are necessary for the study and definition of regional, social and environmental policies affecting particular sectors of the Community. In particular, there is a need to collect detailed information on housing in support of various Community activities, such as the promotion of social inclusion and the monitoring of socia cohesion at regional level, or the protection of the environment and the promotion of energy efficiency.

(3) In view of methodological and technological developments best practices should be identified and the enhancement of the data sources and methodologies used for censuses in the Member States should be fostered.

(4) In order to ensure the comparability of the data provided by the Member States and for reliable overviews to be drawn up at Community level, the data used should refer to the same reference year.

(1) Opinion of the European Parliament of 20 February 2008 (not yet published in the Official Journal) and Council Decision of 23 June publish 2008 .
(5) In accordance with Council Regulation (EC) No 322/97 of 17 February 1997 on Community Statistics $\left({ }^{2}\right)$, which constitutes the reference framework for the provisions of this Regulation, it is necessary for the collection of statistics to conform to the principles of impartiality, in particular objectivity and scientific independence, as well as transparency, reliability, relevance, cost-effectiveness and statistical confidentiality.

(6) The transmission of data subject to statistical confidentiality is governed by Regulation (EC) No 322/97 and Counci Regulation (Euratom, EEC) No $1588 / 90$ of 11 June 1990 on the transmission of data subject to statistical confidentiality to the Statistical Office of the European Communities $\left({ }^{3}\right)$. Measures that are taken in accordance with those Regulations ensure the physical and logical protection of confidential data and that no unlawful disclosure or nonstatistical use occurs when Community statistics are produced and disseminated.

(7) In the production and dissemination of Community statistics under this Regulation, the national and Community statistical authorities should take account of the principles set out in the European Statistics Code of Practice adopted on 24 February 2005 by the Statistical Programme Committee, established by Council Decision 89/382/EEC, Euratom $\left({ }^{4}\right)$ and attached to the Recommendation of the Commission on the independence, integrity and accountability of the national and Community statistical authorities.

(8) Since the objectives of this Regulation, namely the collection and compilation of comparable and comprehensive Community statistics on population and housing, cannot be sufficiently achieved by the Member States, due to the absence of common statistical features and quality requirements as well as a lack of methodological transparency, and can therefore, by way of a common statistical framework, be better achieved at Community level, the Community may adopt measures, in accordance with the principle of subsidiarity as set out in Article 5 of the Treaty. In accordance with the principle of proportionality, as set out in that Article, this Regulation does not go beyond what is necessary in order to achieve those objectives.

( $\left.{ }^{2}\right)$ OJ L $52,22.2 .1997$, p. 1. Regulation as amended by Regulation (EC) No $1882 / 2003$ of the European Parliament and of the Council (O) L $284,31.10 .2003$, p. 1)

(3) Ol L 151, 15.6.1990, p. 1. Regulation as last amended by Regulation (EC) No $1882 / 2003$.

(4) OJ L $181,28.6 .1989$, p. 47. 
(9) The measures necessary for the implementation of this Regulation should be adopted in accordance with Council Decision 1999/468/EC of 28 June 1999 laying down the procedures for the exercise of implementing powers conferred on the Commission $\left({ }^{1}\right)$.

(10) In particular, the Commission should be empowered to establish the conditions for the establishment of subsequent reference years and the adoption of the programme of the statistical data and the metadata. Since those measures are of general scope and are designed to amend non-essential elements of this Regulation, inter alia, by supplementing it with new non-essential elements, they must be adopted in accordance with the regulatory procedure with scrutiny provided for in Article 5a of Decision 1999/468/EC.

(11) The Statistical Programme Committee has been consulted in accordance with Article 3 of Decision 89/382/EEC, Euratom,

\section{HAVE ADOPTED THIS REGULATION:}

\section{Article 1}

\section{Subject matter}

This Regulation establishes common rules for the decennial provision of comprehensive data on population and housing.

Article 2

\section{Definitions}

For the purpose of this Regulation, the following definitions shall apply:

(a) 'population' shall mean the national, regional and local population at its usual residence at the reference date;

(b) 'housing' shall mean living quarters and buildings as well as housing arrangements and the relationship between the population and living quarters at the national, regional and local levels at the reference date;

(c) 'buildings' shall mean permanent buildings that contain living quarters designed for human habitation, or conventional dwellings that are reserved for seasonal or secondary use or that are vacant;

(d) 'usual residence' shall mean the place where a person normally spends the daily period of rest, regardless of temporary absences for purposes of recreation, holidays, visits to friends and relatives, business, medical treatment or religious pilgrimage.

The following persons alone shall be considered to be usual residents of the geographical area in question:

(i) those who have lived in their place of usual residence for a continuous period of at least 12 months before the reference date; or

( $\left.{ }^{1}\right)$ OJ L 184, 17.7.1999, p. 23. Decision as amended by Decision 2006/512/EC (OJ L 200, 22.7.2006, p. 11). (ii) those who arrived in their place of usual residence during the 12 months before the reference date with the intention of staying there for at least one year.

Where the circumstances described in point (i) or (ii) cannot be established, 'usual residence' shall mean the place of legal or registered residence;

(e) 'reference date' shall mean the date to which the data of the respective Member State refer, in accordance with Article $5(1)$;

(f) 'national' shall mean on the territory of a Member State;

(g) 'regional' shall mean at NUTS level 1, NUTS level 2 or NUTS level 3, as defined in the classification of territorial units for statistics (NUTS), established by Regulation (EC) No 1059/2003 of the European Parliament and of the Council $\left({ }^{2}\right)$ in its version applicable at the reference date;

(h) 'local' shall mean at Local Administrative Units level 2 (LAU level 2);

(i) 'essential features of population and housing censuses' shall mean individual enumeration, simultaneity, universality within a defined territory, availability of small-area data and defined periodicity.

Article 3

\section{Data submission}

Member States shall submit to the Commission (Eurostat) data on the population covering determined demographic, social and economic characteristics of persons, families and households, as well as on housing at a national, regional and local level, as set out in the Annex.

Article 4

\section{Data sources}

1. Member States may base the statistics on different data sources, in particular on:

(a) conventional censuses;

(b) register-based censuses;

(c) a combination of conventional censuses and sample surveys;

(d) a combination of register-based censuses and sample surveys;

(e) a combination of register-based censuses and conventional censuses;

$\left.{ }^{2}\right)$ OJ L $154,21.6 .2003$, p. 1. Regulation as last amended by Regulation (EC) No 176/2008 of the European Parliament and of the Council (O) L 61, 5.3.2008, p. 1). 
(f) a combination of register-based censuses, sample surveys and conventional censuses; and

(g) appropriate surveys with rotating samples (rolling censuses).

2. Member States shall take all measures necessary to meet the requirements of data protection. The Member States' own data protection provisions shall not be affected by this Regulation.

3. Member States shall inform the Commission (Eurostat) of any revision or correction of the statistics supplied under this Regulation, as well as of any changes in the chosen data sources and methodology, no later than one month before the release of the revised data.

4. Member States shall ensure that the data sources and the methodology used to satisfy the requirements of this Regulation meet, to the highest possible extent, the essential features of population and housing censuses, as defined in Article 2(i). They shall make continuous efforts to enhance compliance with those essential features.

Article 5

\section{Data transmission}

1. Each Member State shall determine a reference date. The reference date shall fall in a year specified on the basis of this Regulation (reference year). The first reference year shall be 2011. The Commission (Eurostat) shall establish subsequent reference years in accordance with the regulatory procedure with scrutiny referred to in Article 8(3). Reference years shall fall during the beginning of every decade.

2. Member States shall provide the Commission (Eurostat) with final, validated and aggregated data and with metadata, as required by this Regulation, within 27 months of the end of the reference year.

3. The Commission (Eurostat) shall adopt a programme of the statistical data and of the metadata to be transmitted to fulfil the requirements of this Regulation, in accordance with the regulatory procedure with scrutiny referred to in Article 8(3).

4. The Commission (Eurostat) shall adopt the technical specifications of the topics as required by this Regulation as well as of their breakdowns, in accordance with the regulatory procedure referred to in Article 8(2).

5. Member States shall transmit to the Commission (Eurostat) the validated data and metadata in electronic form. The Commission (Eurostat) shall adopt the appropriate technical format to be used for the transmission of the required data, in accordance with the regulatory procedure referred to in $\mathrm{Ar}$ ticle $8(2)$.

6. In the event of a revision or correction in accordance with Article 4(3), Member States shall transmit the modified data to the Commission (Eurostat) no later than on the date of release of the revised data.

Article 6

\section{Quality assessment}

1. For the purpose of this Regulation, the following quality assessment dimensions shall apply to the data to be transmitted:

- 'relevance' shall refer to the degree to which statistics meet the current and potential needs of users,

- 'accuracy' shall refer to the closeness of estimates to the unknown true values,

- 'timeliness' and 'punctuality' shall refer to the delay between the reference period and the availability of results,

- 'accessibility' and 'clarity' shall refer to the conditions under and modalities by which users can obtain, use and interpret data,

- 'comparability' shall refer to the measurement of the impact of differences in applied statistical concepts and measurement tools and procedures when statistics are compared between geographical areas, sectoral domains, or over time, and

- 'coherence' shall refer to the adequacy of the data to be reliably combined in different ways and for various uses.

2. Member States shall provide the Commission (Eurostat) with a report on the quality of the data transmitted. In this context, Member States shall report on the extent to which the chosen data sources and methodology meet the essential features of population and housing censuses as defined in Article 2(i).

3. In applying the quality assessment dimensions laid down in paragraph 1 to the data covered by this Regulation, the modalities and structure of the quality reports shall be defined in accordance with the regulatory procedure referred to in Article 8(2). The Commission (Eurostat) shall assess the quality of the data transmitted.

4. The Commission (Eurostat), in cooperation with the competent authorities of the Member States, shall provide methodological recommendations designed to ensure the quality of the data and metadata produced, acknowledging, in particular, the Conference of European Statisticians Recommendations for the 2010 Censuses of Population and Housing. 
Article 7

\section{Implementing measures}

1. The following measures necessary for the implementation of this Regulation shall be adopted in accordance with the regulatory procedure referred to in Article 8(2):

(a) technical specifications of the topics as required by this Regulation as well as of their breakdowns as provided for in Article 5(4);

(b) the establishment of the appropriate technical format as provided for in Article 5(5); and

(c) modalities and structure of the quality reports as provided for in Article 6(3).

2. The following measures necessary for the implementation of this Regulation, designed to amend non-essential elements of this Regulation by supplementing it, shall be adopted in accordance with the regulatory procedure with scrutiny referred to in Article 8(3):

(a) the establishment of the reference years, as provided for in Article 5(1); and

(b) the adoption of the programme of the statistical data and the metadata, as provided for in Article 5(3).
3. Consideration shall be given to the principles that the benefits of the measures taken must outweigh their costs and that additional costs and burdens must remain within a reasonable limit.

\section{Article 8}

\section{Committee procedure}

1. The Commission shall be assisted by the Statistical Programme Committee.

2. Where reference is made to this paragraph, Articles 5 and 7 of Decision 1999/468/EC shall apply, having regard to the provisions of Article 8 thereof.

The period laid down in Article 5(6) of Decision 1999/468/EC shall be set at three months.

3. Where reference is made to this paragraph, Article $5 \mathrm{a}(1)$ to (4) and Article 7 of Decision 1999/468/EC shall apply, having regard to the provisions of Article 8 thereof.

Article 9

\section{Entry into force}

This Regulation shall enter into force on the 20th day following its publication in the Official Journal of the European Union.

This Regulation shall be binding in its entirety and directly applicable in all Member States.

Done at Strasbourg, 9 July 2008.

\section{For the European Parliament \\ The President}

H.-G. PÖTTERING
For the Council

The President

J.-P. JOUYET 


\section{Appendix 2: List of interviews}

Interview 1: Croatian Bureau of Statistics official, September 2015, Zagreb Interview 2: OSCE official, October 2015, Skopje Interview 3: Eurostat official, March 2014, Luxembourg Interview 4: EU Delegation Sarajevo official, September 2015, Sarajevo Interview 5: DG NEAR official, June 2015, Brussels Interview 6: Statistical Agency official, September 2015, Sarajevo Interview 7: Eurostat official, March 2014, Luxembourg Interview 8: State Agency official, September 2015, Sarajevo Interview 9: International Census Consultant, April 2016, phone interview Interview 10: International Census Consultant, October 2015, Skopje Interview 11: EU Delegation Skopje official, November 2015, Brussels Interview 12: Eurostat official, March 2014, Luxembourg Interview 13: State Statistical Office official, October 2015, Skopje Interview 14: DG NEAR official, March 2016, phone interview

\section{Appendix 3: Topic guide for the interviews}

In March 2014 (Eurostat)

- Factual knowledge, such as "Why is census-taking such an important issue for the EU?" and "Which role has Eurostat next to the UNECE (recommendations) in regard to census-taking? What is the relationship between them?"

- Questions asking for the EU incentives and pressure, rewards and threats of the EU (theory oriented)

- Questions per case country, such as "What was your role during the latest census in ...?", "How compliant would you describe ...?" and "Do you see the ... state as capable of collecting the census?"

- In September and October 2015 (in the case countries)

- Timing and process of accession and the role of the census in this process, "How was the pressure of the EU perceived? How was the IMO perceived?"

- The capacities of the National Statistical Institutes (and with what organizations they had to cooperate and how the cooperation went)

- Census questionnaires, reactions to the sensitive questions on ethnocultural data

- How was the census process in general and which problems were encountered? How was the atmosphere in the country? How did the domestic actors react in the census process? 
In January 2016 (Eurostat)

- More background information on the factual knowledge, on for example the Technical Cooperation Groups

- Update (on especially the developments in Bosnia) and additional information regarding the case countries

\section{Appendix 4: Questionnaire first survey round}

Dear census expert,

This survey has been designed to collect more detailed knowledge on how experts perceive census practices, as well as the regulations and recommendations for the population and housing census. We would appreciate if you would answer from your personal experience, rather than following the official lines of the organisation you are working with (unless they are the same, of course).

The answers to this survey will be treated completely confidential. We will make sure that your answers cannot be traced to your affiliation or name. Your participation is voluntary. The survey is divided in four parts. If you are not familiar with a topic, you can skip to the next one. The survey will allow you to skip forward and backward if you want to reconsider your answer.

The results of the survey will provide us with better understanding of how census experts perceive the practices and regulations behind censustaking. This may have implications for the design of for the design of census questions and variables. This is an essential part of the PhD project 'Europeanization of census-taking in the Western Balkans' at Maastricht University (The Netherlands). Should you have any questions or comments please contact Professor Hans Schmeets (h.schmeets@cbs.nl) and/or Anna-Lena Hoh (anna-lena.hoh@maastrichtuniversity.nl).

Thank you very much for participating!

Anna-Lena Hoh

PhD Candidate - Maastricht University

This PhD project is supported by Pieter Everaers (Director Cooperation in the European Statistical System, International cooperation, resources -Eurostat) and Eric Schulte Nordholt (Senior Researcher- Project Leader of the CensusStatistics Netherlands). 
1. Before starting the questionnaire we would like to know how much experience you have with the population and housing census. Could you please indicate how long you have been working with census issues? Please, click on the appropriate option below.

For 2 years, or less

For 3-5 years

For 6-10 years

For 11-15 years

For more than 16 years

Part 1: UNECE census recommendations

This is the first part of the questionnaire, focusing on the Conference of European Statisticians (CES) Recommendations for the 2010 Censuses of Population and Housing (the UNECE population and housing recommendations). If you do not feel familiar with this part, you can indicate this in the following question and will then be automatically guided to the next part of the questionnaire.

2. Would you consider yourself familiar with the Conference of European Statisticians (CES) Recommendations for the 2010 Censuses of Population and Housing (the UNECE population and housing recommendations)?

Please, click on the appropriate answer below.

Yes

Yes, to some extent

No, not at all

3. Have you ever been present at or participated in the UNECE meetings on the population and housing census?

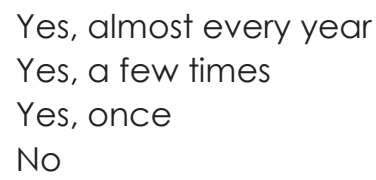

4. What, according to you, are in general the most difficult issues to agree on at the UNECE meetings on the population and housing census?

Open question.

The following questions are about your opinion on the Conference of European Statisticians (CES) Recommendations for the 2010 Censuses of Population and Housing (the UNECE population and housing recommendations), the topics and methodology. Please indicate whether you agree or disagree with the following statements: 
5. The UNECE census recommendations for the 2010 census round were a useful tool for helping design a census.

Strongly agree $\square \square \square \square \square$ Strongly disagree

$\square$ Don't know

6. The UNECE census recommendations for the 2010 census round ensured comparability between the census results of countries.

Strongly agree $\square \square \square \square \square$ Strongly disagree

$\square$ Don't know

7. Is there something you would have liked to have addressed differently with regard to the census topics in the UNECE population and housing census recommendations for the census round of 2010 ?

Yes, please specify...

No

Don't know

8. Is there something you would have liked to have addressed differently with regard to the methodology in the UNECE population and housing census recommendations for the census round of 2010 ?

Yes, please specify...

No

Don't know

According to the UNECE report on Practices of UNECE Countries in the 2010 Round of Censuses (United Nations Economic Commission for Europe, 2014, p. 159), 31 countries (out of 51 who responded to the survey) collect information on ethnicity, language and religion. To what extent do you agree or disagree with the following statement:

9. The UNECE recommendations should be mandatory while designing the census questionnaires?

Strongly agree $\square \square \square \square \square$ Strongly disagree

$\checkmark$ Don't know

10. The questions on ethno-cultural characteristics should be part of the core questions in the UNECE recommendations?

Strongly agree $\square \square \square \square \square$ Strongly disagree

$\square$ Don't know 
11. Ethnicity, language and religion are often considered as problematic topics in the population and housing census. Are there other aspects, apart from these three, which you consider as problematic (difficult to implement) with regard to the UNECE population and housing recommendations?

Yes, please specify...

No

Don't know

Part 2: Census topics

This is the second part of the questionnaire, focussing on the topics covered in the population and housing census. Please remember to answer from your personal perspective, rather than from the official practice of your organisation.

According to the UNECE population and housing census recommendations ethnicity is defined very broadly as "based on a shared understanding of the history and territorial origins (regional, national) of an ethnic group or community as well as on particular cultural characteristics: language and/or religion and/or specific customs and ways of life"(United Nations Economic Commission for Europe, 2006, p. 95).

12. Do you agree with this definition?

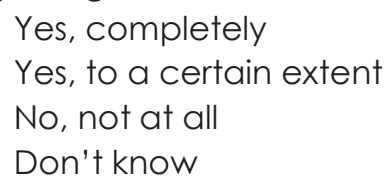

13. Regarding the definition on ethnicity mentioned above, if you do not totally agree with the definition, what would you change about it? Open question.

Another aspect of the ethno-cultural characteristics is religion, which the UNECE population and housing census recommendations is defined as "generally regarded as a set of beliefs and practices, usually involving acknowledgment of a divine or higher being, power or principle, by which people order the conduct of their lives both practically and in a moral sense" (United Nations Economic Commission for Europe, 2006, p. 97).

14. Do you agree with this definition?

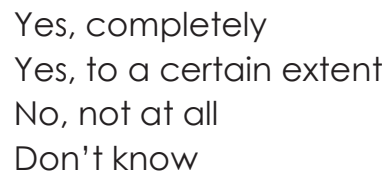


15. Regarding the definition on religion mentioned above, if you do not totally agree with the definition, what would you change about it?

Open question.

Language is also one of the mentioned ethno-cultural characteristics of the UNECE population and housing census recommendations. This is divided in four categories:

"a) "Mother tongue", defined as the first language spoken in early childhood at home;

b) Main language, defined as the language which the person commands best;

c) Language(s) most currently spoken at home and/or work;

d) Knowledge of language(s), defined as the ability to speak and/or write one or more designated languages." (United Nations Economic Commission for Europe, 2006, p. 96)

16. Are these the categories you would use when designing a census questionnaire?

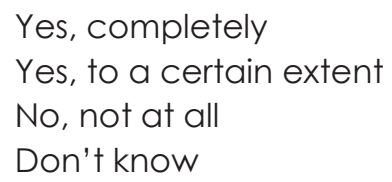

17. Regarding the categories mentioned above, if you would not use them for a census questionnaire, what categories would you use to collect data on language?

Open question.

To what extent do you consider the following aspects necessary/not necessary for the successful implementation of a population and housing census? Please, indicate this in the list below.

18. A strong and independent National Statistical Institute

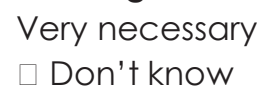

19. Political willingness of the parties in power
Very necessary
Not at all necessary
$\square$ Don't know

20. Support from NGO's

Very necessary

Not at all necessary

$\square$ Don't know 


\title{
21. Support from Eurostat
}
Very necessary
Not at all necessary
$\square$ Don't know

22. Strong state institutions, such as the judicial system, army and police Very necessary

\author{
Not at all necessary
}

$\square$ Don't know

23. Fairly high trust in institutions, such as the judicial system, army and police Very necessary

Not at all necessary
$\square$ Don't know

24. Fairly high political trust, such as in politicians and political parties

Very necessary

Not at all necessary

Don't know

25. Fairly high trust in the countries democracy

Very necessary

- Not at all necessary

Don't know

26. Other, please specify...

Very necessary $\square \square \square \square \square$ Not at all necessary

$\square$ Don't know

Most census topics should not be a problem while addressing the census population. Other topics might be sensitive for some people, and they might be reluctant to answer such questions. Based on the list in the below, how sensitive do you think the topics in the list below are?

\section{Sex}

Highly sensitive

Not at all sensitive

$\checkmark$ Don't know

\section{Age}

Highly sensitive

Not at all sensitive

Don't know

\section{Marital Status}

Highly sensitive

Not at all sensitive

Don't know

30. Status in employment

Highly sensitive

Not at all sensitive

$\square$ Don't know 


\section{Income}

Highly sensitive $\square \square \square \square \square$ Not at all sensitive

$\square$ Don't know

\section{Place of Birth}

Highly sensitive $\quad \square \square \square \square \square$ Not at all sensitive

$\square$ Don't know

33. Country of citizenship/Citizenship

Highly sensitive $\square \square \square \square \square$ Not at all sensitive

$\square$ Don't know

34. Relationship between Household Members

Highly sensitive $\quad \square \square \square \square \square$ Not at all sensitive

$\square$ Don't know

35. Tenure status of housing

Highly sensitive

Not at all sensitive

$\square$ Don't know

\section{Toilet facilities}

Highly sensitive $\square \square \square \square \square$ Not at all sensitive

Don't know

\section{Place of usual residence}

Highly sensitive $\quad \square \square \square \square \square$ Not at all sensitive

Don't know

\section{Place of work}

Highly sensitive $\square \square \square \square \square$ Not at all sensitive

Don't know

\section{Language}

Highly sensitive $\square \square \square \square \square$ Not at all sensitive

$\square$ Don't know

\section{Religion}

Highly sensitive $\square \square \square \square \square$ Not at all sensitive

$\square$ Don't know

\section{Ethnicity}

Highly sensitive $\square \square \square \square \square$ Not at all sensitive

$\square$ Don't know 


\section{Nationality}

Highly sensitive $\square \square \square \square \square$ Not at all sensitive

$\checkmark$ Don't know

43. Other, please specify...

Highly sensitive $\square \square \square \square \square$ Not at all sensitive

$\square$ Don't know

44. Please, could you elaborate on why in your opinion one or more of the above mentioned topics are sensitive or not sensitive?

Open question.

45. Do you think that in general sensitive questions should be part of a population and housing census questionnaire?

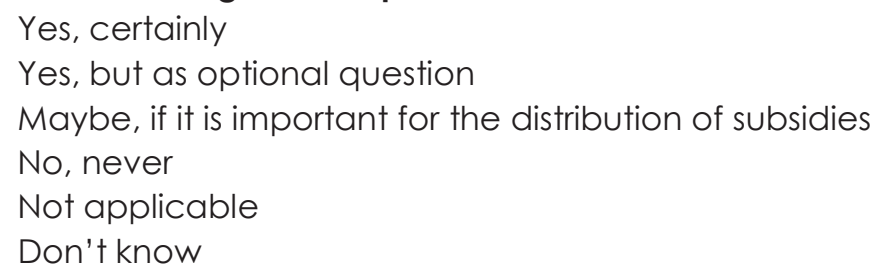

46. Could you please elaborate a bit more on your answer(s) above; why do you think so?

Open question.

Do you agree/disagree with including the following aspects in census questionnaires for all countries in the UNECE region?

\section{Citizenship}

Totally agree

Totally disagree

Don't know

48. Ethnicity

Totally agree

Totally disagree

$\checkmark$ Don't know

\section{Language}

Totally agree

Totally disagree

Don't know

50. Religion

Totally agree

Totally disagree

$\square$ Don't know 
51. Could you please elaborate on your answer(s) above; why did you choose these options?

Open question.

\section{Part 3: EU census regulations}

This is the third part of the questionnaire, focusing on the EU population and housing census regulations. If you do not feel familiar with this part, you can indicate so in the following question and will then be guided to the next part of the questionnaire.

52. Would you consider yourself familiar with the EU population and housing census regulations?

Yes

Yes, to some extent

No, not at all

53. What are, according to you, the most important issues of the EU population and housing census regulations?

Open question.

To what extent do you think that the EU census regulations are a good or a bad tool for national population and housing censuses with regard to the following aspects?

54. The census law

Very good tool

Very bad tool

$\square$ Not applicable

Don't know

55. The census methodology

Very good tool

Very bad tool

$\square$ Not applicable

Don't know

56. The census questionnaire
Very good tool
Very bad tool
$\checkmark$ Not applicable
Don't know

57. The enumeration process

Very good tool

Very bad tool

$\square$ Not applicable

Don't know

58. Other, please specify

Very good tool

Very bad tool

$\square$ Not applicable

Don't know 
59. Apart from the EU population and housing census regulations are there any other international organisations' practices which, you think need to be considered while implementing a census?

Could you please name them.

Open question.

To what extent do you think the EU should do more or less to ensure comparability on the following aspects of the population and housing census?

60. Census results

EU should do more $\square \square \square \square \square$ EU should do less

$\square$ Don't know

61. Census methodology

EU should do more

EU should do less

$\square$ Don't know

62. Census topics

EU should do more $\square \square \square \square \square$ EU should do less

$\square$ Don't know

63. Is there something you would have liked to have addressed differently in the census topics of the EU population and housing census regulations for the census round of 2010 ?

Yes, please specify...

No

Don't know

64. Is there something you would have liked to have addressed differently in the methodological approaches of the EU population and housing census regulations for the census round of 2010?

Yes, please specify...

No

Don't know

65. Unlike the UNECE population and housing recommendations, the EU does not include non-core census topics in the population and housing census regulations. Are there census topics within the EU (and maybe even the EU census regulations) that you would nonetheless identify as sensitive?

Yes, please specify...

No

Don't know 
Please indicate whether you agree or disagree with the following: The EU population and housing census regulations should contain more precise rules for census questions regarding...

\section{Citizenship}

Strongly agree

Strongly disagree

$\square$ Don't know

67. Ethnicity

Strongly agree

Strongly disagree

$\square$ Don't know

68. Language

Strongly agree

Strongly disagree

$\neg$ Don't know

69. Religion

Strongly agree $\quad \square \square \square \square$ Strongly disagree

$\neg$ Don't know

70. Have you been present at a meeting/meetings on the population and housing census organised by Eurostat since 2005, for example in Luxembourg?

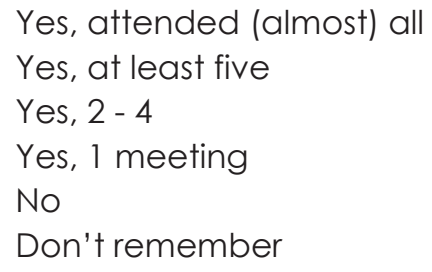

Please indicate whether you agree or disagree with the following statements, keeping in mind that this question takes into account general meetings on the population and housing census at Eurostat:

71.I have learnt new approaches at the meetings at Eurostat

Strongly agree

Strongly disagree

Don't know

72.I am using the approaches I have learnt at the meetings in my own work Strongly agree Strongly disagree

$\square$ Don't know

73. These meetings are relevant for my work.

Strongly agree

Strongly disagree

Don't know 
74. Can you give one example in which you started applying a new approach because of these meetings?

Open question.

To what extent are, according to you, the aspects discussed at the meetings at Eurostat implemented in the population and housing censuses with regard to:

75. The census law

Strong extent

No extent

$\square$ Not applicable

Don't know

76. The census methodology

Strong extent $\quad \square \quad \square \quad \square$ No extent

$\square$ Don't know

77. The census questionnaire
Strong extent
No extent
$\square$ Not applicable
Don't know

78. The enumeration process
Strong extent
No extent
$\square$ Don't know

79. Other, please specify

Strong extent $\quad \square \quad \square \square \square$ No extent

$\square$ Don't know

80. Could you please elaborate on why you think this is the case?

Open question.

\section{Part 4: Western Balkans}

This is the fourth and last part of the questionnaire, focusing on accession countries of the EU, in particular the region of the Western Balkans and census-taking. If you do not feel familiar with this part, you can indicate so in the following question and will then be guided to end of the questionnaire.

81. Would you consider yourself familiar with the political situation in the Western Balkans in general and the population and housing censuses in particular?

Yes

Yes, to some extent

No, not at all 
To what extent do you agree or disagree with the following statement:

82. The countries in the Western Balkans need support with the population and housing census.

Strongly agree $\square \square \square \square \square$ Strongly disagree

Don't know

83. Could you please elaborate on the kind of support you have in mind and for which country/-ies this was/is applicable?

Open question.

To what extent do you agree/disagree with the following statement:

84. The EU faces challenges in influencing the population and housing census in Western Balkan countries.

Strongly agree $\square \square \square \square \square$ Strongly disagree

Don't know

85. Can you remember one or more concrete example where the EU has had an impact on the population and housing census/-es in one or more Western Balkan countries?

Open question.

What is your opinion regarding the following:

86. EU pre-accession incentives have been instrumental in securing compliance behaviour with regard to the population and housing census in the 2010 and 2020 census round in the Western Balkans.

Highly useful $\square \square \square \square \square$ Not at all useful

Don't know

87. Do you know of one or more concrete examples where the EU has used/is using pre-accession incentives for the conduct of the population and housing census in the Western Balkans? Please, also name the country/ies.

Open question.

To what extent do you agree or disagree with the following statements:

88. With regard to EU influence on the population and housing census, financial incentives are most important for accession countries.

Strongly agree

Strongly disagree

Don't know 
89. With regard to EU influence on the population and housing census, support for the general census design (census law, methodology, questionnaires etc.) are most important for accession countries.

Strongly agree $\square \square \square \square \square$ Strongly disagree

$\neg$ Don't know

90. Do you think that there are other stakeholders apart from the EU which influence the population and housing census in accession countries, such as the Western Balkans?

Yes, please specify which and where...

No

Don't know

91. In which direction can these stakeholders (see question above) influence the population and housing census in accession countries, such as the Western Balkans?

Open question.

92. With regard to census-taking, what would you consider as sensitive, difficult and/or problematic topics to include in the census questionnaire in the Western Balkans?

Open question.

93. How sensitive would you regard the issues in your answer above?

Very sensitive $\square \square \square \square \square$ Not at all sensitive

$\neg$ Don't know

94. To what extent do you think these sensitive issues can affect the population and housing census?

Open question.

95. Could you please specify which country/countries you had in mind while answering the question(s) above? More than one answer is possible.

Albania

Bosnia and Herzegovina

Croatia

Kosovo*

The Former Yugoslav Republic of Macedonia

Montenegro

Serbia

Other, please specify...

\footnotetext{
* This designation is without prejudice to position on status, and is in line with UN Security Council Resolution 1244/99 and the International Court of Justice Opinion on the Kosovo declaration of independence.
} 
To what extent do you agree or disagree with the sensitivity of the following aspects in the Western Balkans?

96. Citizenship

Highly sensitive $\square \square \square \square \square$ Not at all sensitive

$\square$ Don't know

97. Ethnicity

Highly sensitive $\square \square \square \square \square$ Not at all sensitive

$\square$ Don't know

\section{Language}

Highly sensitive $\square \square \square \square \square$ Not at all sensitive

$\square$ Don't know

\section{Religion}

Highly sensitive $\square \square \square \square \square$ Not at all sensitive

$\square$ Don't know

Do you think the countries in the Western Balkans are more interested in including citizenship, ethnicity, language and religion in the census questionnaire than most other countries in Europe?

100. Citizenship

Yes, certainly

No, not at all

$\square$ Don'† know

101. Ethnicity

Yes, certainly

No, not at all

$\square$ Don't know

102. Language

Yes, certainly

No, not at all

$\square$ Don't know

103. Religion

Yes, certainly $\square \square \square \square \square$ No, not at all

$\square$ Don'† know

104.Could you please elaborate more on your answer above; why do you think so?

Open question.

End of questionnaire 
Thank you very much!

This is the end of this questionnaire.

105. If you have additional remarks, please leave them here:

Open question.

If you have documents which may be relevant for this project, please let us know (or send them to anna-lena.hoh@maastrichtuniversity.nl). 


\section{Appendix 5: Questionnaire second survey round}

Dear census expert,

Thank you very much for your participation in the survey sent to you in June.

Like last time, we would appreciate if you would answer from your personal experience, rather than following the official lines of the organisation you are working with (unless they are the same, of course). The answers to this survey will be treated completely confidential. We will make sure that your answers cannot be traced to your affiliation or name. Your participation is voluntary. The survey is divided in two parts. If you are not familiar with a topic, you can skip to the next one. The survey will allow you to skip forward and backward if you want to reconsider your answer.

In order to have a better, more coherent insight in the answers from the first survey, we are now collecting more reflections and elaborations of how you and your colleagues perceive the topics, practices and regulations of census-taking. The results of the surveys will provide us with better understanding of how census experts perceive the practices behind census-taking. This may have implications for the design of census questions and variables. Furthermore it is an essential part of the PhD project 'Europeanization of censustaking in the Western Balkans' at Maastricht University (The Netherlands). Should you have any questions or comments please contact Professor Hans Schmeets (h.schmeets@cbs.nl) and/or Anna-Lena Hoh (annalena.hoh@maastrichtuniversity.nl).

Thank you very much for participating!

Anna-Lena Hoh

PhD Candidate - Maastricht University

This PhD project is supported by Dr. Pieter Everaers (Director Cooperation in the European Statistical System, International cooperation, resources Eurostat) and Eric Schulte Nordholt (Senior Researcher- Project Leader of the Census- Statistics Netherlands).

To what extent would you agree/disagree with the following statement:

1. The population and housing census is a good indicator of a functioning state.

Strongly agree $\square \square \square \square \square$ Strongly disagree

Don't know

2. Please could you elaborate on why you think so?

Open question. 
To what extent would you agree/disagree with the following statement:

3. The National Statistical Institutes who conduct censuses should act independent from political influence by the political parties in power?

Strongly agree $\square \square \square \square \square$ Strongly disagree

Don't know

4. Please could you elaborate on why you think so?

Open question.

5. In the survey from June, all of the census experts agreed that with regard to the successful implementation of a census a strong and independent National Statistical Institute is either very necessary $(80 \%)$ or at least necessary (20\%). Could you please elaborate on why you think that a strong and independent National Statistical Institute is that important when conducting a census?

Open question.

6. The second important aspect for the successful implementation of a population and housing census according to the survey from June is the political willingness of the parties in power. $80 \%$ of census experts find this aspect either very necessary or necessary. Could you please elaborate on why you think that the political willingness by the parties in power is regarded as important?

If you do not agree with the general trend, please elaborate why.

Open question.

7. According to the survey from June, the third important aspect for the successful implementation of a population and housing census is support from Eurostat. $70 \%$ of census experts find this aspect either very necessary or necessary. Could you please elaborate on why you think that support from Eurostat is that essential for the conduct of a successful population and housing census?

If you do not agree with the general trend, please elaborate why.

Open question.

We would like to remind you to answer the following questions from your personal experience rather than following the official lines of the organisation you are working with (unless they are the same, of course).

8. With regard to the successful implementation of a population and housing census, strong state institutions (such as the judicial system, army and police), fairly high trust in institutions and politicians and the political parties in general were regarded as either not and/or less necessary (see report page 12). Could you please elaborate on why you think that these as- 
pects are generally seen as less important than the aspects mentioned above for a successful census?

If you do not agree with the general trend, please elaborate why. Open question.

9. In the survey from June, a majority of census experts identified ethnicity as highly sensitive $(\mathbf{7 2 \%})$ or sensitive $(22 \%)$. Could you please elaborate on why you identify the aspect of ethnicity as highly sensitive/sensitive? If you do not agree with the general trend, please elaborate why. Open question.

10. In addition religion was also identified as sensitive. Could you please elaborate on why you think so?

Open question.

11. Income was also identified as a sensitive aspect. Could you please elaborate on why you think so?

Open question.

12. Almost $50 \%$ of the census experts would include a few sensitive census topics in the population and housing census as optional questions. Which questions, if any, would you include and why?

Open question.

13. In the survey from June, when asking for agreement/disagreement with including citizenship, ethnicity, language and religion; the answers showed that $77 \%$ of the census experts agreed with collecting data of citizenship and $46 \%$ also would include data of language in the census topics for all UNECE countries. Why would you include/not include the aspect of citizenship and/or language in the census data collection?

Open question.

14. In contrast, most census experts would not include the aspects of ethnicity and religion in the census topics. Could you explain why you would or would not include these census topics?

Open question.

15. Why do you think most of the census experts would include citizenship and language in the population and housing census topics, but not ethnicity and religion?

Open question. 
Considering that including questions on ethnicity, religion and language can threaten the data collection for the population and housing census; do you think that these should be excluded from the data collection in general? Please indicate what you think per aspect.

\section{Ethnicity}

Yes, certainly

Yes, but as optional question

Maybe, if it is important for the distribution of subsidies

No, never

Not applicable

Don't know

\section{Language}

Yes, certainly

Yes, but as optional question

Maybe, if it is important for the distribution of subsidies

No, never

Not applicable

Don't know

\section{Religion}

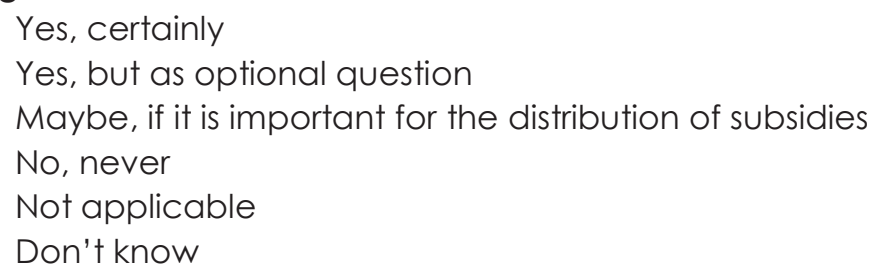

However, in the case that this data is crucial for policies such as to protect minorities, would you still exclude these topics from the population and housing census? Please indicate what you think per aspect.

\section{Ethnicity}

Yes, they should not be part of the census topics

I would include them on a voluntary basis

No, they should definitely be included in the census topics

Not applicable

Don't know 
20. Language

Yes, they should not be part of the census topics

I would include them on a voluntary basis

No, they should definitely be included in the census topics

Not applicable

Don't know

21. Religion

Yes, they should not be part of the census topics

I would include them on a voluntary basis

No, they should definitely be included in the census topics

Not applicable

Don't know

22. Could you please elaborate on your answer(s) above?

Open question.

23. The UNECE population and housing recommendations are by definition not mandatory. However in the survey from June, a few experts (20\%) were in favour of making the Conference of European Statisticians (CES) Recommendations for the 2010 Censuses of Population and Housing (the UNECE population and housing recommendations) mandatory.

Could you please elaborate on why you agreed/disagreed with the statement that the UNECE recommendations should be mandatory while designing the census questionnaire?

Open question.

24. In the survey of June, most experts agreed that the Conference of European Statisticians (CES) Recommendations for the 2010 Censuses of Population and Housing (the UNECE population and housing recommendations) are a useful tool for the population and housing census (93\%). As a follow up we would like to know how legitimate you perceive the CES recommendations. Please indicate your answer in the categories below.

Very legitimate $\square \square \square \square \square$ Not at all legitimate

$\square$ Don't know

25. Could you please elaborate on your answer above; why would you describe the Conference of European Statisticians (CES) Recommendations for the 2010 Censuses of Population and Housing (the UNECE population and housing recommendations) as legitimate/not legitimate?

Open question.

26. Considering that the EU census regulations have to be implemented within the EU, but are also taken into account by accession countries, which 
do not yet have the obligation to implement these. Within this perspective, to what extent would you describe the EU population and housing census regulations as legitimate for the population and housing censuses in enlargement countries?
Very legitimate
Not at all legitimate
$\square$ Don't know

27. Why would you describe the EU population and housing census regulations for enlargement countries as legitimate/not legitimate?

Open question.

\section{Part 2: Western Balkans}

This is the second and last part of the questionnaire, focusing on accession countries of the EU, in particular the region of the Western Balkans and census-taking. If you do not feel familiar with this part, you can indicate so in the following question and will then be guided to end of the questionnaire.

28. Would you consider yourself familiar with the political situation in the Western Balkans in general and the population and housing censuses in particular?

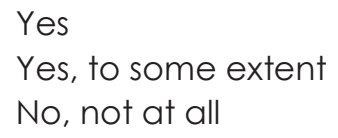

According to the survey from June a majority of census experts answered positively on the question whether the Western Balkan countries need support with the population and housing census. However, the open answer field showed a variation between those countries. Could you please indicate below to what extent which Western Balkan country you think needs support with the population and housing census?

\section{Albania}

No need for support

Need for support

Strong need for support

Don't know

30. Bosnia and Herzegovina

No need for support

Need for support

Strong need for support

Don't know 


\section{Croatia}

No need for support

Need for support

Strong need for support

Don't know

\section{Kosovo*}

No need for support

Need for support

Strong need for support

Don't know

33. The Former Yugoslav Republic of Macedonia

No need for support

Need for support

Strong need for support

Don't know

\section{Montenegro}

No need for support

Need for support

Strong need for support

Don't know

\section{Serbia}

No need for support

Need for support

Strong need for support

Don'† know

The EU may support a population and housing census in various manners, such as providing technical and legal support. Could you please indicate what kind of support you think each of these countries need most in order to conduct a successful population and housing census? More than one answer is possible, but please keep in mind to focus on the most important aspect(s).

\footnotetext{
* This designation is without prejudice to position on status, and is in line with UN Security Council Resolution 1244/99 and the International Court of Justice Opinion on the Kosovo declaration of independence.
} 


\section{Albania}

Technical support (e.g. IT expertise and software)

Methodological support (e.g. with the definitions of the census topics)

Support to strengthen the National Statistical Institute (e.g. against political influence)

Legal support (e.g. with the census law)

Financial support (e.g. fieldwork, payment of enumerators )

Other support

No support needed

Don't know

\section{Bosnia and Herzegovina}

Technical support (e.g. IT expertise and software)

Methodological support (e.g. with the definitions of the census topics)

Support to strengthen the National Statistical Institute (e.g. against

political influence)

Legal support (e.g. with the census law)

Financial support (e.g. fieldwork, payment of enumerators )

Other support

No support needed

Don't know

\section{Croatia}

Technical support (e.g. IT expertise and software)

Methodological support (e.g. with the definitions of the census topics)

Support to strengthen the National Statistical Institute (e.g. against political influence)

Legal support (e.g. with the census law)

Financial support (e.g. fieldwork, payment of enumerators )

Other support

No support needed

Don't know

\section{Kosovo*}

Technical support (e.g. IT expertise and software)

Methodological support (e.g. with the definitions of the census topics)

Support to strengthen the National Statistical Institute (e.g. against political influence)

Legal support (e.g. with the census law)

Financial support (e.g. fieldwork, payment of enumerators )

\footnotetext{
* This designation is without prejudice to position on status, and is in line with UN Security Council Resolution 1244/99 and the International Court of Justice Opinion on the Kosovo declaration of independence.
} 
Other support

No support needed

Don'† know

\section{The Former Yugoslav Republic of Macedonia}

Technical support (e.g. IT expertise and software)

Methodological support (e.g. with the definitions of the census topics)

Support to strengthen the National Statistical Institute (e.g. against political influence)

Legal support (e.g. with the census law)

Financial support (e.g. fieldwork, payment of enumerators )

Other support

No support needed

Don't know

\section{Montenegro}

Technical support (e.g. IT expertise and software)

Methodological support (e.g. with the definitions of the census topics)

Support to strengthen the National Statistical Institute (e.g. against political influence)

Legal support (e.g. with the census law)

Financial support (e.g. fieldwork, payment of enumerators )

Other support

No support needed

Don't know

\section{Serbia}

Technical support (e.g. IT expertise and software)

Methodological support (e.g. with the definitions of the census topics)

Support to strengthen the National Statistical Institute (e.g. against political influence)

Legal support (e.g. with the census law)

Financial support (e.g. fieldwork, payment of enumerators )

Other support

No support needed

Don't know

43. Could you please elaborate on your answer(s) above?

Open question. 
To what extent do you think that the level of advancement of a country within the enlargement process towards European Union membership has influence on the successful performance of the population and housing censuses in the Western Balkan countries? Please, specify per country.

\section{Albania}

Weak influence

No influence

Some influence

Strong influence

Don't know

\section{Bosnia and Herzegovina}

Weak influence

No influence

Some influence

Strong influence

Don't know

46. Croatia

Weak influence

No influence

Some influence

Strong influence

Don't know

\section{Kosovo*}

Weak influence

No influence

Some influence

Strong influence

Don't know

48. The Former Yugoslav Republic of Macedonia

Weak influence

No influence

Some influence

Strong influence

Don't know

\footnotetext{
* This designation is without prejudice to position on status, and is in line with UN Security Council Resolution 1244/99 and the International Court of Justice Opinion on the Kosovo declaration of independence.
} 


\section{Montenegro}

Weak influence

No influence

Some influence

Strong influence

Don't know

50. Serbia

Weak influence

No influence

Some influence

Strong influence

Don't know

51. Could you please elaborate on your answer(s) above? Open question.

Thank you very much! This is the end of this questionnaire.

52. If you have additional remarks, please leave them here:

Open question. 


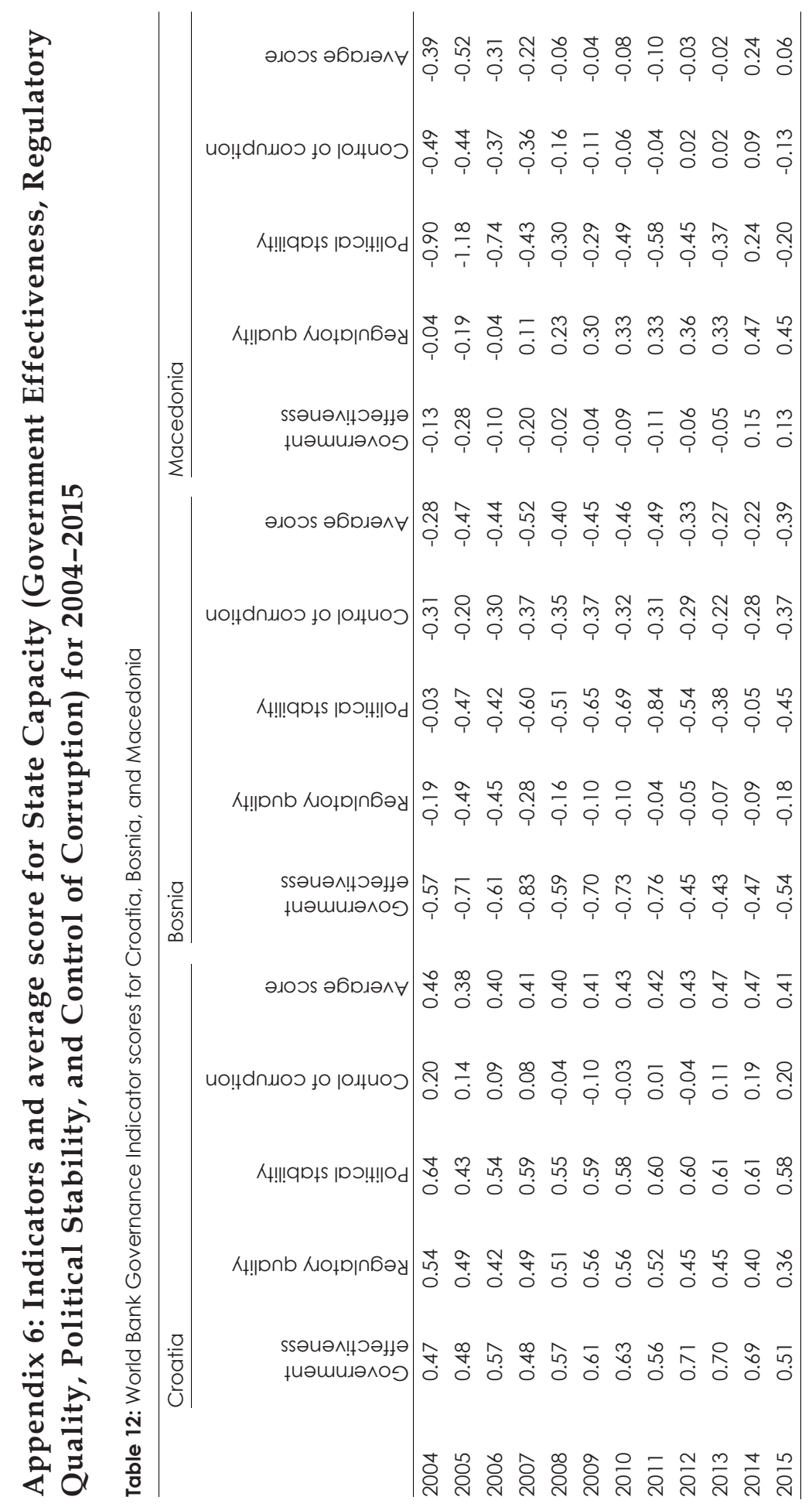




\section{Valorisation addendum}




\section{Introduction}

It is commonly believed that censuses are a purely technical exercise. However, in reality the collection of population data is highly political, and many laypeople do not understand the implications and possible complications inherent in the collection of population data. As censuses in the Netherlands are conducted via registers, many Dutch citizens are unaware of the process of data collection. In Germany, where in 2011 the first census was taken since the 80's, the topic of census-taking was long neglected. ${ }^{36}$ As censustaking is already a complicated process in established democracies such as Germany, one might expect that in post-conflict countries with less stable institutions, there are even more obstacles when it comes to the population count. For example, the countries in the Western Balkans, which are except for Albania all countries that were part of former Yugoslavia, there is a wide variation in recent census outcomes. These countries are however also prospective members of the European Union (EU) and since the census is part of the acquis communautaire, the full body of EU rules and norms, there is considerable pressure on enlargement countries to comply with the EU census regulations.

This thesis assesses the census processes in three of the Western Balkan countries Croatia, Bosnia and Macedonia, which are all (or in the case of Croatia were) part of EU enlargement and as such have to comply with the EU regulations, but show different outcomes when it comes to census-taking. Croatia's 2011 census was successful, whereas Bosnia's 2013 census was the first census after the wars (1992-1995) and long delayed. Macedonia's 2011 census was aborted after the enumeration started.

\section{The politics of numbers}

Censuses were already conducted in ancient Babylon 6000 years ago (United Nations Economic Commission for Europe, 2006, p. 9). Whereas in the beginning the data was purely used to count people, it currently also includes the collection of data on social and economic life (United Nations Economic Commission for Europe, 2006, p. 9). As the first tool to collect data on complete populations, the census can be seen as the mother of big data. Big data nowadays is a term 'to mark a departure from conventional

\footnotetext{
${ }^{36}$ Due to protests based on the fear of invasion of personal privacy, Germany stopped collecting census data after 1987 (in West Germany population numbers have been based on municipality registers, and in the former East Germany the last population data is from 1990). Population data was thus based on estimates until the 2011 census, which revealed that the total population was 1.5 million less than expected, which in the end led to a decrease in subsidies for municipalities and cities where the number of inhabitants was lower than anticipated (Bundeszentrale für politische Bildung, 2013).
} 
forms of data and statistical knowledge' (Ruppert, Isin, \& Bigo, 2017, p. 2), but has different meanings and applications. It remains nonetheless crucial to study where such data derives from and how this data is collected, as this can have serious implications for its validity and reliability.

Even more important is that the data may have a severe impact on the life of the people behind the numbers: the citizens. As census data is used to allocate resources, for example the distribution of funds and subsidies, ultimately some profit more than others, which makes census processes highly political and even more so, when rights of minority and ethnic groups are connected to the census outcomes, as in the case countries. In Croatia minority rights are linked to the census results (Petričušić, 2002). In Bosnia the population data of 1991 is linked to the Dayton Peace Agreement, which divides the political system among the three constituent ethnic groups (Bosniak, Croat and Serb) (Armakolas \& Maksimovic, 2014; Bieber, 2004). In Macedonia, the census is linked to the Ohrid Framework Agreement which stopped the armed conflict between ethnic Albanians and Macedonians in 2001 , and according to which minorities making up more than $20 \%$ of the population receive language rights and proportional representation in the police and bureaucracy (Brunnbauer, 2002; Vasilev, 2013). In general these outcomes show that there should be more awareness of the fact that censuses are always political processes and can feed existing tensions. Since census data is used for policy-making, ultimately some will gain and others will lose on the basis of the census data. There should also be more awareness of the political implications that are inherent to census-taking, especially if the census results are linked to peace agreements and minority rights. These situations call for more additional measures, such as supervision through international monitoring missions and/or a clear agreement on the census regulations by all actors involved.

When data is collected, people are quantified into categories with which they have to identify. Inclusion or exclusion based these categories is best described by the saying: 'If you are not counted, you do not exist'. To gain attention and rights, people have to be visible, and counting is one way to be seen, as has been highlighted in chapter 4 of this research by addressing the paradox of collecting ethnic and cultural data. This paradox entails that if a minority group is not counted, it is also not recognised. However, if counted, that group can be affected by discrimination, either in a positive or a negative way. Especially after the violent dissolution of Yugoslavia, issues of ethnicity and geographic belonging developed into tools for ethnic bargaining over borders, rights and political representation (Visoka \& Gjevori, 2013, p. 6). Whereas until the dissolution of the country in 1991, identity questions in Yugoslavian censuses were common and based on self-identification (Bieber, 2015, p. 10), the census questionnaires in Croatia and Bosnia nowadays are a mix of closed and open answers favouring the most prominent 
ethnic groups. When the census questionnaire includes questions on ethnic and cultural belonging, such as ethnicity, language and religion, it not only provides an overview of the demographic, social and economic characteristics of a country's population (Valente, 2010), but also creates an opportunity for individuals to identify as being part of this population (Ruppert, 2007). As such the census can be used as a tool for state building, but potentially also misused to (re)assure legitimacy and supremacy over others.

The implications that can follow from this is not only restricted to census data and can for example be extended to the collection of data on migration (Broeders \& Dijstelbloem, 2016). We have to be careful while categorising people into groups and the potential consequences that might follow. A typical example is Germany, where due to the abuse of the Sinti lists by the Nazi police it is not allowed to register minorities (Salentin \& Schmeets, 2017, p. 7). There is no easy answer to the paradox of whether or not ethnocultural data should be collected; however, in the light of increasing numbers of refugees and minority groups, as well as more right wing and populist parties, awareness of this paradox and its potential implications is paramount.

\section{Counting to be counted - EU enlargement}

Not only is census data important for the national statistics, but also within the context of the European Union. As evidence-based decision making is becoming more important, the need for reliable and harmonised data is increasing. Therefore the EU has made it mandatory for its members to have a decennial population count. The census is included in the acquis communautaire and thus also important for the enlargement countries. They do not officially need to comply with the EU regulations as they are not yet members, but it is highly recommended that they do so.

This thesis addresses the puzzle of why, despite the EU conditions being the same for all three countries, there are differences in compliance with the EU census regulations in Croatia, Bosnia and Macedonia. Whereas Croatia had a complete census with almost no complications, Bosnia's census has significant delays and Macedonia's census was aborted. The results of this research show that the influence of the EU, as well as domestic actors in the census processes is of high importance. In addition, this project also highlighted the political nature of the census processes, especially if the census includes questions on ethnic and cultural characteristics. The case analysis of chapter 5 and 6 showed that in Bosnia and Macedonia domestic actors hindered the census processes in order to favour the dominant population groups. 
The analysis in chapter 5 has shown that Bosnia and Macedonia needed financial and/or technical assistance when conducting a census. One finding from the Macedonian case was that a shorter and smaller operation is not necessary a viable solution. If there is assistance, it should be sufficient and tailored to the situation at hand. The tailoring to the situation at hand should also be relevant for the enlargement process in general. This thesis has shown that there is no one-size-fits-all process of enlargement into the EU. After Croatia became an EU member in 2013, enlargement currently seems to be on hold. Internal EU issues and Brexit seem to be more important than bringing the remaining Western Balkan countries into the Union. Enlargement, however, was conceived with the intention to spread peace and prosperity, and if taken serious by all actors involved, it is a powerful tool. In March 2017, the European Council reaffirmed its 'unequivocal support for the European perspective of the Western Balkans' (European Commission, 2018). The prospect of the inclusion of the remaining Balkan countries and the, even though at times very slow, progress should be something that should not be nullified by taking away the prospect of ever becoming a member of the EU.

Next to the willingness of the EU to accept new members, are of course the countries in the Western Balkans who have to step up and show that they are worthy of becoming EU members. This research has shown in chapter 6 that the domestic context and actors should not be underestimated when it comes to census-taking, and this also holds for the enlargement process in general. Recently, Macedonia has made enormous progress and the name dispute with Greece seems to be almost resolved, which could finally start the membership negotiations. How this will affect the future plans for a census remains to be seen, but this research has highlighted the ethnocultural sensitivities present in the country which need to be taken into account in any future census and enlargement plans. With regard to Bosnia, there is however less good news. Even though the census data has finally been published, the same issues as always seem to present themselves. Next to the publication of the census results, another step in the right direction would be to find a solution to the Sejdić-Finci case ${ }^{37}$ and to increase political equality. Once there is development in the Balkans towards the EU principles there might be hope for future enlargement.

\footnotetext{
37 Under the Dayton Peace Accord only members of the three main constituent groups can be elected for the House of Peoples or for the Presidency in Bosnia. Dervo Sejdić and Jakob Finci are Bosnian citizens, but respectively Roma and Jewish. However, to stand for the elections, they would have to be a member of one of the main constituent groups (Bosniak, Croat or Serb). The European Court of Human Rights found that this was discriminatory and Bosnia's 'constitution remains in breach of the European Convention on Human Rights' (European Commission, 2018).
} 


\section{Dissemination of results}

The results of this research are important for the academic world, where research on census-taking especially within the framework of Europeanisation is a novelty. Next to this, the results are of importance for the National Statistical Institutes and the Directorate General European Statistics (DG ESTAT) of the European Commission (Eurostat) as they highlight the sensitivities, which need to be taken into account in census-taking processes. Furthermore, the results are interesting for international organisations, such as the United Nations Economic Commission for Europe (UNECE) and the Organisation for Security and Cooperation in Europe (OSCE).

To answer the research question of this thesis, two different methods were used to gather the data. In-depth interviews were complemented with survey data that was collected in two different rounds. This data is not only of crucial value for this research, but could potentially be used for follow-up research and be of interest for the international census community. The survey results in particular could be used for example to review the Conference of European Statisticians census recommendations and potentially also the EU census regulations. The results from this thesis are thus not only of value for the academic world, but contribute to a better understanding of censustaking in general and among European Statisticians and decision makers in particular.

The results of this research may have a direct impact on the next census round, which includes all censuses from 2015 until 2024. Croatia, the case country which now is a member of the EU, will have to comply with EU census regulations. The results of this research show that other enlargement countries, such as Bosnia and Macedonia, who had difficulties in their last censuses, will also require technical and financial assistance in the next census round. As minority and linguistic rights are connected to the census outcomes, the next censuses in these countries will also be highly political undertakings. This research has demonstrated that in addition to support by the EU, the domestic context is crucially important, and that past experience and better scores on state capacity do not guarantee a good census, as was visible in Macedonia. When planning a census, domestic developments, especially when there is domestic contestation, need to be taken into account. This should be taken on board in the EU census regulations and emphasised in the Conference of European Statisticians recommendations by the UNECE.

To disseminate the results, preliminary results were presented at several academic conferences, including the Association for the Study of Nationalities World Convention at Columbia University in April 2014. This study was also supported by an external advisory board, which included members working at Eurostat and Statistics Netherlands. In addition, visits have been made to 
the Conference of European Statisticians Recommendations on the population census of the UNECE in Geneva in September 2013 and in September/October 2015. A short academic visit was made to the ARITHMUS project at Goldsmiths, University of London in November 2016. Next to this, some preliminary results were presented at the Fifth International Conference of Balkans Demography in in October 2015 in Ohrid, where not only people from Eurostat and the UNECE were present, but also all census experts from the National Statistical Offices of all the Western Balkan countries.

In addition, two of the three chapters of this thesis have already been published as academic articles, and the third empirical chapter is currently being revised for resubmission. Another academic article has been published during the time of this project, which however only analyses the 2011 census in Croatia (Hoh, 2015) and therefore is not part of this thesis. Apart from these academic contributions a policy note discussing the challenges and controversies of census-taking in the Western Balkans was published with the Democratization Policy Council in 2016. 

Summary/Samenvatting 


\section{English summary}

This thesis analysed census-taking processes in Croatia, Bosnia and Macedonia within the framework of EU enlargement. Although EU enlargement is currently suffering from enlargement fatigue, the European Commission recently expressed its unequivocal support to the EU perspective of countries in the Western Balkan region (European Commission, 2018b). To become an EU member, countries need to fulfil certain conditions. These consist of the Copenhagen Criteria, the political criteria of the EU, and the 35 chapters of the acquis communautaire, which is the full body of EU rules and norms and tend to be seen as more technical (Anastasakis, 2008). Chapter 18 of the acquis outlines the statistical requirements and one of these aspects in this chapter is the population and housing census (hereafter census). Although (potential) EU candidate countries do not yet have a legal obligation to follow EU rules, they are strongly advised to do so, because it shows their level of preparedness for accession.

Although sometimes seen as an outdated concept, a population census is crucial in modern society. Census data forms the backbone for vital national statistics such as GDP per capita, and provides the state with information on its population and living standards. On average population censuses are collected every ten years, and involve a census law and the preparation of the enumeration, as well as the collection, processing, publication and dissemination of the population data. The collection of population data is very expensive and labour intensive (Schulte Nordholt, 2014, p. 9), but this data is needed to distribute subsidies and to make policy decisions. In the Western Balkans, after the Yugoslav wars, ethnicity and geographic belonging were used as tools for ethnic bargaining over borders, rights and political representation (Visoka \& Gjevori, 2013, p. 6). This led to the potential misuse of population data as a means to increase or decrease power and rights of certain population groups and as a result census-taking is highly political.

There is a wide variation in census outcomes in the Western Balkans when we look at the most recent censuses. Whereas in Croatia, Serbia and Montenegro the census processes were not very problematic and have been described as only marginally contested, 38 the Albanian census is partially contested by the ethnic minorities present in the country (Visoka \& Gjevori, 2013); in Kosovo the census was boycotted in some municipalities (Visoka \& Gjevori, 2013); and in Bosnia it was postponed twice before being conducted in October 2013, and the results were not published until June 2016. Final-

\footnotetext{
38 In Montenegro the census was marginally contested by the ethnic communities over lines of ethnic, religious and linguistic differences (Visoka \& Gjevori, 2013, p. 13). In Serbia the complex relationship between the Serb majority and the Albanian and Bosniak minority led to minor contestations (Visoka \& Gjevori, 2013, p. 16). In Croatia the census data has been accepted overall, but because of the wording of the questionnaires the results are marginally contested by the Serb minority (Pavelic, 2012).
} 
ly, the census in Macedonia was aborted after a couple of days into the enumeration (Daskalovski, 2013). Based on the method of crucial cases (Blatter \& Haverland, 2012, p. 176), this thesis has analysed the 2011 census in Croatia, the 2013 census in Bosnia and the 2011 census in Macedonia.

This research analyses the variation in census-taking outcomes in Croatia, Bosnia and Macedonia to understand why even though they had the same EU conditions to comply with, their census processes were so different.

\section{Theoretical contribution and methodology}

In this thesis, the concept of Europeanisation is used for analysing EU enlargement and census-taking in the Western Balkans. In order to do so, this thesis makes a distinction between internal and external Europeanisation, which respectively is the influence of the $\mathrm{EU}$ on its members and nonmembers. Based on the definitions from Radaelli (2006) and Elbasani (2013), this thesis defines Europeanisation as the influence of the EU on its enlargement countries.

Within the framework of Europeanisation there is scant research on census-taking (Keil, 2015; Keil \& Perry, 2015). Recently more attention has been paid to the censuses in the Western Balkan region, but this research focuses foremost on the construction of national identity through the census categories (Bieber, 2015) or on the aspect of ethnicity (Daskalovski, 2013; Visoka \& Gjevori, 2013). The politics of numbers behind the population count have also been described as an important aspect (Daskalovski, 2013; Keil \& Perry, 2015) and, even though censuses form part of the 'technical' acquis, scholars agree that they are not technical, but in fact highly political (Keil, 2015; Nobles, 2000; Perry, 2013; Vrgova, 2015). By analysing the censuses in Croatia, Bosnia and Macedonia within the framework of EU enlargement this thesis contributes not only to research on census-taking and the politics of numbers, but also to the literature on Europeanisation by analysing compliance with a specific aspect of the acquis communautaire.

The latter is described in detail in chapter 2. This chapter outlines the specific aspects countries need to comply with when it comes to census-taking, the EU census regulations. In addition, this chapter explains the three phases of compliance with the EU census regulations: non-compliance, partial compliance and full compliance. This chapter also displays how the different angles of Europeanisation-the explicit and implicit compliance with the EU census regulations, the direct influence of the $\mathrm{EU}$ and the influence of the domestic aspects-are used in this thesis to analyse the census processes of the three case countries (Croatia, Bosnia and Macedonia).

Chapter 3 of this thesis outlines the overall research design of this thesis. Using the additional coverage mixed methods model, data was collected via an expert survey in two rounds and in-depth interviews. The additional coverage mixed methods model (Morgan, 2014) was chosen as it contrib- 
utes to a more coherent understanding of the same phenomena by using qualitative as well as quantitative methods. To understand the census-taking processes in the case countries, in-depth interviews were conducted with representatives of the National Statistical Institutes (NSIs) of the case countries, as well as the European Commission (for example at DG Estat (Eurostat) and DG NEAR) and International Census Consultants. In addition, official documents from the EU and (for example) the NSIs, as well as newspaper articles have been used for contextualisation. Finally, based on the Delphi method in which survey data is being collected in two rounds, 75 census experts were asked to fill in a questionnaire. The survey had a response rate of $69 \%$ [ $n=52]$ in the first round and $50 \%$ [n=38] in the second round. Collecting the data in more than one round allowed for more interaction with and response from the census experts. The survey data provides important insights into the census-taking processes in the EU and the regulations and recommendations for census-taking.

\section{Empirical contribution}

Chapter 4 highlights the paradox of collecting ethno-cultural data and the linkage of rights and numerical thresholds to the census outcomes which lead to domestic disputes and contestations. Although the Western Balkan region has a post-war history and the aspect of collecting data on ethnocultural data is regarded as sensitive, there is still a strong focus on these questions in the census (Bieber, 2015). In all case countries the census outcomes are connected to minority and/or language rights, and as a result the census has to collect data on ethno-cultural characteristics. In Croatia, for example, minority rights are linked to the census results (Petričušić, 2002). In Bosnia the population data of 1991 is linked to the Dayton Peace Agreement, which divides the political system among the three constituent ethnic groups (Bosniak, Croat and Serb) (Armakolas \& Maksimovic, 2014; Bieber, 2004). In Macedonia, the census is linked to the Ohrid Framework Agreement which stopped the armed conflict between ethnic Albanians and Macedonians in 2001, and according to which minorities making up more than $20 \%$ of the population receive language rights and proportional representation in the police and bureaucracy (Brunnbauer, 2002; Vasilev, 2013). Consequent$l y$, some groups in the population tend to benefit from the census, whereas other groups tend to lose. Since the collection of data on ethno-cultural characteristics is not part of the EU requirements, this chapter analysed data from a survey conducted among census experts in order to assess the general practice and implicit compliance of collecting ethno-cultural data. This chapter argues that censuses are always political processes and this is especially crucial if the domestic circumstances are as complex as in the Western Balkans. 
The fifth chapter goes deeper into the analysis of the Europeanisation of census-taking. Earlier research on Europeanisation has looked into the normative and strategic dimensions of EU external power (Noutcheva, 2009, 2012) and 'EU member state building', a concept used for the EU's approach of building functional states while integrating them (Bieber, 2011; Denti, 2014; Keil, 2013a). As the EU has high stakes in the stability of the Western Balkan region, it wants to develop reliable statistics in its potential member states (Bieber, 2015, p. 11). All the Western Balkan countries were in the 2010 census round either financially and/or technically supported by the European Commission, through for example Eurostat, the Directorate General European Statistics of the European Commission. The effects of Europeanisation on the census processes in the case countries are analysed by looking at the mechanisms of conditionality and legitimacy. Conditionality is based on the rational-choice calculation of the EU (dis-)incentives and legitimacy analyses whether the EU regulations are accepted or contested based on the perception of appropriateness. This chapter concludes that in Croatia legitimacy was more effective whereas in Bosnia the EU rewards and pressure were able to tip the balance in favour of compliance. In Macedonia noncompliance can be explained either by conditionality-since there were no concrete EU rewards, the cost/benefit calculation could not outweigh the domestic adoption costs-or by legitimacy, since there was a strong contestation against the EU census regulations. Both mechanisms have been effective in the three case countries and by stating that conditionality and legitimacy do matter, this chapter contributes to the general literature on Europeanisation.

Besides the influence of the EU, domestic aspects are also important when looking at enlargement processes (Börzel, 2013; Elbasani, 2013a). Chapter 6 therefore analyses the influence of domestic aspects, such as state capacity and domestic actors, but also external actors, on the census processes. Census-taking is closely connected to state institutions and is 'an assertion of sovereign authority over people and social relations' (Curtis, 2001, p. 36). Also within the EU 'good quality statistics are a part of the basic infrastructure' (Everaers, 2015, p. 188) and therefore countries aiming to join the EU need to show that they can collect reliable population data. Earlier research (Börzel, 2013; Elbasani, 2013a, p. 6) suggests that limited statehood-the lack of structures to constrain human action and execute EU rules-is one of the main obstacles for the Western Balkans' compliance with EU regulations. In addition to the structural aspect of state capacity, which can potentially inhibit the compliance behaviour of accession countries, chapter 6 assesses the agency of domestic and external actors. The evidence shows that when there are domestic disputes, as in the case of Bosnia, the influence of the EU as an external actor is important. However, if the EU has little leverage and there are domestic disputes, census processes can 
also be hindered to the extent that they have to be aborted, as in Macedonia. The case of Croatia shows that if there are almost no domestic disputes, the influence of external actors is not needed to be compliant with the EU census regulations. This also confirms the finding in Chapter 5, where for Croatia the Europeanisation mechanism of legitimacy was most important and for Bosnia conditionality was able to tip the balance in favour of compliance, but in the case of Macedonia the EU could not overcome the domestic contestations. This chapter concludes that domestic agency should not be underestimated when it comes to census processes.

The overall results of this research can be summarised in three main findings. First, the analysis shows that especially if rights and proportional representation of power are connected to the census outcomes, this can politicise and seriously hinder census processes. Second, by accepting or disputing the EU census regulations, domestic actors can respectively either facilitate or obstruct the compliance with the EU census regulations. This is related to the first aspect, because the acceptance of the EU census regulations depends on the potential gain or loss of power based on the census outcomes for the domestic actors. Third, depending on the available rewards and direct pressure of the EU, the EU might be able to overcome domestic disputes and tip the balance in favour of compliance. The results of this research lead to a better understanding of census-taking and show that although the census is based on statistical procedures and regulations, it ultimately remains highly politicised. 


\section{Nederlandse samenvatting}

Dit proefschrift analyseert volkstellingsprocessen in Kroatië, Bosnië en Macedonia in het perspectief van de vitbreiding van de Europese Unie (EU). Ondanks het feit dat de EU-uitbreiding sinds 2004 nog maar in een vertraagd tempo plaatsvindt, ${ }^{39}$ ook enlargement fatigue genoemd, heeft de Europese Commissie recentelijk nog haar steun uitgesproken voor de landen op de Westelijke Balkan, die als toekomstige EU-lidstaten zijn aangewezen (European Commission, 2018b). Om EU-lidstaat te worden, moeten deze landen aan bepaalde condities voldoen. Deze condities bestaan vit twee delen. Ten eerste de Copenhagen Criteria: de politieke criteria van de EU, zoals stabiele instituties die een democratie garanderen en mensenrechten. Ten tweede moeten landen aan de acquis communautaire voldoen. Dit zijn 35 hoofdstukken die de volledige EU-regels en -normen beschrijven. Een van deze hoofdstukken, nummer 18, beschrijft de statistieken die landen moeten implementeren, en een onderdeel hiervan is de volkstelling. Als EUuitbreidingsland hoeven de Westelijke Balkanstaten volgens de wet nog niet aan de EU-regels te voldoen, maar het wordt sterk aangeraden, omdat ze hiermee laten zien dat ze bereid zijn om lidstaat te worden.

Je zou kunnen zeggen dat een volkstelling een ouderwets concept is, maar ook in een moderne samenleving zijn de data die hierdoor verzameld worden cruciaal. Deze worden bijvoorbeeld gebruikt voor nationale statistieken, zoals het bruto binnenlands product per hoofd van de bevolking en de distributie van subsidies. Ook geven ze een breed overzicht van de bevolking en de levensstandaard van een land. In het algemeen wordt een volkstelling iedere tien jaar vitgevoerd, in verschillende stappen, beginnende met de wet over de volkstelling en de voorbereidingen zoals de vragenlijst waarmee de data worden verzameld. Dan volgen de dataverzameling en verwerking, met uiteindelijk de publicatie en disseminatie van de resultaten. Al met al is het een tijdrovend proces dat ook hoge kosten met zich meebrengt (Schulte Nordholt, 2014, p. 9). Data over de bevolking zijn echter nodig voor een goede politieke besluitvorming en het daarop toegesneden beleid.

Ondanks dat alle EU-uitbreidingslanden aan dezelfde condities moeten voldoen, variëren de laatste volkstellingen sterk per land. Zo was de laatste volkstelling in Kroatië, Servië en Montenegro niet heel problematisch en werd deze weinig betwist. 40 De Albanese volkstelling werd echter deels in twijfel

\footnotetext{
${ }^{39}$ Sindsdien zijn alleen nog Roemenië en Bulgarije lid geworden in 2007 en Kroatië in 2013.

40 In Montenegro waren er marginale betwistingen bij de etnische gemeenschappen (Visoka \& Gjevori, 2013, p. 13). In Servië is er een complexe relatie tussen de Servische meerderheid en de Albanese en Bosnische minderheden en dit leidde tot kleine onenigheden (Visoka \& Gjevori, 2013 , p. 16). In Kroatië zijn de data van de volkstellingen bijna overal geaccepteerd, er was vooral kritiek vooraf de volksteling door de Servische minderheid op formulering van de vragen in de vragenlijst.
} 
getrokken door de etnische minderheden in het land (Visoka \& Gjevori, 2013) en in Kosovo werd de volkstelling geboycot in sommige gemeenten (Visoka \& Gjevori, 2013). In Bosnië is de volkstelling twee keer vertraagd voordat deze viteindelijk plaatsvond in oktober 2013, maar de resultaten zijn pas in juni 2016 gepubliceerd. De volkstelling in Macedonië ging van start in 2011, maar werd na een paar dagen geannuleerd (Daskalovski, 2013). Na de gewelddadige oorlog in de jaren negentig, die leidde tot opsplitsing van Joegoslavië, wordt in de regio onder andere etniciteit gebruikt om meer macht, rechten en grondgebied te verkrijgen (Visoka \& Gjevori, 2013, p. 6). De dataverzameling over de bevolkingsgroepen was een van de mogelijkheden om de macht van de eigen groep te vergroten en die van de andere groep te decimeren. Hierdoor zijn volkstellingen gevoelige en politieke kwesties. In deze thesis is de methode van de cruciale casussen als basis gebruikt (Blatter \& Haverland, 2012, p. 176) voor het bestuderen van de volkstellingen in Kroatië van 2011, in Bosnië van 2013 en in Macedonië van 2011.

De onderzoeksvraag die in deze thesis is onderzocht, focust zich op de variaties in de vitvoering en processen rondom de volkstellingen in Kroatië, Bosnië en Macedonië die, ondanks dat ze aan dezelfde EU-regels moesten voldoen, erg verschillend zijn verlopen.

\section{Theoretische bijdrage en methoden}

Europeanisering wordt in deze thesis gebruikt om de EU-uitbreiding en de volkstellingen op de Westelijke Balkan te onderzoeken. Om dit te kunnen doen, wordt er in het theoretische hoofdstuk een verschil gemaakt tussen interne en externe europeanisering. Waar interne europeanisering de focus legt op de processen binnen de EU, kijkt externe europeanisering vooral naar de invloed van de EU op haar toekomstige lidstaten: de vitbreidingslanden. Europeanisering in deze thesis wordt gedefinieerd als de invloed van de EU op haar vitbreidingslanden (Radaelli, 2006; Elbasani 2013).

Binnen het kader van europeanisering is er weinig onderzoek gedaan naar het effect van EU-uitbreiding op volkstellingen (Keil, 2015; Keil \& Perry, 2015). Recentelijk is er meer over verschenen, maar dit onderzoek richt zich vooral op de constructie van nationale identiteiten (Bieber, 2015) en op etniciteit (Daskalovski, 2013; Visoka \& Gjevori, 2013). Het politieke spel achter de cijfers wordt desondanks als vitermate belangrijk geacht (Daskalovski, 2013; Keil \& Perry, 2015).

Dit onderzoek draagt bij aan de literatuur over europeanisering door de effecten van EU-uitbreiding op de implementatie van een van de aspecten van de acquis communautaire te bestuderen. In hoofdstuk 2 van deze thesis worden onder andere de verschillende eisen voor EU-regelgeving gedetailleerd vitgelegd. Verder wordt beschreven hoe de drie implementatiefases van de regelgeving worden geanalyseerd: non-compliance, partial compli- 
ance en full compliance. In dit theoretische hoofdstuk worden ook de verschillende kanten van europeanisering belicht: expliciete en impliciete compliance met de EU-regelgeving voor volkstellingen, de directe invloed van de EU en de invloed van lokale aspecten.

In hoofdstuk 3 worden de overkoepelende methoden voor de dataverzameling en het analyseren van de gegevens van dit onderzoeksproject besproken. Door het gebruik van het additional coverage mixed methods model (Morgan, 2014) zijn in dit onderzoek data van een expertenquête (in twee rondes) gecombineerd met diepte-interviews. Door het toepassen van dit model ontstaat een coherenter beeld over de volkstellingsprocessen in de casuslanden. De diepte-interviews bij onder andere de nationale statistische bureaus, de Europese Commissie en Eurostat, werden gebruikt om, tegen de achtergrond van de volskstellingen in de drie landen, een beeld te schetsen van de politieke en maastschappelijke situatie in de deze landen. De aanvullende internet-enquête is gebaseerd op de Delphimethode en werd afgenomen onder 75 volkstellingsexperts. De enquête werd gebruikt om meer informatie te verkrijgen over onder andere de achtergronden van de EU-regelgeving over volkstellingen. Door de twee opeenvolgende enquêterondes (met een respons van 69\% [n=52] in de eerste ronde en $50 \%$ [ $n=38$ ] in de tweede ronde) konden op basis van antwoorden in de eerste ronde, gerichte vervolgvragen gesteld worden.

\section{Empirische bijdrage}

Hoofdstuk 4 belicht de paradox van het verzamelen van etnische en culturele data en de verbinding met numerieke drempels die leiden tot lokale conflicten. Ondanks het feit dat de landen op de Westelijke Balkan een oorlogsverleden hebben en dat binnen deze oorlogen etniciteit een belangrijke rol speelde, verzamelen alle landen in de regio data over etniciteit, taal en religie. Wat dit nog problematischer maakt, is dat in de casuslanden de vitkomsten van de volkstellingen gebruikt worden voor de bescherming van minderheden en om het recht toe te kennen bepaalde talen te gebruiken. In Kroatië zijn de rechten voor minderheden afhankelijk van het percentage van de minderheid in dat land. In Bosnië rust het hele politieke systeem sinds het Dayton Vredesakkoord op de machtsverdeling tussen de drie etnische groepen (de Bosniaken, de Kroaten en de Serviërs) (Armakolas \& Maksimovic, 2014; Bieber, 2004). In Macedonië is in het Ohrid Vredesakkoord vastgelegd dat minderheden die meer dan twintig procent van de bevolking uitmaken meer rechten krijgen voor bijvoorbeeld het gebruik van hun eigen taal (Brunnbaver, 2002; Vasilev, 2013). Dit heeft geleid tot verschillende conflictsituaties. Omdat het verzamelen van etnische en culturele data niet verplicht is binnen de EU, zijn voor dit onderzoek de enquêtedata gebruikt om de praktijk rondom de implementatie van de etnisch en culturele kwesties in volkstellingen te onderzoeken. De conclusie van dit hoofdstuk is 
dat volkstellingen altijd politiek zijn, in ieder geval in complexe samenlevingen zoals op de Westelijke Balkan.

Het vijfde hoofdstuk van deze thesis gaat dieper in op de analyse van de europeaniseringsprocessen van volkstellingen. In eerder onderzoek zijn de normatieve en strategische aspecten van de EU-dimensies als externe macht geanalyseerd (Noutcheva, 2009, 2012) en wordt het concept van 'EU member state building'(Bieber, 2011; Denti, 2014; Keil, 2013a) gebruikt om het proces van staatsvorming, dat gepaard gaat met de voorbereiding op het EU-lidmaatschap, te beschrijven. Recentelijk wordt meer onderzoek gedaan naar de lokale factoren die een rol spelen in het EU-vitbreidingsproces, zoals de problematiek rond fragiele staten (Börzel, 2013; Elbasani, 2013a). Omdat de EU veel gelegen is aan de stabiliteit van deze regio, wil ze graag dat de desbetreffende landen als onderdeel van de vitbreiding, goede en betrouwbare statistieken hebben (Bieber, 2015, p. 11). Alle landen op de Westelijke Balkan werden daarom financieel en/of technisch ondersteund bij hun laatste volkstelling, door bijvoorbeeld Eurostat. Om de europeaniseringprocessen beter te begrijpen wordt in hoofdstuk 5 de werking van twee europeaniseringsmechanismes getest: conditionality, dat zich baseert op een rationele kosten-batenberekening, en legitimacy, waar gekeken wordt in hoeverre de EU-regelgeving geaccepteerd wordt, omdat het als legitiem en toepasselijk wordt ervaren. Dit hoofdstuk concludeert dat in Kroatië het mechanisme van legitimacy een grote rol heeft gespeeld, terwijl in Bosnië en Macedonië de invloed van de EU, door financiële en politieke voordelen, belangrijker is. Beide mechanismes speelden dus een rol en hiermee draagt dit hoofdstuk bij aan de literatuur over europeanisering die deze mechanismes als complementair beschouwt.

Naast de invloed van de EU zijn ook de lokale aspecten erg belangrijk als het gaat om volkstellingen. In het zesde hoofdstuk wordt de invloed van de capaciteiten van de staat, maar ook de invloed van lokale en externe actoren op de volkstellingen onderzocht. Volkstellingen zijn nauw verbonden met de instituties van de staat en worden ook gebruikt om autoriteit over de bevolking en haar sociale relaties uit te oefenen (Curtis, 2001, p. 36). Binnen de EU worden statistieken van goede kwaliteit gezien als de ruggengraat van een nationale infrastructuur (Everaers, 2015, p. 188). Daarom moeten ook EUvitbreidingslanden laten zien dat ze hun statistieken op orde hebben. Onderzoek (Börzel, 2013; Elbasani, 2013a, p. 6) suggereert dat fragiele staten een groot nadeel hebben als het gaat om het implementeren van de EUregelgeving, simpelweg omdat ze de capaciteiten missen om deze in te voeren. Daarnaast wordt ook aangenomen dat actoren, lokaal en extern, een sterke invloed kunnen hebben op de implementatie van de EUregelgeving. De analyse laat zien dat vooral lokale actoren een cruciale rol spelen als het gaat om de implementatie van de EU-regelgeving voor volkstellingen. Maar de analyse laat ook zien, dat ondanks lokale conflicten de 
volkstelling door de externe invloed van de EU alsnog kan slagen. Dit was te zien bij de volkstelling in Bosnië. De casus van Macedonië laat zien dat als de EU niet veel invloed heeft, het hele proces van de volkstelling moeilijk kan verlopen en zelfs kan worden geannuleerd. In Kroatië was de volkstelling redelijk rustig en er was er geen sprake van een lokaal conflict. Dit bevestigt de eerdere conclusie van hoofdstuk 5 over Kroatië, waar de EU-regelgeving voor de volkstellingen als goed toepasbaar werd ervaren. Al met al laten de bevindingen van hoofdstuk 6 over Bosnië en Macedonië zien dat de lokale context niet moet worden onderschat.

De empirische bijdrage van deze thesis kan worden samengevat in drie hoofdbevindingen. Ten eerste wordt aangetoond dat als de verdeling van macht gerelateerd is aan de volkstelling, deze vitermate gepolitiseerd kan worden met als gevolg dat het implementatieproces aanzienlijk wordt vertraagd. Ten tweede komt naar voren dat lokale actoren, door het accepteren of juist betwisten van de EU-regelgeving ten aanzien van volkstellingen, het proces van de implementatie respectievelijk kunnen versnellen of vertragen. Ten derde kunnen hulpbronnen van de EU gepaard met het uitoefenen van druk door de EU lokale twisten voorkomen en het tij keren, zodat EU-regelgeving voor volkstellingen geïmplementeerd kan worden. De resultaten van dit onderzoek leiden tot een beter begrip over de processen rondom volkstellingen en laten zien dat volkstellingen vooral politieke processen zijn. 



\section{About the author}

Anna-Lena Hoh (Bergisch Gladbach, 1988) obtained a Bachelor and Master degree in Human Geography at Radboud University Nijmegen. In addition, she also received a Research Master in Social and Cultural Sciences at the same University. After a detour to Brussels, she returned to the Netherlands and conducted the present research as PhD candidate at Maastricht University. During this time she also taught in the Bachelor programme European Studies at the Faculty of Arts and Social Sciences. Anna-Lena currently works as a lecturer at the Centre for International Conflict - Analysis \& Management (CICAM) in Nijmegen. 
